DOE-HTGR-88111

Revision 0

\section{AUG 051991}

\title{
GRAPHITE DESIGN HANDBOOK
}

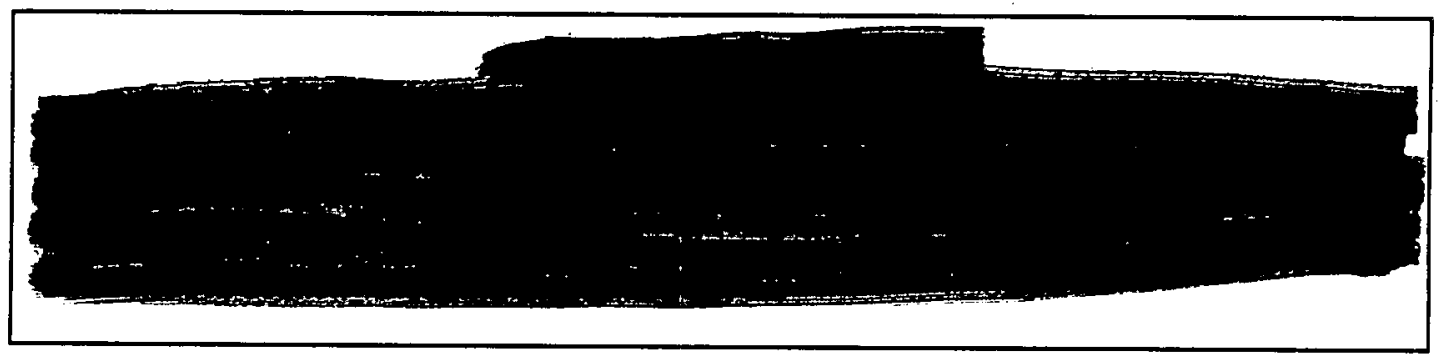

\section{AUTHORS/CONTRACTORS}

\section{GENERAL ATOMICS}

DISTRIBUTION OF THIS DOCUMENT IS UNLIMTTED

This document is PUBLICLY RELEASABLE Per memo - DAvit A. STeinman, general Atomics cilassificatiar africer 1/22/ol W.A.

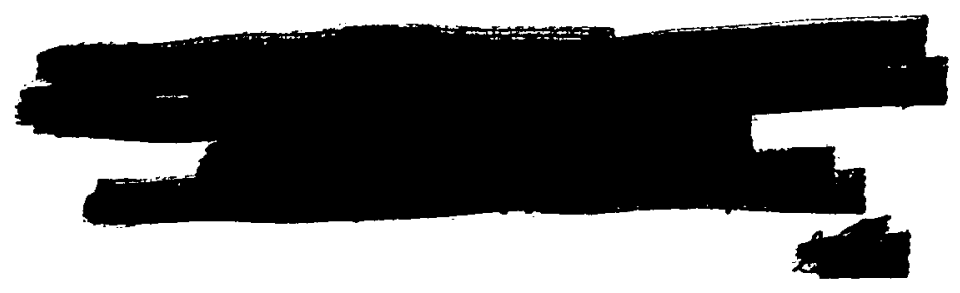

ISSUED BY GENERAL ATOMICS FOR THE DEPARTMENT OF ENERGY CONTRACT DE-AC03-88SF17367 
DOE-HTGR-88111

Revision 0

909597/0

\title{
CAUTION
}

Do not publick release this document.

This technical report is being transmitted in advance of DOE patent clearance and no further dissentnation or publication shall be made of the report without prior approval of the DOE Patent Counsel.

This document will be returned upon request or when no

$$
\begin{aligned}
& \text { PATENT } \\
& \text { CLEARED } \\
& 7-9-91
\end{aligned}
$$

longer needed, unless notification has been recelyed that this focument has been cleared for release or publication.

\section{GRAPHITE DESIGN HANDBOOK}

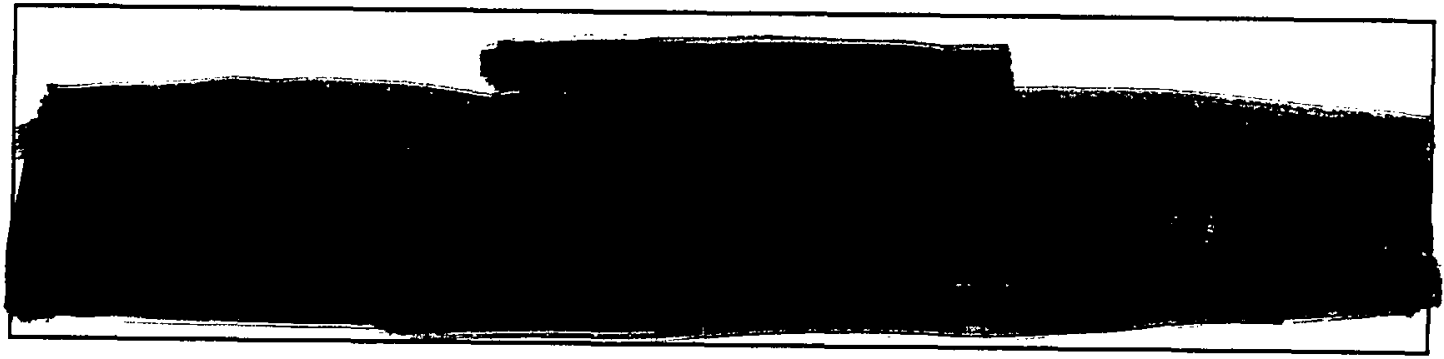

DISTRIBUTION OF THIS DOCUMENT IS UNLIMITED

Thls document is

PUBLICLY RELEASABLE

Per memo-David A. STEINMAN Generat ATOMics Classirican AlleN

\author{
Issued By \\ General Atomics \\ P.O. Box 85608
}

San Diego, California 92138-5608

DOE CONTRACT DE-AC03-88SF17367

GA Project 6300 


\section{Roll 2166}

GA 1485 (REV. 4/88)

GENERAL ATOMICS

ISSUE SUMMARY

TITLE

Graphite Design ĩandbook

$\square R \& D$

DV \& S

APPROVAL LEVEL

5

要 DESIGN

\begin{tabular}{|l|l|l|l|}
\hline DISCIPLINE & SYSTEM & DOC. TYPE & PROJECT \\
\hline
\end{tabular} 0 11 MAN

DOCUMENT NO. DOE-HTGR-88111

ISSUE NO./LTR. 6300 0 \begin{tabular}{|l|l|l}
\hline QUALITY ASSURANCE LEVEL SAFETY CLASSIFICATION & SEISMIC CATEGORY
\end{tabular} N/A $\mid \begin{array}{r}\text { SAFETY CLASSIFI } \\ \mathrm{N} / \mathrm{A}\end{array}$ N/A ELECTRICAL CLASSIFICATION ICATION

LSUE

DATE

PREPARED
BY

SEP 29 TBgF. H. HO

D Tha to
$9-22-88$

R.: Vollman $f F i$

APPROVAL

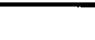

A
$N / A$

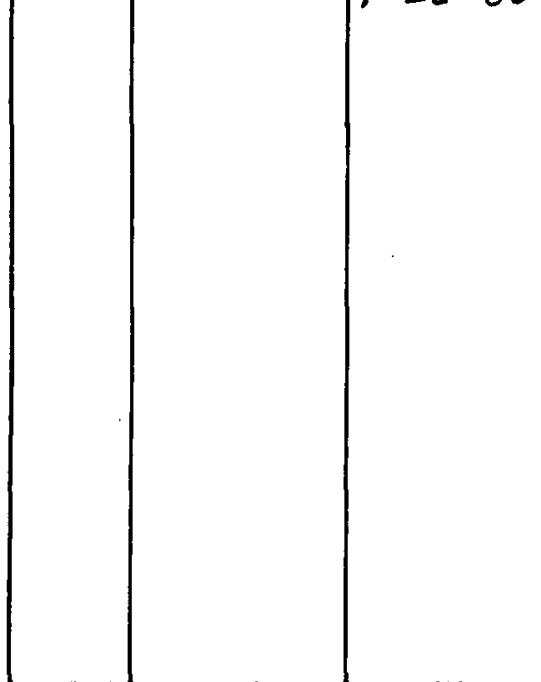

$9 \cdot 26 \cdot 30$ R. Turner STHLT $9-26-58$ Interface A'ssurance CONTINUE ON GA FORM $1485-1$

*See List of Effective Pages

NEXT INDENTURED DOCUMENTS

908438

DOE-HTGR-86035 


\section{LIST OF EFFECTIVE PAGES}

\author{
Page Number \\ $i-x i$ \\ 1-1 through 1-3 \\ $2-1$ \\ 3-1 through 3-56 \\ 4-1 through 4-50 \\ Total Pages
}

\begin{tabular}{c} 
Page Count \\
\hline 11 \\
3 \\
1 \\
56 \\
50 \\
\hline
\end{tabular}

121

\begin{tabular}{c} 
Revision \\
\hline 0 \\
0 \\
0 \\
0 \\
0
\end{tabular}


CONTENTS

LIST OF ILLUSTRATIONS . . . . . . . . . . . . . . . . . v v LIST OF TABLES . . . . . . . . . . . . . . . . . . . . . vii SYMBOLS, ACRONYMS, AND ABBREVIATIONS ................. ix

1. INTRODUCTION . . . . . . . . . . . . . . . . . 1-1

1.1. Objective . . . . . . . . . . . . . . . 1-1

1.2. Scope ....................... . 1-1

1.3. Applicability ................... . . 1-2

1.4. Organization of this Handbook . . . . . . . . . . 1-2

1.5. Definition of Symbols and Acronyms . . . . . . . . . 1-2

1.6. References . . . . . . . . . . . . . . . 1-2

2. RESPONSIBILITY AND AUTHORITY . . . . . . . . . . . . 2-1

2.1. Responsibility . . . . . . . . . . . . . 2-1

2.2. Quality Assurance ................. 2-1

2.3. Reference .................... . 2-1

3. NUCLEAR GRADE 2020 GRAPHITE ................ . . . . . . .

3.1. Description of Grade . . . . . . . . . . . . . 3-1

3.2. Application . . . . . . . . . . . . . . 3-2

3.3. Cylindrical Nuclear Grade 2020 Graphite . . . . . . 3-2

3.3.1. Introduction............... 3-2

3.3.2. Physical and Chemical Properties....... . 3-3

3.3.3. Thermal Properties.... . . . . . . . 3-8

3.3.4. Mechanfcal Properties ........... 3-14

3.3.5. References............... . 3-27

3.4. Large Rectangular Nuclear Grade 2020 Graphite. . . . . 3-30

3.4.1. Introduction............. 3-30

3.4.2. Physical and Chemical Properties....... 3-30

3.4.3. Thermal Properties ............ . 3-36

3.4.4. Mechanical Properties ........... 3-42

3.4.5. References.............. . 3-54 
4. GRADE H-451 GRAPHITE ................... . . 4-1

4.1. Description of Grade... . . . . . . . . . . . . 4-1

4.2. Application ..................... . 4-1

4.3. Physical and Chemical Properties........... 4-2

4.3.1. Density ............... 4-2

4.3.2. Transport and Reaction Rates....... . . 4-2

4.4. Thermal Properties.... . . . . . . . . . . 4-8

4.4.1. Specific Heat . . . . . . . . . . . . 4-8

4.4.2. Thermal Expansivity ............ 4-8

4.4.3. Thermal Conductivity ............ 4-14

4.4.4. Emissivity ............... 4-19

4.5. Mechanical Properties ............... 4-19

4.5.1. Transversely Isotropic Linear Elastic
Constants ......... . . . . 4-19

4.5.2. Stress-Strain Curve ............ 4-24

4.5.3. Strength.............. . 4-24

4.5.4. Fracture Toughness and the Critical Defect

Size.............. . 4-33

4.5.5. Effect of Oxidation on Mechanical Properties . 4-33

4.6. Neutron Irradiation Effects on Dimensions . . . . . 4-34

4.6.1. Irradiation-Induced Dimensional Change . . . . 4-34

4.6.2. Irradiation-Induced Creep . . . . . . . . 4-40

4.7. References . . . . . . . . . . . . . 4 4-47

\section{IIST OF ILLUSTRATIONS}

Figure

$\underline{\text { Page }}$

3.3-1. Specific heat of graphite as a function of temperature ....... . . . . . . . . . 3-9

3.3-2. Design curves for change in room temperature thermal resistivity of 2020 graphite as a function of irradiation conditions ............. 3-13

3.3-3. Design curves for change in elastic modulus of 2020 graphite as a function of irradiation conditions . . . 3-17

3.3-4. Tensile stress-strain curve for 2020 graphite. . . . . 3-19

3.3-5. Compressive stress-strain curve for 2020 graphite . . . 3-20 


\section{LIST OF ILLUSTRATIONS (Continued)}

3.3-6. Specified minimum biaxial fallure surface for 2020 graphite . . . . . . . . . . . . . . . 3-23

3.3-7. Design fatigue diagram of nuclear grade 2020 graphite at $99 \%$ survival probability with $95 \%$ confidence level . . 3-26

3.4-1. Specific heat of graphite as a function of temperature............. . . 3-37

3.4-2. Design curves for change in room temperature thermal resistivity of 2020 graphite as a function of irradiation conditions .. . . . . . . . . 3-41

3.4-3. Design curves for change in elastic modulus of 2020 graphite as a function of irradiation conditions . . . 3-44

3.4-4. Tensile stress-strain curve for 2020 graphite. . . . . 3-46

3.4-5. Comprehensive stress-strain curve for 2020 graphite. . 3-47

3.4-6. Specified minimum biaxial strength surface for 2020 graphite. . . . . . . . . . . . . 3-51

3.4-7. Design fatigue diagram of nuclear grade 2020 graphite at $99 \%$ survival probability with $95 \%$ confidence level . . 3-53

4.4-1. Specific heat of graphite as a function of temperature................. 4-9

4.4-2. Thermal expansion of H-451 graphite......... . 4-11

4.4-3. Change in mean CTE of H-451 graphite as a function of irradiation conditions ( 865 to $1205 \mathrm{~K}$ ), axial and radial dimensions............. . 4-12

4.4-4. Change in mean CTE of H-451 graphite as a function of irradiation conditions ( 1250 to $1705 \mathrm{~K})$, axial and radial directions... . . . . . . . . . 4-13

4.4-5. Thermal conductivity of $\mathrm{H}-451$ graphite as a function of neutron irradiation .. . . . . . . . . . . . 4-20

4.5-1. Fractional change in elastic modulus of H-451 graphite as a function of irradiation conditions . . . . . . . . 4-23

4.5.2a. Tensile stress-strain curve for H-451 graphite, axial orientation ...................44-25

4.5.2b. Tensile stress-strain curve for $\mathrm{H}-451$ graphite, radial orientation ............... . 4-26

4.5.3a. Compressive stress-strain curve for H-451 graphite, axial orientation .............. . 4-27

4.5.3b. Compressive stress-strain curve for H-451 graphite, radial orientation ............... . 4-28

4.5-4a. Tensile stress-strain curve for irradiated H-451 graphite ................... . 4-29 
LIST OF ILLUSTRATIONS (Continued)

4.5-4b. Compressive stress-strain curve for irradiated H-451 graphite .. .. . . . . . . . . . . 4 4-30

4.6-1. Design curves for dimensional change of H-451 graphite, axial orientation, as a function of irradiation conditions ................... . 4-36

4.6-2. Design curves for dimensional change of H-451 graphite, radial orientation, as a function of irradiation conditions .. . . . . . . . . . . . . . 4-37

4.6-3. Maximum densification point and crossover point for irradiated $\mathrm{H}-451$ graphite as a function of irradiation temperature . . . . . . . . . . . . . . 4-39

\section{LIST OF TABLES}

Table

Page

3.3-1. Summary of oxidation kinetic constants for nuclear 2020 graphite . . . . . . . . . . . . . . . 3-4

3.3-2. Air-graphite reaction rate coefficients ....... 3-6

3.3-3. Thermal conductivity of 2020 graphite . . . . . . . 3-11

3.3-4. Thermal resistivity constant F, used in Eq. 3.3-7 . . . 3-12

3.3-5. Percent increase (P) in elastic modulus as a function of fluence and temperature ............. 3-16

3.3-6. Unfaxial fatigue strength limits for 2020 graphite . . . 3-24

3.4-1. Summary of oxidation kinetic constants for nuclear 2020 graphite . . . . . . . . . . . . . 3-32

3.4-2. Air-graphite reaction rate coefficients ........ 3-34

3.4-3. Thermal conductivity of 2020 graphite . . . . . . . 3-38

3.4-4. Thermal resistivity constant F, used in Eq. 3.4-8 . . . 3-40

3.4-5. Percent increase $(P)$ in elastic modulus as a function of fluence and temperature . . . . . . . . . . 3-45

3.4-6. Uniaxial fatigue strength 1imits for 2020 graphite. . . 3-52

4.3-1. Constants for H-451 graphite oxidation rate equation. . 4-4

4.3-2. Air-graphite reaction rate coefficients . . . . . . . 4-5

4.4-1. Thermal expansion of H-451 graphite .......... 4-10

4.4-2. Temperature-dependent conductivity components of H-451 graphite... . . . . . . . . . . . 4-16 


\section{LIST OF TABLES (Continued)}

4.4-3. Material constants for H-451 graphite thermal conductivity . . . . . . . . . . . . . . . 4-17

4.5-1. Percentage change in elastic modulus of H-451 graphite during neutron irradiation . . . . . . . . . . . . 4-22

4.6-1. Polynomial coefficlents for dimensional change design equations: H-451 graphite... . . . . . . . . 4-35 
SYMBOLS, ACRONYMS, AND ABBREVIATIONS

A

b

$\mathrm{b}$

$\mathrm{CR}$

$\mathrm{C}_{\mathrm{p}}$

CTE

$\mathrm{D}_{\mathrm{H}_{2} \mathrm{O}}$

$\mathrm{D}_{\mathrm{CO}}$

$\mathrm{D}_{\mathrm{H}_{2}}$

$\mathrm{D}_{2}$

d

E

$E_{j}, j=1,2,3$

E

F

$F_{b}, F_{c}$

G

GA axial direction

percent graphite burnoff

inverse of the crystallite boundary spacing (Eq. 4-6)

central reflector

specific heat at constant pressure

coefficient of thermal expansion

effective diffusion coefficient of steam in graphite

effective diffusion coefficient of carbon monoxide in graphite

effective diffusion coefficient of hydrogen in graphite

effective diffusion coefficient of oxygen in graphite irradiation damage parameter (Eq. 4-6)

elastic modulus (see sections on mechanical properties), may have subscript $x, z, 1$, or 3

Activation energy (see sections on oxidation rates)

energy level (of neutron)

fractional increase in thermal resistivity due to neutron irradiation

modifying factors for effects of burnoffs and catalysts on oxidation rates

shear modulus (see sections on mechanical properties), may have subscript $x, z, 1$, or 3

General Atomics 


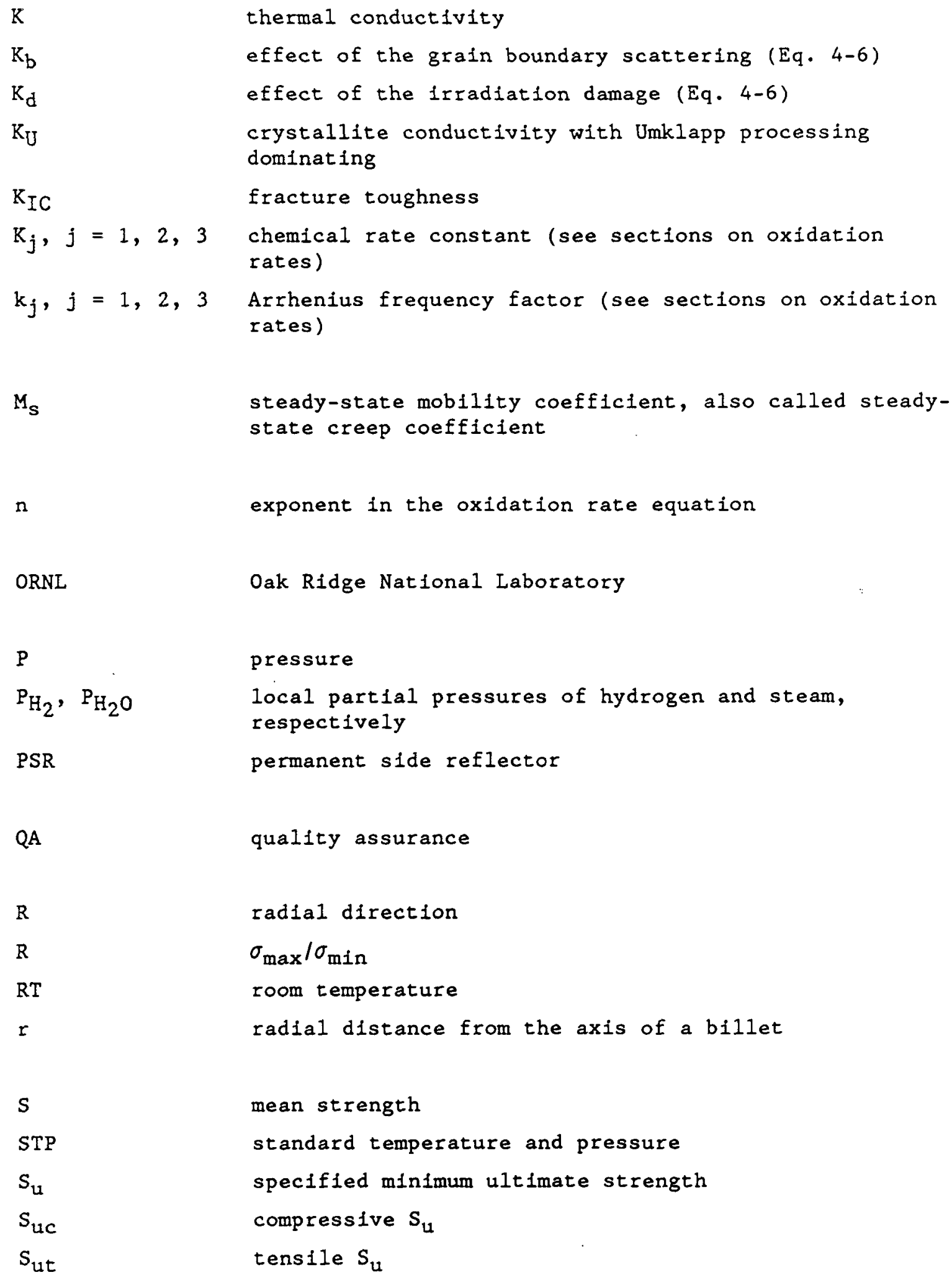


$T_{\phi}$

UCS

UTS

$\mathbf{x}$

2

$a$

$\epsilon$

$\epsilon^{\mathrm{C}}$

$\epsilon^{e}$

$\epsilon^{I}$

$\epsilon^{S}$

$\epsilon^{\mathrm{T}}$

$\epsilon^{\theta}$

$\gamma$

5

$\nu$

$\sigma$

$\sigma_{\max }, \sigma_{\min }$

$\tau$

$\tau$

$\Phi$

$\Phi_{\mathrm{R}}$ temperature

irradiation temperature

ultimate compressive strength

ultimate tensile strength

fractional weight loss from oxidation (burnoff)

axial distance from midlength of a billet

thermal expansivity

strain, may have subscript $x, y$, or $z$

irradiation-induced creep strain

elastic strain

irradiation-induced dimensional change (stress-free)

steady state part of $\epsilon^{C}$

transient part of $\epsilon^{c}$

thermal strain

shear strain, may have subscript $x y, y z$, or $2 x$

internal damping factor (see Section 3.3.4.6)

Poisson's ratio (see sections on mechanical properties), may have subscript 12 or 13

applied normal stress, may have subscript $x, y$, or $z$ maximum and minimum applied stresses, respectively, during a cycle in fatigue tests

exponential relaxation time in units of neutron fluence

shear stress, may have subscript $x y, y z$, or $z x$

fast neutron fluence expressed as equivalent HTGS fast fluence, $E>29 \mathrm{fJ}$ or equivalently $\mathrm{E}>0.18 \mathrm{MeV}$

relaxation time (Eq. 4-32) 


\section{INTRODUCTION}

\subsection{OBJECTIVE}

The objectives of the Graphite Design Handbook (GDH) are (1) to provide and maintain a single source of graphite properties and phenomenological model of mechanical behavior to be used for design of MHTGR graphite components of the Reactor System, namely, core support, permanent side reflector, hexagonal reflector elements, and prismatic fuel elements; (2) to provide a single source of data and material models for use in MHTGR graphite component design, performance, and safety analyses; (3) to present properties and equations representing material models in a form which can be directly used by the designer or analyst without the need for interpretation and is compatible with analytical methods and structural criteria used in the MHTGR project; and (4) to control the properties and material models used in the MHTGR design and analysis to proper Quality Assurance standards and project requirements.

\subsection{SCOPE}

The Reactor System includes graphite parts in the reactor core, reflector, and internals (Ref. 1-1). The reference graphite in the reactor core and replaceable hexagonal reflector components is grade H-451. These components are to be designed to meet the structural criteria for core graphite (Ref. 1-2).

The reference graphite in the reactor internals components is the nuclear grade 2020. There are two subgrades of interest, the cylinder nuclear grade and the large rectangular nuclear grade. The large rectangular nuclear grade is molded in large rectangular blocks. It is the 
reference material for the permanent side reflector and the central column support structure. The cylindrical nuclear grade is isostatically pressed and is intended for use as the core support component. This nuclear grade is provided as cylindrical logs. Both components are designed to meet the structural criteria for graphite core supports (Ref. 1-3). Since the material properties of graphite are dependent on both process and size, the properties of these two subgrades are defined separately.

This report gives the design properties for both $\mathrm{H}-451$ and 2020 graphite as they apply to their respective criteria. The properties are presented in a form for design, performance, and safety calculations that define or validate the component design.

\subsection{APPLICABILITY}

The properties presented in this handbook are the reference properties that are approved for use in MHTGR design, performance, and safety calculations.

1.4. ORGANIZATION OF THIS HANDBOOK

(Later)

1.5. DEFINITION OF SYMBOLS AND ACRONYMS

(Later)

1.6. REFERENCES

1-1. "Reactor System Design Description," DOE-HTGR-86035, Rev. 2 (GA Document 908438/3), Apr11 1988. 
1-2. "Structural Design Criteria for Replaceable Graphite Core Elements," DOE-HTGR-88150, Rev. O (GA Document 909729/0), August 1988.

1-3. "Proposed Section III, Division 2, ASME Boiler and Pressure Vessel Code, Subsection CE, Design Requirements for Graphite Core Supports," April 1984. 


\section{RESPONSIBILITY AND AUTHORITY}

\subsection{RESPONSIBILITY}

Responsibility for maintaining this document is vested in General Atomics.

\subsection{QUALITY ASSURANCE}

All structures and components that are designated as "safetyrelated" shall come under a Quality Assurance Program which fully complies with the requirements of Title 10 of the Code of Federal Regulations Part 50 (10CFR50), Appendix B. The basic requirements and supplements of ANSI/ASME NQA-1 (as endorsed by USNRC Regulatory Guide 1.28, Revision 3) shall be implemented for activities that affect the quality of such items. The core supports, permanent side reflectors, hexagonal reflector elements, and prismatic fuel elements are "safety-related" structures and components (Ref. 2-1). Therefore, the graphite used in these structures and components is "safety-related."

\subsection{REFERENCE}

2-1. "Equipment Classification List for the Modular High Temperature Gas-Cooled Reactor," DOE-HTGR-86032, Rev. 2 (GA Document $908792 / 2)$, July 1987 . 


\section{NUCLEAR GRADE 2020 GRAPHITE}

\subsection{DESCRIPTION OF GRADE}

There are two subgrades of nuclear grade 2020 graphite used for the reactor internals components, the large rectangular nuclear grade and the cylindrical nuclear grade. The large rectangular grade 2020 graphite is a fine-grained, molded artificial graphite produced in large rectangular blocks. It is the reference material for permanent side reflectors and central reflector column support blocks. To date, the largest $\log$ fabricated and tested was $1.067 \mathrm{~m}$ (42 in.) long $x 0.914 \mathrm{~m}$ (36 in.) wide $\times 0.457 \mathrm{~m}$ (18 in.) thick. The log intended for use as central reflector column support blocks and permanent side reflector column supports at the entrance of the hot duct will be slightly larger than the above. For preliminary design analysis, the properties of the log tested are assumed to apply to the larger size (until such time as the experimental data are available).

The cylindrical nuclear grade 2020 graphite is a fine-grained, isostatically molded artificial graphite produced in cylindrical logs. The nuclear grade differs from the off-the-shelf commercial grade only in that the raw material has been carefully controlled in impurity content, hence its oxidation characteristics improved. All other material properties are nearly identical to those of a commercial grade of the same size log. Nuclear grade is the reference material for the core support structure, including the post block, post and lower plenum floor block. The $\log$ tested (except oxidation rate) was a comercial grade of $1.98 \mathrm{~m}$ (78 in.) long $\times 0.254 \mathrm{~m}$ (10 in.) in diameter. The properties of the cylindrical $\log$ varied somewhat with axial position along the $\log$ because one end has a higher density than the other. 
For the present, unless otherwise noted, design data given hereafter were derived from a $0.254 \mathrm{~m}$ (10 in.) diameter $10 \mathrm{~g}$.

\subsection{APPLICATION}

Application of 2020 grade graphite to the reactor internals components is summarized below:

1. Large rectangular nuclear grade: permanent side reflector (PSR), PSR support block at the entrance of the hot duct and central reflector column support structure.

2. Cylindrical nuclear grade: post block, $T$-post, and lower plenum floor block.

\subsection{CYLINDRICAL NUCLEAR GRADE 2020 GRAPHITE}

\subsubsection{Introduction}

The nuclear 2020 graphite properties are consistent with the structural criteria for graphite core supports (Ref. 3.3-1). Unless otherwise noted, the material properties given below for the nuclear grade 2020 are mean values.

The maximum predicted fast neutron fluence to the graphite core support structure is $2 \times 10^{23} \mathrm{n} / \mathrm{m}^{2}$ ( $E>29 \mathrm{fJ}$, HTGR), which is less than $1 \%$ of the maximum fluence accumulated by fuel element graphite. Experience with fuel element graphite has shown that only elastic modulus and thermal conductivity will be noticeably affected by a total fast neutron fluence of $5 \times 10^{23} \mathrm{n} / \mathrm{m}^{2}$. Therefore, irradiation effects on other properties described below are insignificant and not discussed. 


\subsubsection{Physical and Chemical Properties}

3.3.2.1. Density. The bulk density of 2020 graphite is $1.78 \mathrm{Mg} / \mathrm{m}^{3}$ averaged over the $\log$ (Refs. 3.3-2 and 3.3-3).

\subsubsection{Transport and Reaction Rates.}

3.3.2.2.1. Steam-Graphite Oxidation Rates. The LangmuirHinshelwood equation, Eq. 3.3-1, is used to predict steam-graphite oxidation rates for nuclear grade 2020 graphite (Ref. 3.3-4):

$$
\text { Rate }=\frac{\mathrm{K}_{1} \mathrm{P}_{\mathrm{H}_{2} \mathrm{O}} \mathrm{F}_{\mathrm{b}}}{1+\mathrm{K}_{2}\left(\mathrm{P}_{\mathrm{H}_{2}}\right)^{\mathrm{n}}+\mathrm{K}_{3} \mathrm{P}_{\mathrm{H}_{2} \mathrm{O}}}
$$

where

$$
\begin{aligned}
\text { Rate }= & \text { local graphite mass fraction reacting per second, } \\
\mathrm{P}_{\mathrm{H}_{2}}, \mathrm{P}_{\mathrm{H}_{2} \mathrm{O}}= & \text { local partial pressures of hydrogen and steam, } \\
& \text { respectively, } \\
\mathrm{F}_{\mathrm{b}}= & \text { modifier for effects of burnoff, } \\
\mathrm{n}= & \text { exponent, } \\
\mathrm{K}_{\mathrm{j}}= & \mathrm{k}_{\mathrm{j}} \exp \left(\mathrm{E}_{\mathrm{j}} / \mathrm{RT}\right), \\
& \text { where } \mathrm{j}=1,2 \text {, or } 3, \\
\mathrm{k}_{\mathrm{j}}= & \text { Arrhenius frequency factor, } \\
\mathrm{E}_{\mathrm{j}}= & \text { activation energy, } \\
\mathrm{R} & =8.314 \mathrm{~J} / \mathrm{mole} \cdot \mathrm{K} .
\end{aligned}
$$

The values of $K_{1}, K_{2}, K_{3}$, and $n$ given in Table 3.3-1 are based on data for the temperatures indicated. Until data at other temperatures are available, it is assumed that $k_{j}$ in Table 3.3-1 can be extrapolated to other temperatures.

For preliminary design, $F_{b}$ is the same as that used to predict burnoff effects for steam oxidation of H-451 graphite (until such time 
TABLE $3 \cdot 3-1$

SUMMARY OF OXIDATION KINETIC CONSTANTS FOR

NUCLEAR 2020 GRAPHITE

\begin{tabular}{|c|c|c|c|c|c|c|c|c|}
\hline \multirow[b]{2}{*}{$\begin{array}{c}\text { Temperature } \\
\left({ }^{\circ} \mathrm{C}\right)\end{array}$} & \multirow[b]{2}{*}{$\mathrm{n}$} & \multicolumn{4}{|c|}{ High Water $>100 \mathrm{~Pa} \mathrm{H}_{2} \mathrm{O}$} & \multicolumn{3}{|c|}{ Low Water $<100 \mathrm{~Pa} \mathrm{H} \mathrm{H}_{2} \mathrm{O}$} \\
\hline & & $\begin{array}{c}K_{1} \\
(s \cdot P a)-1\end{array}$ & $\begin{array}{c}\mathrm{K}_{2} \\
\mathrm{~Pa}^{-I} \cdot 3\end{array}$ & & $\underset{\mathrm{Pa}_{3}-1}{\mathrm{~K}_{3}}$ & $\begin{array}{c}\mathrm{K}_{1} \\
(\mathrm{~s} \cdot \mathrm{Pa})-1\end{array}$ & $\begin{array}{c}\mathrm{K}_{2} \\
\mathrm{~Pa}-1.3\end{array}$ & $\begin{array}{c}\mathrm{K}_{3} \\
\mathrm{~Pa}-1\end{array}$ \\
\hline 980 & 1.3 & 8. $7 E-10$ & $1.1 E-3$ & 2.6 & $-8.7 E-4$ & $7.2 E-9$ & $9.0 \mathrm{E}-3$ & $8 \cdot 1 E-2$ \\
\hline 930 & 1.3 & $3.8 E-10$ & $1.6 E-3$ & 3.8 & $-16 \mathrm{E}-4$ & $2 \cdot 3 E-9$ & $9.5 E-3$ & $1.7 \mathrm{E}-1$ \\
\hline 900 & 1.3 & $2.0 E-10$ & $2.0 E-3$ & 2.0 & $-4.0 E-4$ & & & \\
\hline
\end{tabular}


as additional 2020 graphite oxidation data are available). The oxidation rate of the nuclear grade 2020 graphite is about one-fifth that of H-451 graphite.

3.3.2.2.2. Air-Graphite Reaction Rates. The rate of oxidation of graphite by air is given by Eq. 3.3-2 (Ref. 3.3-8):

$$
\text { Rate }=\mathrm{K} \exp (-\mathrm{E} / \mathrm{RT}) \mathrm{P}_{\mathrm{O}_{2}},
$$

where Rate = local graphite mass fraction reacting per second (SI) or local graphite mass fraction reacting per hour (units normally used in OXIDE code calculations), $\mathrm{P}_{\mathrm{O}_{2}}=$ local partial pressure of oxygen.

Table 3.3-2 gives the system of units derived from $\mathrm{H}-327$ experimental data. It is assumed that the air-graphite reaction rate of $\mathrm{H}-451$ is identical to that of $\mathrm{H}-327$.

Since there are no experimental data on air-graphite reaction rate reported for the grade 2020 graphite, Eq. 3.3-2, together with Table 3.3-2, shall be used. The value of $K$ given in Table 3.3-2 needs to be modified by a factor equal to the ratio of the steam-graphite oxidation rate of nuclear grade 2020 graphite to that of H-451 graphite at the environmental conditions of interest.

3.3.2.2.3. Radiolytic Effect on Oxidation Rate. The available experimental data show that there is a small and negligible radiolytic effect on oxidation rate in air (see discussion in Section 4.3.2.3). 
TABLE 3.3-2

AIR-GRAPHITE REACTION RATE COEFFICIENCTS(a)

\begin{tabular}{llllll}
\hline Systems of Units & \multicolumn{1}{c}{$\mathrm{K}$} & \multicolumn{1}{c}{$\mathrm{E}$} & $\mathrm{T}$ & \multicolumn{1}{c}{$\mathrm{R}$} \\
\hline $\mathrm{SI}$ & $\begin{array}{l}0.79 \\
(\mathrm{~s} \cdot \mathrm{Pa})^{-1}\end{array}$ & $\begin{array}{l}1.7 \times 10^{5} \\
\mathrm{~J} / \mathrm{mol} \cdot \mathrm{K}\end{array}$ & $\mathrm{K}$ & $\begin{array}{l}8.314 \\
\mathrm{~J} / \mathrm{mol} \cdot \mathrm{K}\end{array}$ \\
OXIDE code & $\begin{array}{l}2.88 \times 10^{10} \\
(\% \mathrm{~h} \cdot \mathrm{atm})^{-1}\end{array}$ & $\begin{array}{l}4.06 \times 10^{4} \\
\mathrm{cal} / \mathrm{mol}\end{array}$ & $\mathrm{K}$ & $\begin{array}{l}1.986 \\
\mathrm{ca} 1 / \mathrm{mol} 1 \cdot \mathrm{K}\end{array}$
\end{tabular}

(a) See text for the appropriate values to be used in Eq. 3.3-2 for nuclear grade 2020 graphite. 
3.3.2.2.4. Transport of Steam in Helium by Diffusion. The effective diffusion coefficient of steam in graphite is given by Eq. 3.3-3 (Refs. 3.3-5 through 3.3-7):

$$
D_{\mathrm{H}_{2} \mathrm{O}}=\frac{1.0 \times 10^{-10} \times \mathrm{T}^{1.58} \times \mathrm{P}}{\mathrm{P}_{\text {total }}}\left(\mathrm{m}^{2} / \mathrm{s}\right)
$$

where $\mathrm{D}_{\mathrm{H}_{2} \mathrm{O}}=$ effective diffusion coefficient through graphite, $T=$ temperature $(\mathrm{K})$,

$\mathrm{P}=$ pressure at $\operatorname{STP}^{*}(\mathrm{~Pa})$,

$P_{\text {total }}=$ total pressure $(\mathrm{Pa})$.

A parameter such as diffusion through graphite is recognized to vary by as much as a factor of three from sample to sample or from position to position in the graphite block. Equation 3.3-3 describes the present best estimate for $\mathrm{H}_{2} \mathrm{O}$ diffusion in graphite having $1 \%$ average oxidation burnoff.

Equation 3.3-3 was obtained by pooling all available experimental data on steam diffusion through graphite in helium. No corrections were made for the differences in porosity and pore structure. Equation 3.3-3 is assumed to be applicable to all reference HTGR graphites.

The effective diffusion coefficients recommended for carbon monoxide, oxygen, and hydrogen are as follows (until such time as experimental data are available):

$$
\begin{aligned}
& \mathrm{D}_{\mathrm{CO}}=\mathrm{D}_{\mathrm{H}_{2} \mathrm{O}}, \\
& \mathrm{D}_{\mathrm{O}_{2}}=\mathrm{D}_{\mathrm{H}_{2} \mathrm{O}}, \\
& \mathrm{D}_{\mathrm{H}_{2}}=2 \mathrm{D}_{\mathrm{H}_{2} \mathrm{O}}
\end{aligned}
$$

\footnotetext{
${ }^{\text {*}}$ STP - standard temperature and pressure.
} 
3.3.2.2.5. Transport of Steam in Helium by Convection. The transport of steam by convection involves the permeation of graphite. The permeability coefficients of graphite (Ref. 3.3-29) are:

$$
\begin{aligned}
& \mathrm{K}_{\mathrm{I}}=1.55 \mathrm{E}-13 \mathrm{~m}^{2}, \\
& \mathrm{~K}_{\mathrm{P}}=9.20 \mathrm{E}-14 \mathrm{~m}^{2},
\end{aligned}
$$

where the subscripts represent the following regions of the hexagonal graphite blocks:

$I=$ interior region consisting of a hexagonal block having an area in the plane of the hexagon one-seventh of the corresponding area of the entire block,

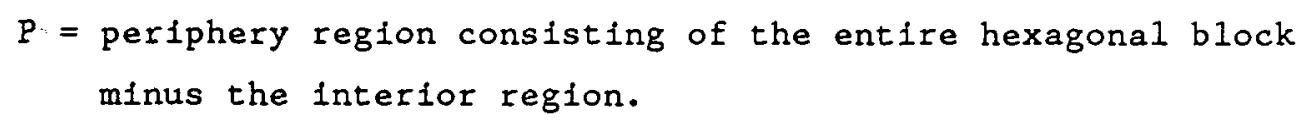

The values of $\mathrm{K}_{\mathrm{F}}$ and $\mathrm{K}_{\mathrm{P}}$ are derived from data on $\mathrm{H}-327$ graphite; they are assumed to apply to 2020 graphite (until such time as experimental data are available).

\subsubsection{Thermal Properties}

3.3.3.1. Specific Heat. The specific heat of graphite over the temperature range 250 to $3000 \mathrm{~K}$ is given by Eq. 3.3-5 (Ref. 3.3-9):

$$
\begin{aligned}
C_{p}= & \left(0.54212-2.42667 \times 10^{-6} \mathrm{~T}-90.2725 \mathrm{~T}^{-1}\right. \\
& -4.34493 \times 10^{4} \mathrm{~T}^{-2}+1.59309 \times 10^{7} \mathrm{~T}^{-3} \\
& \left.-1.43688 \times 10^{9} \mathrm{~T}^{-4}\right) \times 4184,
\end{aligned}
$$

where $C_{p}=$ specific heat at constant pressure $(\mathrm{J} / \mathrm{kg}-\mathrm{K})$, $T=$ temperature $(K)$.

Equation 3.3-5 is also presented graphically in Fig. 3.3-1.

$$
\text { 3-8 DOE-HTGR-88111/Rev. } 0
$$




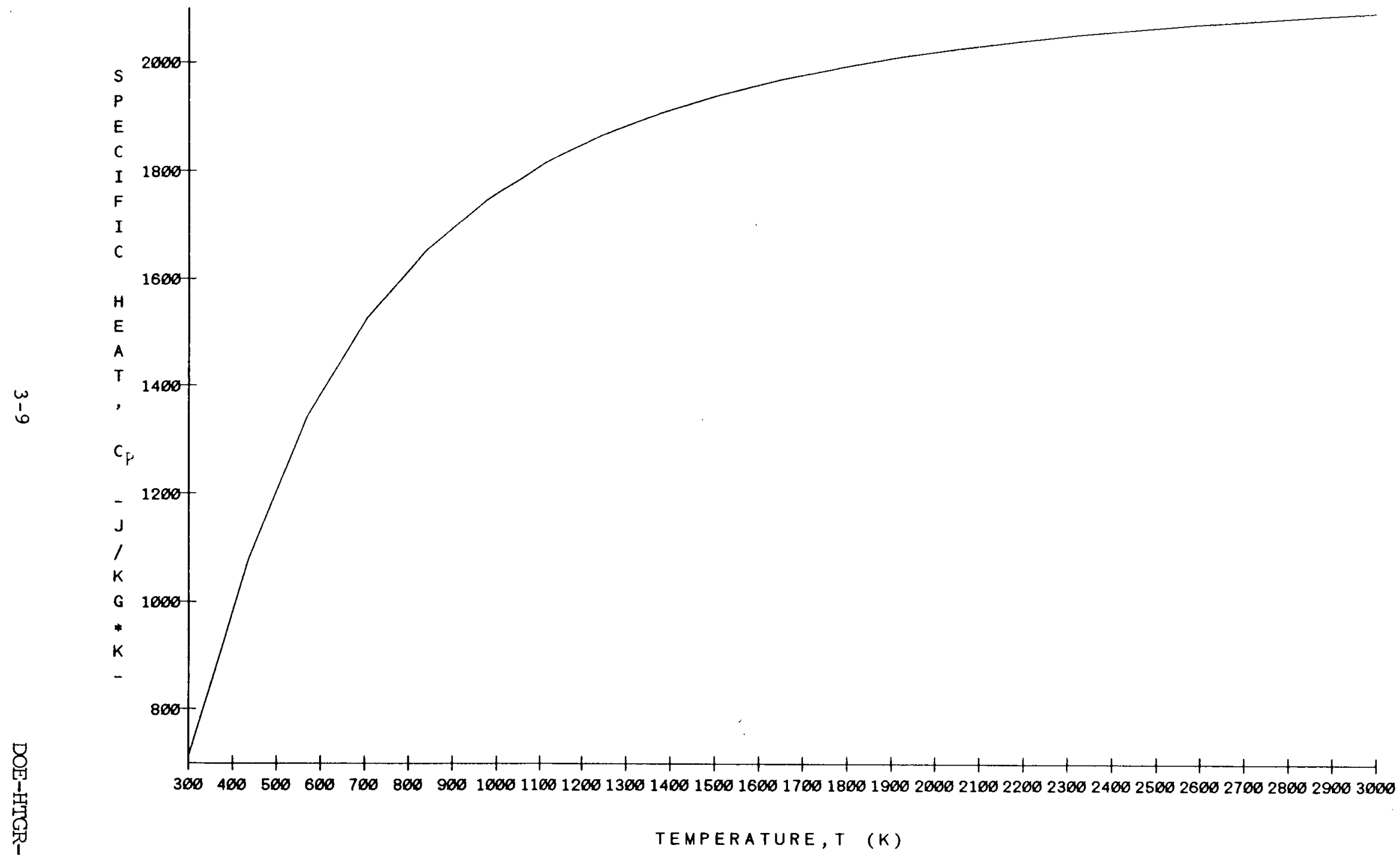

Fig. 3.3-1 Specific Heat of Graphite as a Function of Temperature 
3.3.3.2. Thermal Expansivity. The thermal expansivity of 2020 graphite is given below (Ref. 3.3-10):

$$
\alpha=A+B(\Delta T),
$$

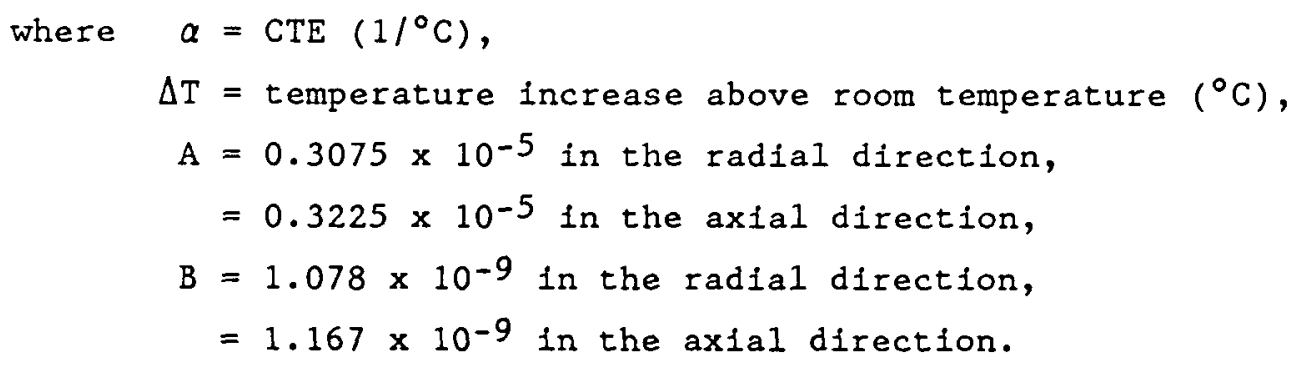

3.3.3.3. Thermal Conductivity. The thermal conductivity of unirradiated 2020 graphite is given in Table 3.3-3 as a function of measurement temperature (Ref. 3.3-3). The change in thermal conductivity of irradiated 2020 graphite at irradiation temperature is given in Eq. 3.3-6 (Ref. 3.3-11).

$$
\frac{1}{K_{i}(T)}=\frac{1}{K_{0}(T)}+\frac{F}{K_{0}(295 K)}
$$

where $\quad K_{i}(T)=$ thermal conductivity of irradiated graphite at temperature $T(K)$,

$$
\begin{aligned}
K_{0}(T)= & \text { thermal conductivity of unirradiated graphite at tem- } \\
& \text { perature } T(K) \text { (derived from Table 3.3-3), }
\end{aligned}
$$

$\mathrm{K}_{\mathrm{o}}(295 \mathrm{~K})=$ thermal conductivity of unirradiated graphite at room temperature,

$$
\begin{aligned}
F= & \text { fractional increase in thermal resistivity due to } \\
& \text { neutron irradiation (fluence dependence is given in } \\
& \text { Table } 3 \cdot 3-4 \text { and Fig. } 3 \cdot 3-2 \text { ). }
\end{aligned}
$$


TABLE $3.3-3$

THERMAL CONDUCTIVITY OF 2020 GRAPHITE

\begin{tabular}{llllll}
\hline & \multicolumn{5}{c}{ Conductivity $\begin{array}{c}\text { at Measurement } \\
(\mathrm{W} / \mathrm{m} \cdot \mathrm{K})\end{array}$} \\
\cline { 2 - 6 } Orientation & $295 \mathrm{~K}$ & $473 \mathrm{~K}$ & $673 \mathrm{~K}$ & $873 \mathrm{~K}$ & $1073 \mathrm{~K}$ \\
\hline Radial & 62.4 & 67.2 & 57.2 & 49.8 & 43.9 \\
Axial & 63.0 & 63.7 & 53.7 & 45.2 & 40.8 \\
\hline
\end{tabular}


TABLE $3.3-4$

THERMAL RESISTIVITY CONSTANT F, USED IN EQ. 3.3-7

\begin{tabular}{|c|c|c|c|}
\hline \multirow{2}{*}{$\begin{array}{l}\text { Fast Neutron Fluence } \\
\left(10^{22} \mathrm{n} / \mathrm{m}^{2}\right)\end{array}$} & \multicolumn{3}{|c|}{$\begin{array}{c}\text { Irradiation Temperature } \\
(\mathrm{K})\end{array}$} \\
\hline & 673 & 873 & 1073 \\
\hline 0.4 & 0.075 & 0.0885 & 0.0215 \\
\hline 1 & 0.125 & 0.063 & 0.036 \\
\hline 4 & 0.27 & 0.138 & 0.078 \\
\hline 10 & 0.445 & 0.225 & 0.124 \\
\hline 20 & 0.665 & 0.33 & 0.185 \\
\hline
\end{tabular}




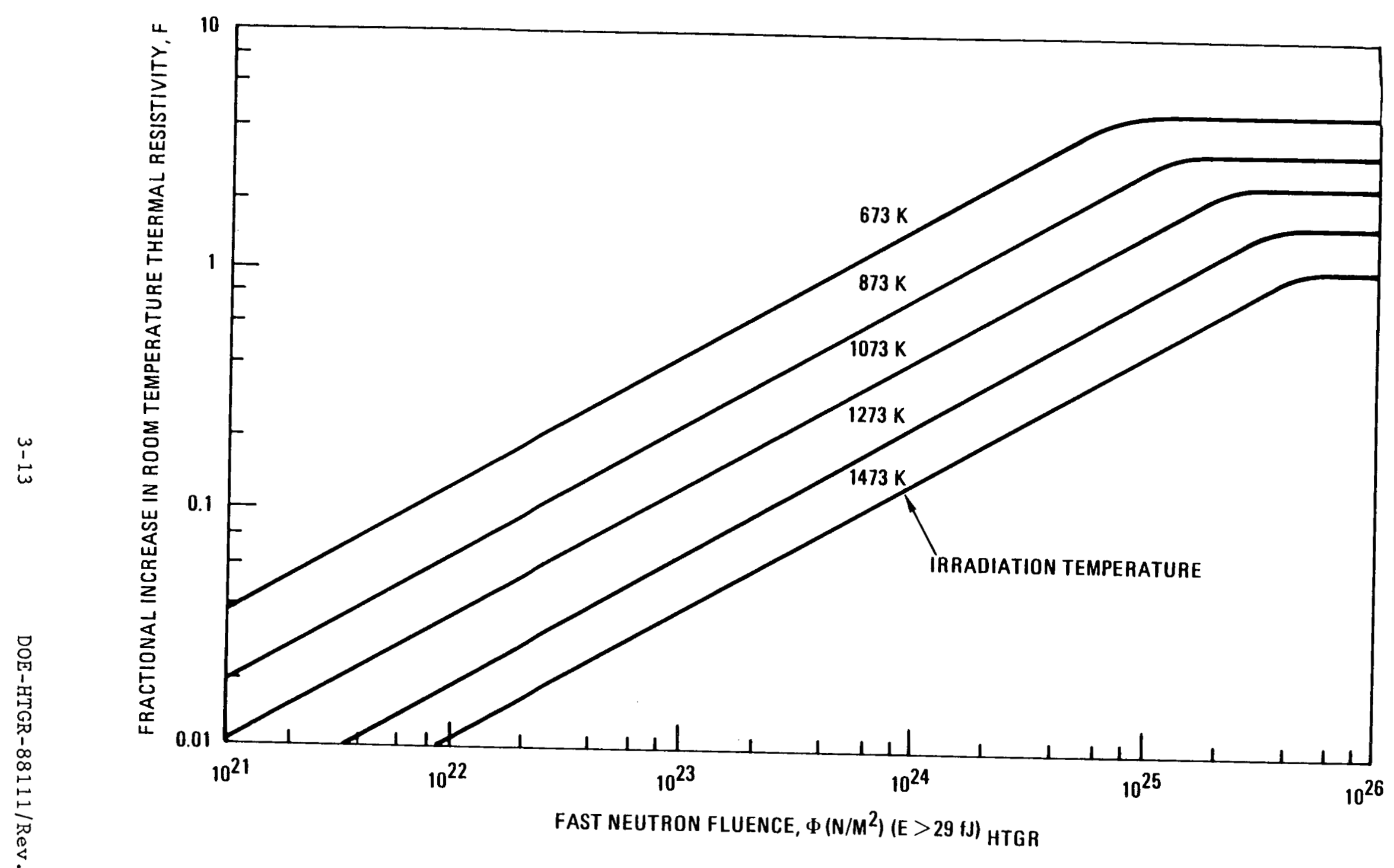

Fig. 3.3-2. Design curves for change in room temperature thermal resistivity of 2020 graphite 
The tabulated data on $F$ were established from analysis of experimental data measured on miscellaneous graphites. Until such time as 2020 graphite thermal conductivity data under low irradiation level are available, it is assumed that Table 3.3-4 is applicable to 2020 graphite.

For other fast fluences, a linear relationship may be used between logarithms of $F$ and fast fluence. An approximately linear relationship also exists between $T$ and logarithm of $F$.

Thermal annealing on thermal conductivity appears to begin at $1273 \mathrm{~K}$ and is completed by $1573 \mathrm{~K}$ (Refs. 3.3-12 and 3.3-13). In this temperature range the fractional change in conductivity is close to linearly proportional to temperature. The fractional increase in thermal resistivity, $F$, in Eq. 3.3-7 is assumed to linearly decrease to zero over the above temperature range.

\subsubsection{Emissivity. The emissivity of 2020 graphite for machined} surface is 0.85 (Refs. 3.3-14 through 3.3-16).

\subsubsection{Mechanical Properties}

\subsubsection{Transversely Isotropic Linear Elastic Constants. The} mechanical properties of 2020 graphite can be modeled as transversely isotropic. The isotropic plane is in the across grain direction of an isostatically molded cylindrical graphite log. The with-grain direction is the axial direction, and is labelled as the 3 -axis. The five independent parameters in the transversely isotropic linear elastic material are two elastic moduli, $E_{1}$ and $E_{3}$; shear modulus, $G_{1}$; and two Poisson's ratios, $\nu_{12}$ and $\nu_{13}$. 
The properties given below are the average of the combined tensile and compressive moduli at room temperature. The difference between two moduli is less than $10 \%$ (Refs. $3.3-2,3.3-3$ and $3.3-17$ through $3.3-19$ ):

$$
\begin{aligned}
E_{1} & =9.5 \mathrm{GPa}, \\
E_{3} & =8.9 \mathrm{GPa}, \\
\mathrm{G}_{1} & =4.1 \mathrm{GPa}, \\
\nu_{12} & =\nu_{13}=0.15 .
\end{aligned}
$$

The elastic moduli given above are the secant moduli of the second loading curve between 0 and $6.9 \mathrm{MPa}$.

The following modulus/temperature relationship applies to $E_{1}, E_{3}$, and $G_{1}$, but not $\nu_{12}$ and $\nu_{13}$ (Ref. 3.3-20):

$$
\begin{aligned}
C(T)= & C_{R T}-9.94 \times 10^{-4}(T-21) \\
& +3.09 \times 10^{-6}(T-21)^{2},
\end{aligned}
$$

$$
\text { where } \begin{aligned}
C_{R T} & =E_{1}, E_{3} \text {, or } G_{1} \text { at room temperature (GPa), } \\
T & =\text { temperature }\left({ }^{\circ} \mathrm{C}\right), \\
C(T) & =E_{1}, E_{3}, \text { or } G_{1} \text { at temperature } T(G P a) .
\end{aligned}
$$

The relationship is valid up to $1100^{\circ} \mathrm{C}$.

The moduli increase with fast neutron irradiation. The percent increase $(P)$ is given in Table $3.3-5$ as well as plotted in Fig. $3 \cdot 3-3$ as a function of neutron fluence and irradiation temperature (Ref. 3.3-21). To calculate modulus $\left(E_{1}\right)$ at any point during neutron irradiation, the following equation applies:

$$
E_{1}=E_{0}(1+P / 100),
$$


TABLE $3 \cdot 3-5$

PERCENT INCREASE (P) IN ELASTIC MODULUS AS

A FUNCTION OF FLUENCE AND TEMPERATURE

\begin{tabular}{crrr}
\hline & \multicolumn{3}{c}{ Irradiation Temperature } \\
Fast Neutron Fluence & \multicolumn{3}{c}{$(\mathrm{K})$} \\
\cline { 2 - 4 }$\left(10^{22} \mathrm{n} / \mathrm{m}^{2}\right)$ & 673 & 873 & 1173 \\
\hline 1 & 4.3 & 3.1 & 2.3 \\
4 & 13.3 & 9.8 & 7.4 \\
10 & 24.0 & 18.3 & 13.9 \\
\hline
\end{tabular}




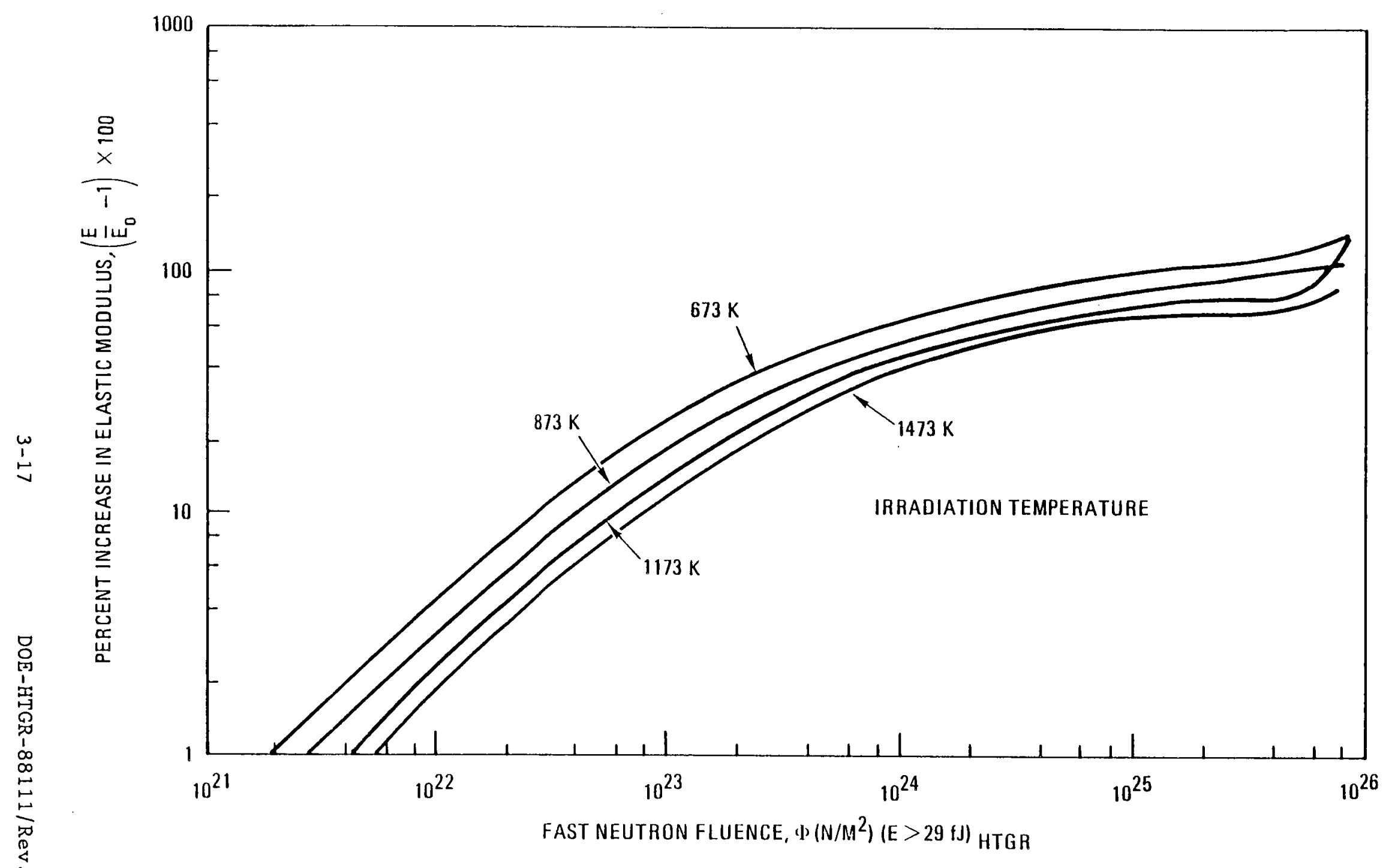

Fig. 3.3-3. Design curves for change in elastic modulus of 2020 graphite as a function of Irradiation conditions 
where $E_{0}=$ elastic modulus of unirradiated graphite at room temperature,

$$
P=\left(\frac{E_{0}}{E_{i}}-1\right) \times 100
$$

$E_{1}=$ elastic modulus of irradiated graphite measured at room temperature.

For $P$ at irradiation temperature and fast neutron fluence other than that given in Table $3.3-5$, the following relationship applies:

1. Logarithm of $P$ is a quadratic function of logarithm of $\phi$. 2. Logarithm of $P$ is a quadratic function of temperature $\left({ }^{\circ} \mathrm{C}\right)$.

\subsubsection{Stress-Strain Curve. Typical room temperature (RT) tensile} and compressive stress-strain curves for 2020 graphlte are shown in Figs. 3.3-4 and 3.3-5, respectively (Refs. 3.4-2, 3.4-3, and 3.4-22). The curves are applicable to a nonlinear design analysis.

Typical RT tensile and compressive stress strain curves when compared in the stress range below the specified minimum ultimate tensile strength ( $\mathrm{S}_{\mathrm{ut}}$ in Section 3.3.4.3) are slightly deviated from each other by less than one "within log" standard deviation. For practical purpose in the design analysis, the typical RT compressive stress strain curve can be considered as the same as the tensile curve when the maximum stress is expected to be lower than $S_{u t}$. The above assumption is not valid for test evaluation on component failure. 


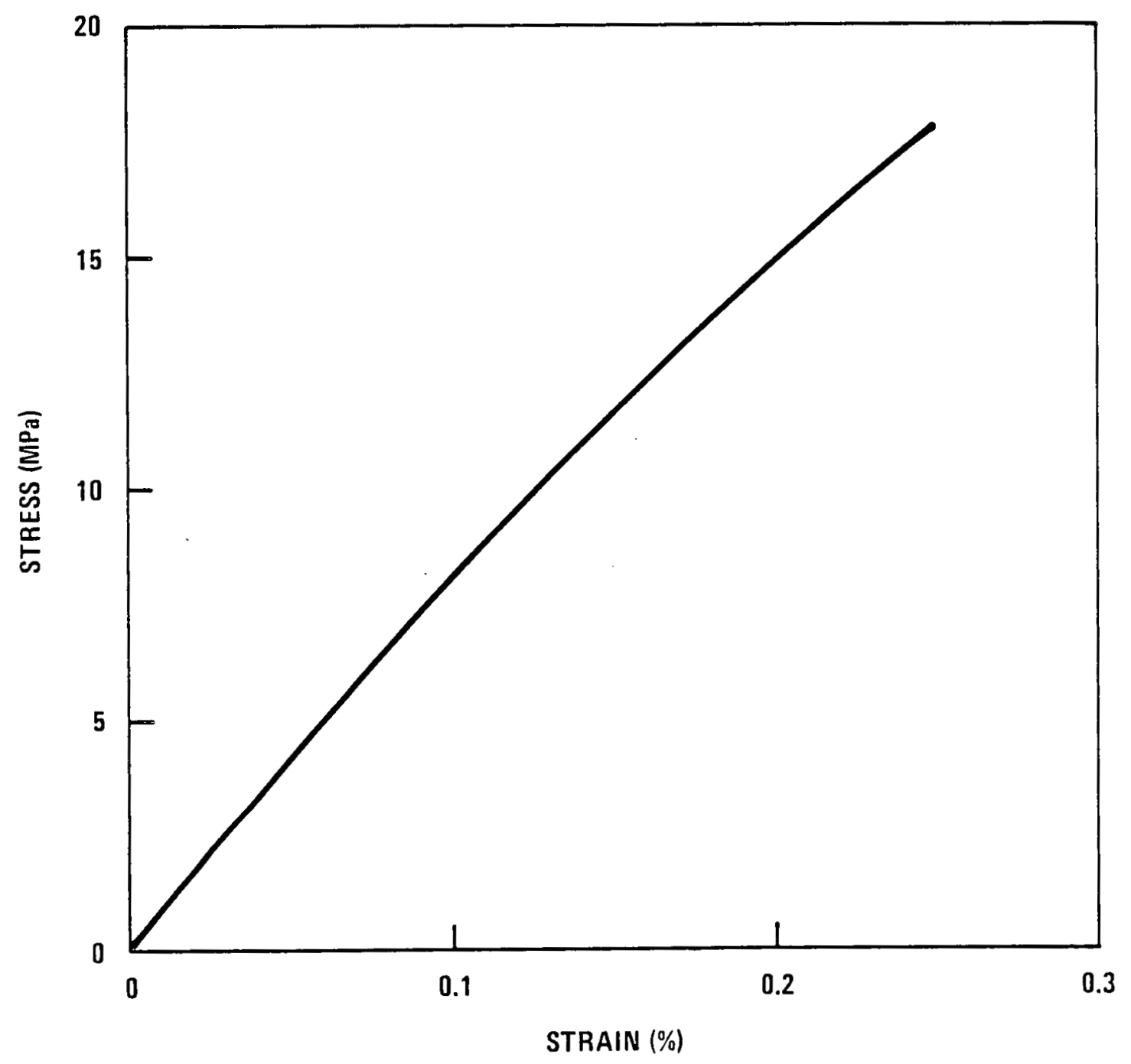

Fig. 3.3-4 Tensile stress-strain curve for 2020 graphite 


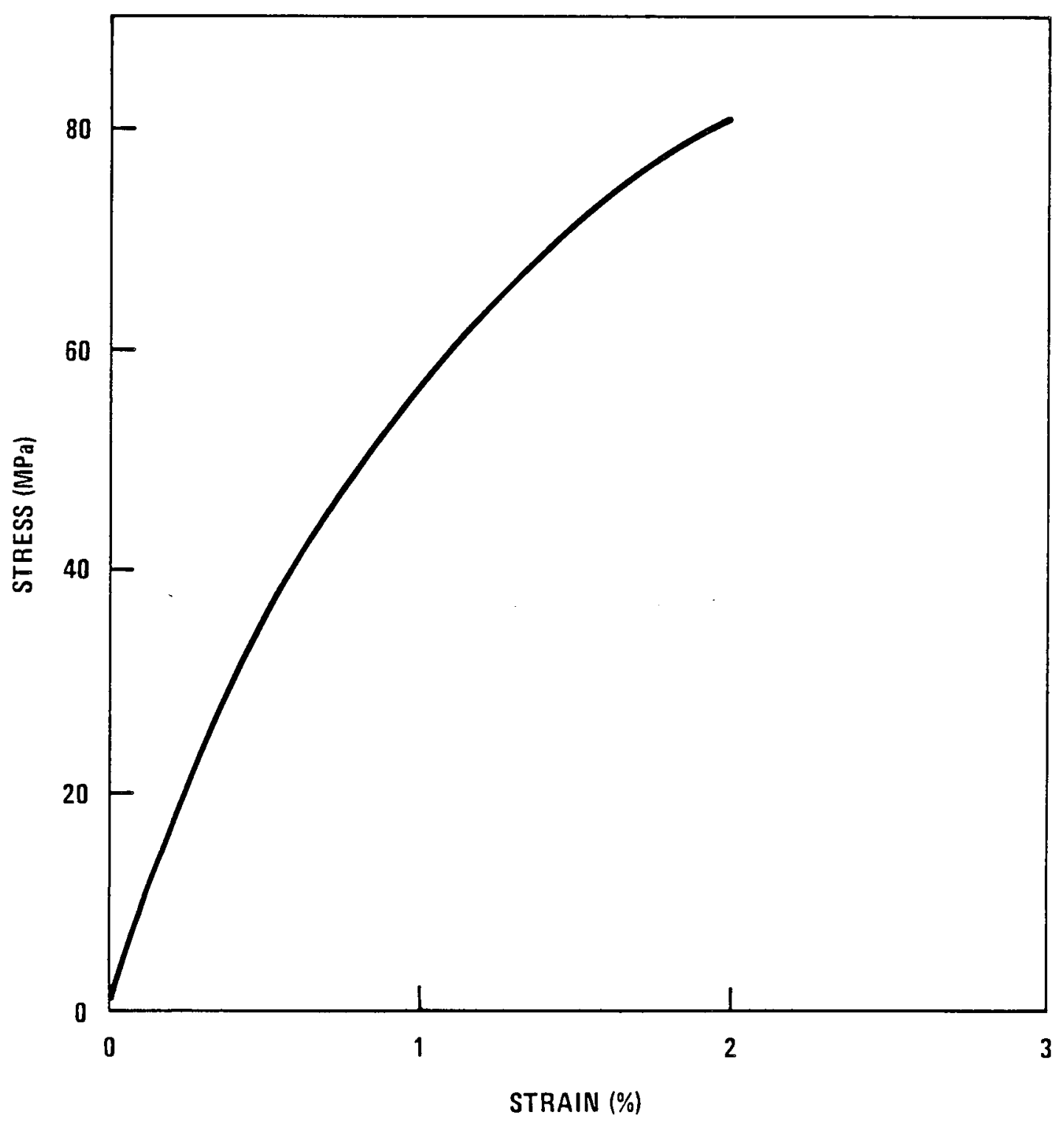

Fig. 3.3-5 Compressive stress-strain curve for 2020 graphite 


\subsubsection{Strength.}

Specified Minimum Ultimate Strength $\left(S_{u}\right)$. Specified minimum ultimate strength is the uniaxial strength along a principal stress direction which is used in design analysis to measure the structural integrity of a given core support graphite component against the design and accident condition stresses. Per ASME Code Subsection CE (Ref. 3.3-1), specified minimum strength is established from statistical treatment of graphite strength data such that the survival probability is $99 \%$ with a confidence level of $95 \%$.

For unirradiated 2020 graphite at room temperature along the material axes the specified minimum tensile strength ( $\left.S_{\text {ut }}\right)$ (Refs. 3.3-2, 3.3-3, and 3.3-17 through 3.3-19):

$$
\begin{aligned}
\mathrm{S}_{\mathrm{ut}}= & 14.7 \mathrm{MPa} \text { in the axial direction, } \\
& , 16.1 \mathrm{MPa} \text { in the radial direction. }
\end{aligned}
$$

The specified minimum compressive strength $\left(S_{u c}\right)$ is

$$
\begin{aligned}
\mathrm{S}_{\mathrm{uc}}= & 51.0 \mathrm{MPa} \text { in the axial direction, } \\
& 52.5 \mathrm{MPa} \text { in the radial direction,. }
\end{aligned}
$$

In the off-axis case, the following Hankinson's formula is recommended for use:

$$
\mathrm{S}_{\mathrm{ut}}(\theta)=\frac{14.7 \times 16.1}{14.7 \times \sin ^{2} \theta+16.1 \times \cos ^{2} \theta} \mathrm{MPa}
$$

where $\theta$ is the angle between the direction of the principal stress and the axial (material) axis.

Both $S_{u t}$ and $S_{u c}$ may be assumed to increase with temperature and neutron fluence identical to that for UTS (until such time as the 
experimental data are available). The relationship is (Refs. 3.3-20 and $3.3-21)$

$$
S_{u}(T)=\left[\left(S_{u}\right)_{R T}+0.00392(T-294)\right]\left(E_{i} / E_{o}\right)^{1 / 2}
$$

where $\left(S_{\mathrm{u}}\right)_{\mathrm{RT}}=$ room temperature unirradiated $\mathrm{S}_{\mathrm{ut}}(\mathrm{MPa})$,

$$
\begin{aligned}
T= & \text { temperature }(\mathrm{K}), \\
E_{1}= & \text { modulus of irradiated graphite at room temperature } \\
& (\mathrm{GPa}), \\
E_{0}= & \text { modulus of unirradiated graphite at room temperature } \\
& (\mathrm{GPa}), \\
\mathrm{S}_{\mathrm{u}}(\mathrm{T})= & \mathrm{S}_{\mathrm{u}} \text { of unirradiated } 2020 \text { at temperature } \mathrm{T} \text { (MPa). }
\end{aligned}
$$

Specified Minimum Blaxial Strength. In the biaxial stress state, the Coulomb-Mohr theory, modified to include a maximum tensile strength cutoff, is the failure theory currently recommended for graphite (Ref. 3.3-23). This theory defines that the maximum principal stress governs failure in the first and third stress quadrants. In the second and fourth quadrants, the maximum principal stress or the Coulomb-Mohr theory, whichever is more restrictive, is applied.

The specified minimum biaxial strength surface is established similar to that of the above failure surface. The surface is given in Fig. 3.3-6. Caution is required when using the biaxial strength in the third quadrant. Early failure may occur in other modes prior to biaxial compressive failure. Minimum values are determined by the ASME rules of $\operatorname{Ref}$. 3.3-1.

Fatigue Strength. The normalized fatigue strength (normalized with respect to mean strength) is defined in Table 3.3-6 (Ref. 3.3-24) as a 


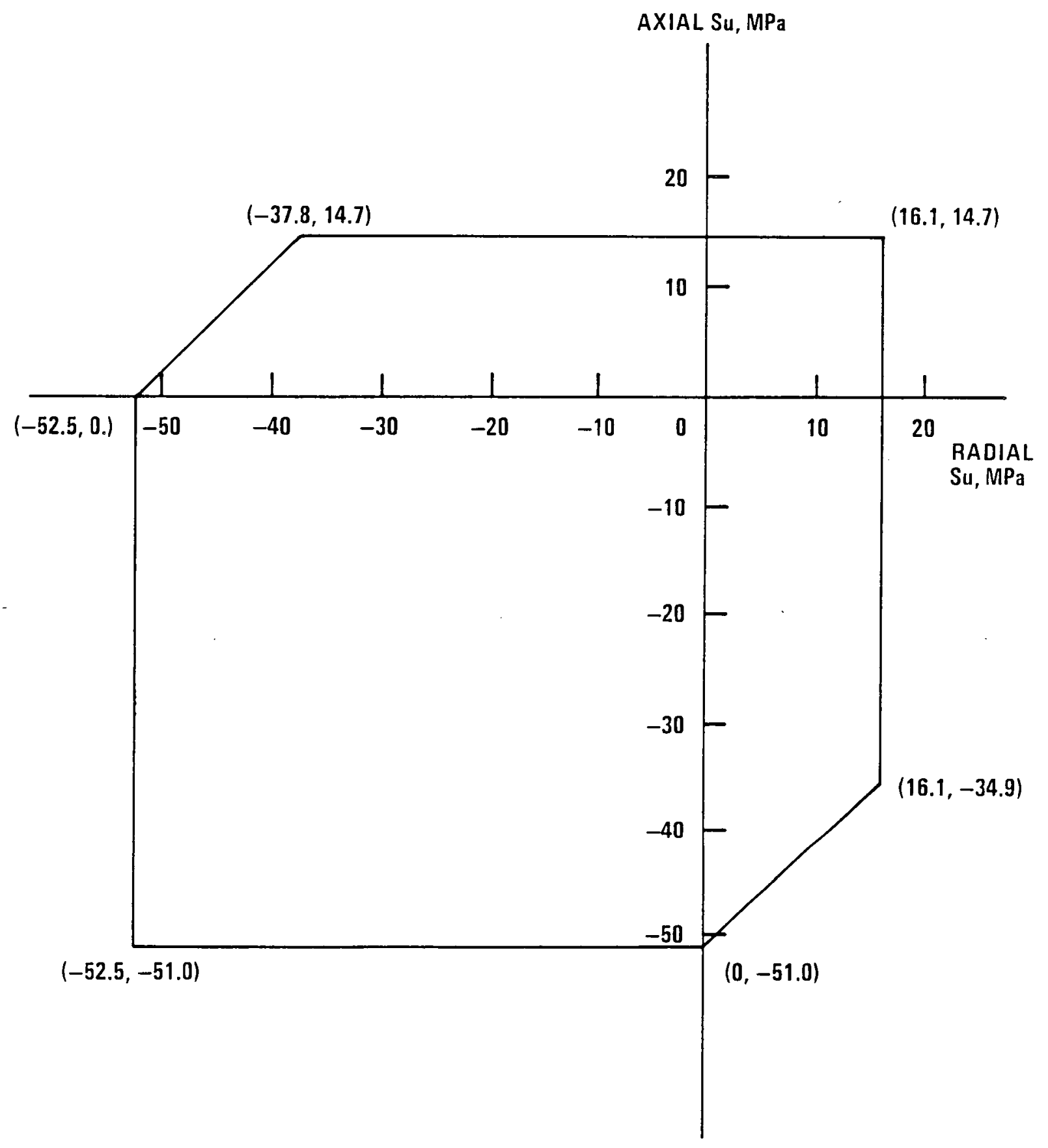

Fig. 3.3-6 Specified Minimm Biaxial Strength Surface for 2020 Graphite 
TABLE $3 \cdot 3-6$

UNIAXIAL FATIGUE STRENGTH LIMITS FOR 2020 GRAPHITE

\begin{tabular}{|c|c|c|c|c|c|}
\hline \multirow[b]{2}{*}{ Orientation } & \multicolumn{5}{|c|}{ Fatigue Strength Limits, Peak Stress/Mean Strength } \\
\hline & $\begin{array}{c}\mathrm{R} \\
\left(\sigma_{\min } / \sigma_{\max }\right)\end{array}$ & $\begin{array}{l}\text { Number of } \\
\text { Cycles }\end{array}$ & $50 \%$ & Survival & $\begin{array}{l}\text { 99/95 Lower } \\
\text { Tolerance Limit }\end{array}$ \\
\hline \multirow[t]{12}{*}{ Axial } & 0 & 100 & & 0.87 & 0.69 \\
\hline & & 1,000 & & 0.83 & 0.66 \\
\hline & & 10,000 & & 0.80 & 0.63 \\
\hline & & 100,000 & & 0.76 & 0.60 \\
\hline & -1 & 100 & & 0.84 & 0.66 \\
\hline & & 1,000 & & 0.79 & 0.62 \\
\hline & & 10,000 & & 0.74 & 0.58 \\
\hline & & 100,000 & & 0.70 & 0.54 \\
\hline & -2 & 100 & & 0.85 & 0.66 \\
\hline & & 1,000 & & 0.80 & 0.62 \\
\hline & & 10,000 & & 0.75 & 0.58 \\
\hline & & 100,000 & & 0.71 & 0.55 \\
\hline \multirow[t]{12}{*}{ Radial } & 0 & 100 & & 0.86 & 0.71 \\
\hline & & 1,000 & & 0.81 & 0.67 \\
\hline & & 10,000 & & 0.77 & 0.64 \\
\hline & & 100,000 & & 0.73 & 0.60 \\
\hline & -1 & 100 & & 0.79 & 0.61 \\
\hline & & 1,000 & & 0.73 & 0.56 \\
\hline & & 10,000 & & 0.68 & 0.52 \\
\hline & & 100,000 & & 0.63 & 0.48 \\
\hline & -2 & 100 & & 0.81 & 0.66 \\
\hline & & 1,000 & & 0.76 & 0.61 \\
\hline & & 10,000 & & 0.71 & 0.57 \\
\hline & & 100,000 & & 0.66 & 0.53 \\
\hline
\end{tabular}


function of stress ratio $(R)$ and number of cycles. Survival is shown up to $10^{5}$ cycles under uniaxial cyclic loading in air at ambient temperature. Mean strength of graphite, as well as fatigue strength, increases with fast fluence and temperature in the range of interest. However, it is assumed that normalized fatigue strength remains constant for the design use.

The design fatigue diagram can be used to interpolate the fatigue strength at other $R$ ratios (Fig. 3.3-7).

\subsubsection{Eracture Toughness and the Critical Defect Size. Fracture} toughness of unirradiated 2020 graphite at room temperature is (Ref. 3.3-25):

$$
\mathrm{K}_{\mathrm{IC}}=1.25 \mathrm{MPa} \sqrt{\mathrm{m}} .
$$

The calculated critical defect size is $0.6 \mathrm{~mm}$.

The reduction of $\mathrm{K}_{\mathrm{IC}}$ with oxidation follows the relationship

$$
\mathrm{K}_{\mathrm{IC}} /\left(\mathrm{K}_{\mathrm{IC}}\right)_{0}=\exp (-7 \mathrm{x})
$$

where $x$ = fractional weight loss due to oxidation and the subscript "o" represents the unoxidized state. The calculated critical defect size remains unchanged with oxidation.

3.3.4.5. Effect of Oxidation on Mechanical Properties. The reduction in tensile strength (S) and elastic modulus (E) is assumed to be the same for the commercial and the nuclear 2020 grades, which may be represented by the following relationship (Refs. 3.3-26 and 3.3-27):

$$
\frac{S}{S_{0}}=\frac{E}{E_{0}}=\exp (-10 x),
$$




\section{(Later)}

Fig. 3.3-7. Design fatigue diagram of nuclear grade 2020 graphite at $99 \%$ survival probability with $95 \%$ confidence level 
where $x$ = fractional weight loss due to oxidation and the subscript "o" represents the unoxidized state.

For the preliminary calculation on the component subjected to external loads, it may be conservatively assumed that any portion of graphite that oxidized to $\geq 0.1 \%$ loses its entire strength.

3.3.4.6. Material Internal Damping Factor. The internal damping factor 5 , defined as the ratio of actual damping to critical damping is dependent on the stress amplitude. At a stress amplitude of $7.35 \mathrm{MPa}, 5$ is equal to $0.596 \%$ (Ref. 3.3-28). This is for $0.5 \mathrm{~S}_{\mathrm{ut}}$, approximately the $99 / 95$ endurance limit. When the stress amplitude is reduced to half, 5 decreases on 1 y by $12 \%$.

\subsubsection{References}

3.3-1. "Proposed Section III, Division 2, ASME Boiler and Pressure Vessel Code, Subsection CE, Design Requirements for Graphite Core Supports," Apr11 1984.

3.3-2. Engle, G. B., "Properties of Unirradiated HTGR Core Support and Permanent Side Reflector Graphites: PGX, HLM, 2020, and H-440N," ERDA Report GA-A14328, May 1977.

3.3-3. Engle, G. B., and L. A. Beavan, "Properties of Unirradiated Graphites PGX, HLM, and 2020 for Support and Permanent Side Reflector LHTGR Components," DOE Report GA-A14646, June 1978.

3.3-4. Burnette, R. D., and G. R. Hightower, "Oxidation Kinetics of SC 2020 Graphite Nuclear Grade, Lot 1," GA Document 908038/0, May $31,1985$.

3.3-5. Peroomian, M. B., A. W. Barsell, and J. C. Seager, "OXIDE-3: A Computer Code for Analysis of HTGR Steam or Air Ingress Accidents," GA Report GA-A12493 (GA-LTR-7), January 15, 1974.

3.3-6. Burnette, R. D., et al., "Studies of the Rate of Oxidation of ATJ Graphite by Steam," in Proceedings of 13th Biennial Conference on Carbon at Irvine, California, July 13-22, 1977. 
3.3-7. "HTGR Fuels and Core Development Program, Quarterly Progress Report for the Period Ending August 31, 1977," ERDA Report GA-A14479, September 1977, p. 11-16.

3.3-8. Jensen, D., M. Tagami, and C. Velasquez, "Air/H-327 Graphite Reaction Rate as a Function of Temperature and Irradiation," GA Report Gulf-GA-A12647, September 24, 1973.

3.3-9. Butland, A. T. D., and R. J. Maddison, "The Specific Heat of Graphite: An Evaluation of Measurements," Journal of Nuclear Material, 49, 45 (1973-1974).

3.3-10. "Graphite Data Manua1," DOE-HTGR [LATER], to be issued.

3.3-11. Price, R. J., "Review of the Thermal Conductivity of Nuclear Graphite under HTGR Conditions," GA Report Gulf-GA-A12615, September 1973.

3.3-12. Engle, G. B., and K. Koyama, "Dimensional and Property Changes of Graphites Irradiated at High Temperatures," Carbon, $\underline{6}$, p. 455,1968 .

3.3-13. Kelly, B. T., et al., "The annealing of Irradiation Damage in Graphite, " Journal Nuclear Materials, 20, p. 195, 1966.

3.3-14. Grenis, A. F., and A. P. Levilt, "The Spectral Emissivity and Total Normal Emissivity of Commercial Graphites at Elevated Temperatures," Proceedings of Fifth Conference on Carbon, p. $639,1961$.

3.3-15. Plunkett, J. D., and W. D. Kingery, "The Spectral and Integrated Emissivity of Carbon and Graphite," Proceedings of Fourth Carbon Conference, p. 457, 1960.

3.3-16. Autio, G. W., and E. Scula, "The Normal Spectral Emissivity of Isotropic and Anisotropic Materials, " Carbon, 4, pp. 13-28, 1966.

3.3-17. "HTGR Fuels and Core Development Program. Quarterly Progress Report for the Period Ending February 28, 1977," ERDA Report GA-A14298, March 1977.

3.3-18. "HTGR Generic Technology Program, Semiannual Report for the Period Ending September 30, 1979," DOE Report GA-A15606, November 1979 . 
3.3-19. "HTGR Generic Technology Program, Semiannual Report for the Period Ending September 30, 1980," DOE Report GA-A16127, November 1980.

3.3-20. Ho, F. H., and E. Chin, "Test Evaluation Report of the Thermal Stress ( $T / S)$ Test for Core Support Graphite," Document $904445 / B$, August 12, 1980.

3.3-21. Price, R. J., "Mechanfcal Properties of Graphite of HighTemperature Gas-Cooled Reactors: A Review," ERDA Report GA-A13524, September 22, 1975.

3.3-22. Price, R. J., "Test Report: Instrumented Beam Tests on 2020 Graphite," GA Document 906550, Issue 1, June 1982.

3.3-23. Ho, F. H., et al., "Biaxial Fallure Surfaces of 2020 and PGX Graphites," Paper No. [4/6, P. 127, Transactions of the 7th International Conference on Structural Mechanics in Reactor Technology, Chicago, IL, August 22, 1983.

3.3-24. Price, R. J., "Test Report: Fatigue Tests on 2020 Graphite," GA Document 906202/1, September 1981.

3.3-25. Eatherly, W. P., and C. R. Kennedy, ORNL 1982 HTGR Program Review, ORNL Progress Report, ORNL GCR/B-87/11, December 1987.

3.3-26. Beavan, L. A., "Test Report: Strength of Oxidized Fine Grain Graphite," GA Document 906249, Issue 1, September 1981.

3.3-27. "Core Support Post and Seat Graphites: Grades 2020 and ATJ," in "HTGR Generic Technology Prograra: Fuels and Core Development, Quarterly Progress Report for the Period Ending August 31, 1978," DOE Report GA-A15093 (Section 3.6.3.1), September 1978, p. 3-36.

3.3-28. Ho, F. H., and R. Salavatcioglu, "Internal Damping Factor for HTGR Core Support Post Materials," GA Document 904365/1, November 1979.

3.3-29. "Fuel Design Data Manual," GA Document 901866/F, April 1987. 


\subsection{LARGE RECTANGULAR NUCLEAR GRADE 2020 GRAPHITE}

\subsubsection{Introduction}

The large rectangular nuclear grade 2020 graphite is referenced for the permanent side reflector (PSR) and central reflector (CR) column support structure. The properties given in this section are presented to be consistent with the structural criteria for graphite core supports (Ref. 3.4-1). Unless otherwise noted, the raterial properties given below for this nuclear grade 2020 graphite are mean values.

The maximum predicted fast neutron fluence to the PSR and the CR column support structure is $1.2 \times 10^{24} \mathrm{n} / \mathrm{m}^{2}$ ( $\mathrm{E}>29 \mathrm{fJ}$, HTGR), which is only $3 \%$ of the maximum fluence accumulated by fuel element graphite. Experience with fuel element graphite has shown that only elastic modulus and thermal conductivity will be noticeably affected by a total fast neutron fluence of $2 \times 10^{24} \mathrm{n} / \mathrm{m}^{2}$. Therefore, irradiation effects on other properties described below are insfgnificant and not discussed.

\subsubsection{Physical and Chemical Properties}

3.4.2.1. Density. The bulk density of 2020 graphite is $1.78 \mathrm{Mg} / \mathrm{m}^{3}$ averaged over the $\log$ (Refs. $3.4-2$ and 3.4-3).

\subsubsection{Transport and Reaction Rates.}

\subsection{Steam-Graphite Oxidation Rates. The Langmuir-} Hinshelwood equation, Eq. 3.4-1, is used to predict steam-graphite oxidation rates for nuclear grade 2020 graphite (Ref. 3.4-4):

$$
\text { Rate }=\frac{\mathrm{K}_{1} \mathrm{P}_{\mathrm{H}_{2} \mathrm{O}} \mathrm{F}_{\mathrm{b}}}{1+\mathrm{K}_{2}\left(\mathrm{P}_{\mathrm{H}_{2}}\right)^{n}+\mathrm{K}_{3} \mathrm{P}_{\mathrm{H}_{2} \mathrm{O}}} \text {. }
$$


where Rate = local graphite mass fraction reacting per second,

$$
\begin{aligned}
\mathrm{P}_{\mathrm{H}_{2}}, \mathrm{P}_{\mathrm{H}_{2} \mathrm{O}}= & \text { local partial pressures of hydrogen and steam, } \\
& \text { respectively, } \\
\mathrm{F}_{\mathrm{b}}= & \text { modifier for effects of burnoff, } \\
\mathrm{n}= & \text { exponent, } \\
\mathrm{K}_{\mathrm{j}}= & \mathrm{k}_{\mathrm{j}} \exp \left(\mathrm{E}_{\mathrm{j}} / \mathrm{RT}\right), \\
\text { where } \mathrm{j} & =1,2 \text {, or } 3, \\
k_{j} & =\text { Arrhenius frequency factor, } \\
E_{j} & =\text { activation energy, } \\
\mathrm{R} & =8.314 \mathrm{~J} / \mathrm{mole} \cdot \mathrm{K} .
\end{aligned}
$$

The values of $\mathrm{K}_{1}, \mathrm{~K}_{2}, \mathrm{~K}_{3}$, and $\mathrm{n}$ given in Table 3.4-1 are based on data for the temperatures indicated. Before additional data at other temperatures will be generated to allow $k_{j}$ to be determined, it is assumed that $\mathrm{k}_{j}$ in Table 3.4-1 can be extrapolated to other temperatures.

For preliminary design, $F_{b}$ is the same as that used to predict burnoff effects for steam oxidation of H-451 graphite (until such time as additional 2020 graphite oxidation data are available). The oxidation rates of the nuclear grade 2020 graphite is about one-fifth that of H-451 graphite.

3.4.2.2.2. Air-Graphite Reaction Rates. The rate of oxidation of graphite by air is given by Eq. $3.4-2$ (Ref. 3.4-8):

$$
\text { Rate }=K \exp (-E / R T) \quad P_{O_{2}}
$$

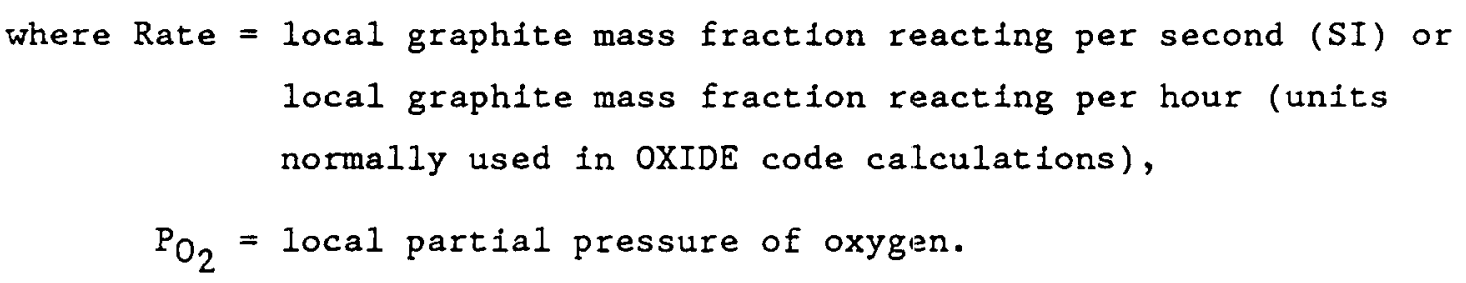


TABLE 3.4-1

SUMMARY OF OXIDATION KINETIC CONSTANTS FOR NUCLEAR 2020 GRAPHITE

\begin{tabular}{|c|c|c|c|c|c|c|c|c|}
\hline \multirow[b]{2}{*}{$\begin{array}{c}\text { Temperature } \\
\left({ }^{\circ} \mathrm{C}\right)\end{array}$} & \multirow[b]{2}{*}{$\mathrm{n}$} & \multicolumn{4}{|c|}{ High Water $>100 \mathrm{~Pa} \mathrm{H}{ }_{2} \mathrm{O}$} & \multicolumn{3}{|c|}{ Low Water $<100 \mathrm{~Pa} \mathrm{H} \mathrm{H}_{2} \mathrm{O}$} \\
\hline & & $\begin{array}{c}\mathrm{K}_{1} \\
(\mathrm{~s} \cdot \mathrm{Pa})^{-1}\end{array}$ & $\underset{\mathrm{Pa}^{-1} \cdot 3}{\mathrm{~K}_{2}}$ & & $\begin{array}{c}\mathrm{K}_{3} \\
\mathrm{~Pa}^{-1}\end{array}$ & $\begin{array}{c}\mathrm{K}_{1} \\
(\mathrm{~s} \cdot \mathrm{Pa})^{-1}\end{array}$ & $\underset{P a-I .3}{\mathrm{~K}_{2}}$ & $\underset{\mathrm{Pa}_{3}-1}{\mathrm{~K}_{3}}$ \\
\hline 980 & 1.3 & $8 \cdot 7 E-10$ & $1.1 E-3$ & 2.6 & $-8 \cdot 7 E-4$ & $7.2 E-9$ & $9.0 \mathrm{E}-3$ & $8 \cdot 1 E-2$ \\
\hline 930 & 1.3 & $3.8 \mathrm{E}-10$ & $1.6 \mathrm{E}-3$ & 3.8 & $-16 E-4$ & $2.3 E-9$ & $9.5 E-3$ & $1.7 E-1$ \\
\hline 900 & 1.3 & $2.0 E-10$ & $2.0 \mathrm{E}-3$ & 2.0 & $-4.0 E-4$ & & & \\
\hline
\end{tabular}


Table 3.4-2 gives the system of units derived from $\mathrm{H}-327$ experimental data. It is assumed that the air-graphite reaction rate of $H-451$ is identical to that of $\mathrm{H}-327$.

Since there are no experimental data on air-graphite reaction rate reported for the grade 2020 graphite, Eq. 3.4-2, together with Table 3.4-2, shall be used. With the exception that the $K$ appeared in Eq. 3.4-2 and value given in Table 3.4-2 needs to be modified by a factor equal to the ratio of the oxidation rate of nuclear grade 2020 graphite to that of H-451 graphite at the environmental conditions of interest.

\subsection{Radiolytic Effect on Oxidation Rate. The available} experimental data show that there is a small and negligible radiolytic effect on oxidation rate in air (see discussion in Section 4.3.2.3).

3.4.2.2.4. Transport of Steam in Helium by Diffusion. The effective diffusion coefficient of steam in graphite is given by Eq. 3.4-3 (Refs. 3.4-5 through 3.4-7):

$$
\mathrm{D}_{\mathrm{H}_{2} \mathrm{O}}=\frac{1.0 \times 10^{-10} \times \mathrm{T}^{1.58} \times \mathrm{P}}{\mathrm{P}_{\text {total }}}\left(\mathrm{m}^{2} / \mathrm{s}\right) \text {, }
$$

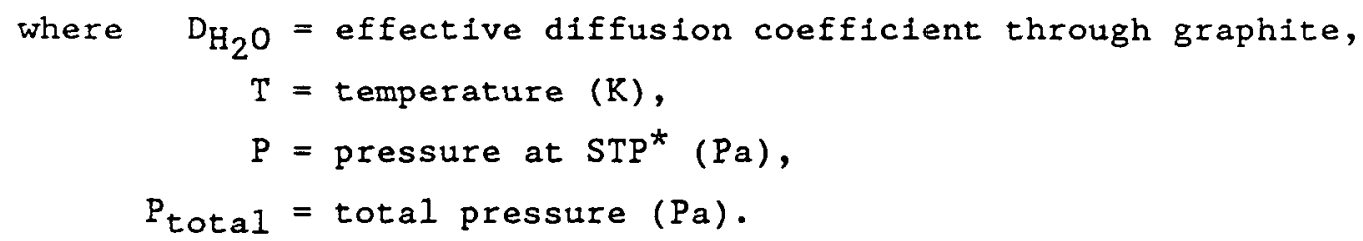

A parameter such as diffusion through graphite is recognized to vary by as much as a factor of three from sample to sample or from position to position in the graphite block. Equation 3.4-3 describes the present best estimate for $\mathrm{H}_{2} \mathrm{O}$ diffusion in graphite having $1 \%$ average oxidation burnoff.

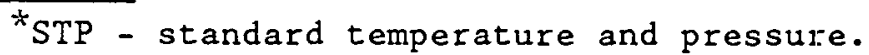


TABLE $3 \cdot 4-2$

AIR-GRAPHITE REACTION RATE COEFFICIENTS(a)

\begin{tabular}{|c|c|c|c|c|}
\hline Systems of Units & $\mathrm{K}$ & $E$ & $\mathrm{~T}$ & $R$ \\
\hline SI & $\begin{array}{l}0.79 \\
(\mathrm{~s} \cdot \mathrm{Pa})^{-1}\end{array}$ & $\begin{array}{l}1.7 \times 10^{5} \\
\mathrm{~J} / \mathrm{mol} \cdot \mathrm{K}\end{array}$ & K & $\begin{array}{l}8.314 \\
\mathrm{~J} / \mathrm{mol} \cdot \mathrm{K}\end{array}$ \\
\hline OXIDE code & $\begin{array}{l}2.88 \times 10^{10} \\
(\% \mathrm{~h} \cdot \mathrm{atm})^{-1}\end{array}$ & $\begin{array}{l}4.06 \times 10^{4} \\
\mathrm{cal} / \mathrm{mol}\end{array}$ & $\mathrm{K}$ & $\begin{array}{l}1.986 \\
\mathrm{cal} / \mathrm{mol} \cdot \mathrm{K}\end{array}$ \\
\hline
\end{tabular}

(a) See text for the appropriate values to be used in Eq. 3.3-2 for nuclear grade 2020 graphite. 
Equation 3.4-3 was obtained by pooling all available experimental data on steam diffusion through graphite in helium. No corrections were made for the differences in porosity and pore structure. Equation 3.4-3 is assumed to be applicable to all reference HTGR graphites.

The effective diffusion coefficients recommended for carbon monoxide, oxygen, and hydrogen are as follows (until such time as experimental data are available):

$$
\begin{aligned}
& \mathrm{D}_{\mathrm{CO}}=\mathrm{D}_{\mathrm{H}_{2} \mathrm{O}}, \\
& \mathrm{D}_{\mathrm{O}_{2}}=\mathrm{D}_{\mathrm{H}_{2} \mathrm{O}}, \\
& \mathrm{D}_{\mathrm{H}_{2}}=2 \mathrm{D}_{\mathrm{H}_{2} \mathrm{O}},
\end{aligned}
$$

3.4.2.2.5. Transport of Steam in Helium by Convection. The transport of steam by convection involves the permeation of graphite. The permeability coefficients of graphite Ref. 3.4-29 are:

$$
\begin{aligned}
& \mathrm{K}_{\mathrm{I}}=1.55 \mathrm{E}-13 \mathrm{~m}^{2}, \\
& \mathrm{~K}_{\mathrm{P}}=9.20 \mathrm{E}-14 \mathrm{~m}^{2},
\end{aligned}
$$

where the subscripts represent the following regions of the hexagonal graphite blocks:

$I$ = interior region consisting of a hexagonal block having an area in the plane of the hexagon one-seventh of the corresponding area of the entire block,

$\mathrm{P}=$ periphery region consisting of the entire hexagonal block minus the interior region. 
The values of $\mathrm{K}_{\mathrm{F}}$ and $\mathrm{K}_{\mathrm{P}}$ are derived from data on $\mathrm{H}-327$ graphite; they are assumed to apply to 2020 graphite (until such time as experimental data are available).

\subsubsection{Therma1 Properties}

3.4.3.1. Specific Heat. The specific heat of graphite over the temperature range 250 to $3000 \mathrm{~K}$ is given by Eq. 3.4-6 (Ref. 3.4-9):

$$
\begin{aligned}
C_{p}= & \left(0.54212-2.42667 \times 10^{-6} \mathrm{~T}-90.2725 \mathrm{~T}^{-1}\right. \\
& -4.34493 \times 10^{4} \mathrm{~T}^{-2}+1.59309 \times 10^{7} \mathrm{~T}^{-3} \\
& \left.-1.43688 \times 10^{9} \mathrm{~T}^{-4}\right) \times 4184,
\end{aligned}
$$

where $C_{p}=$ specific heat at constant pressure $(\mathrm{J} / \mathrm{kg}-\mathrm{K})$, $T=$ temperature $(K)$.

Equation 3.4-6 is also presented graphically in Fig. 3.4-1.

3.4.3.2. Thermal Expansivity. The thermal expansivity of 2020 graphite is given below (Ref. $3.4-10$ ):

$$
\alpha=A+B(\Delta T),
$$

$$
\text { where } \begin{aligned}
a= & \operatorname{CTE}\left(1 /{ }^{\circ} \mathrm{C}\right), \\
\Delta \mathrm{T}= & \text { temperature increase above room temperature }\left({ }^{\circ} \mathrm{C}\right), \\
\mathrm{A}= & 0.3075 \times 10^{-5} \text { in the radial direction, } \\
& 0.3225 \times 10^{-5} \text { in the axial direction, } \\
\mathrm{B}= & 1.078 \times 10^{-9} \text { in the radial direction, } \\
& 1.167 \times 10^{-9} \text { in the axial direction. }
\end{aligned}
$$

3.4.3.3. Thermal Conductivity. The thermal conductivity of unirradiated 2020 graphite is given in Table $3.4-3$ as a function of measurement temperature (Ref. 3.4-3). The change in thermal conductivity of irradiated 2020 graphite at irradiation temperature is given in Eq. 3.4-8 (Ref. 3.4-11). 


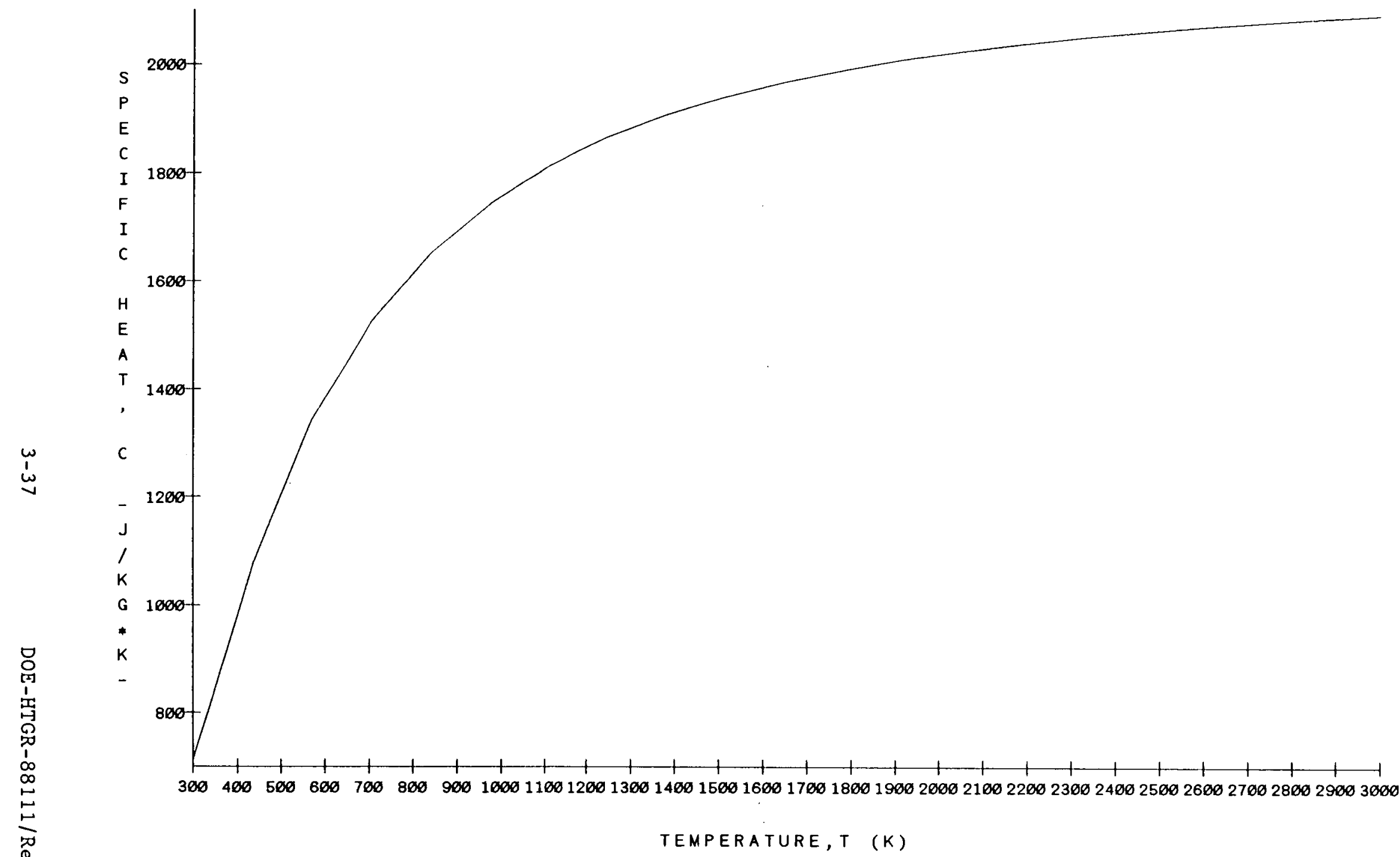

Fig. 3.4-1 Specific Heat of Graphite as a Function of Temperature 
TABLE $3 \cdot 4-3$

THERMAL CONDUCTIVITY OF 2020 GRAPHITE

\begin{tabular}{llllll}
\hline & \multicolumn{5}{c}{ Conductivity $\begin{array}{c}\text { at Measurement } \\
(\mathrm{W} / \mathrm{m} \cdot \mathrm{K})\end{array}$} \\
\cline { 2 - 6 } Orientation & $295 \mathrm{~K}$ & $473 \mathrm{~K}$ & $673 \mathrm{~K}$ & $873 \mathrm{~K}$ & $1073 \mathrm{~K}$ \\
\hline Radial & 62.4 & 67.2 & 57.2 & 49.8 & 43.9 \\
Axial & 63.0 & 63.7 & 53.7 & 45.2 & 40.8 \\
\hline
\end{tabular}




$$
\frac{1}{K_{i}(T)}=\frac{1}{K_{0}(T)}+\frac{F}{K_{0}(295 K)},
$$

where

$$
\begin{aligned}
\mathrm{K}_{1}(\mathrm{~T})= & \text { thermal conductivity of irradiated graphite at temper- } \\
& \text { ature } \mathrm{T}(\mathrm{K}), \\
\mathrm{K}_{0}(\mathrm{~T})= & \text { thermal conductivity of unirradiated graphite at tem- } \\
& \text { perature } \mathrm{T}(\mathrm{K}) \text { (derived from Table } 3.4-3),
\end{aligned}
$$

$\mathrm{K}_{\mathrm{o}}(295 \mathrm{~K})=$ thermal conductivity of unirradiated graphite at room temperature,

$F=$ fractional increase in thermal resistivity due to neutron irradiation (fluence dependence is given in Table 3.4-4 and Fig. 3.4-2).

The tabulated data on $F$ were established from analysis of experimental data measured on miscellaneous graphites. Until such time as 2020 graphite thermal conductivity data under low irradiation level are available, it is assumed that Table 3.4-4 is applicable to 2020 graphite.

For other fast fluences, a linear relationship may be used between logarithms of $\mathrm{F}$ and fast fluence. An approximately linear relationship also exists between $T$ and logarithm of $F$.

Thermal annealing on thermal conductivity appears to begin at $1273 \mathrm{~K}$ and is completed by $1573 \mathrm{~K}$ (Refs. 3.4-12 and 3.4-13). In this temperature range the fractional change in conductivity is close to linearly proportional to temperature. The fractional increase in thermal resistivity, $F$, in Eq. 3.4-8 is assumed to linearly decrease to zero over the above temperature range. 
TABLE $3.4-4$

THERMAL RESISTIVITY CONSTANT F, USED IN EQ. 3.4-8

\begin{tabular}{clll}
\hline & \multicolumn{3}{c}{ Irradiation Temperature } \\
\cline { 2 - 4 } $\begin{array}{c}\text { Fast Neutron Fluence } \\
\left(10^{22} \mathrm{n} / \mathrm{m}^{2}\right)\end{array}$ & 673 & \multicolumn{3}{c}{873} & 1073 \\
\hline 0.4 & 0.075 & 0.0885 & 0.0215 \\
1 & 0.125 & 0.063 & 0.036 \\
4 & 0.27 & 0.138 & 0.078 \\
10 & 0.445 & 0.225 & 0.124 \\
20 & 0.665 & 0.33 & 0.185 \\
\hline
\end{tabular}




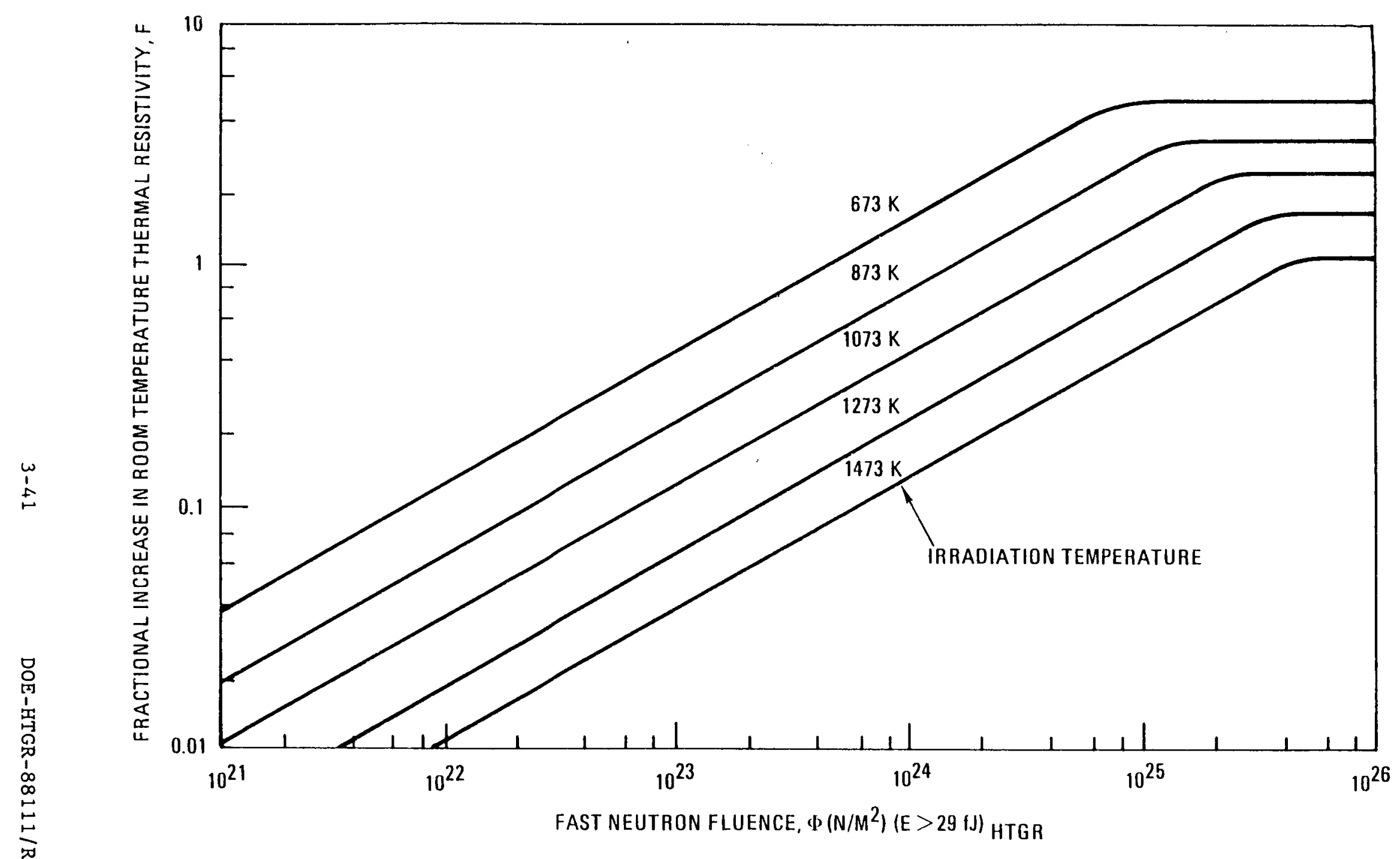

Fig. 3.4-2. Design curves for change in room temperature thermal resistivity of 2020 graphtte as a function of trradiation conditions 
3.4.3.4. Emissivity. The emissivity of $2020 \mathrm{graphite}$ for machined surface is 0.85 (Refs. 3.4-14 through 3.4-16).

\subsubsection{Mechanical Properties}

\subsubsection{Transversely Isotropic Linear Elastic Constants. The}

mechanical properties of commercial 2020 graphite can be modeled as transversely isotropic. The isotropic plane is in the direction perpendicular to molding pressure (with-grain) for rectangular graphite logs. The axes in this plane are designated 1 -axis and 2-axis. The across-grain direction is the axial direction, and is labelled as the 3-axis. The five independent unknowns in the transversely isotropic linear elastic material are two elastic moduli, $E_{1}$ and $E_{3}$; shear modulus, $G_{1}$; and two Poisson's ratios, $\nu_{12}$ and $\nu_{13}$.

The properties given below are the average of the combined tensile and compressive moduli at room temperature. The difference between two moduli is less than $10 \%$ (Refs. 3.4-17 through 3.4-19):

$$
\begin{aligned}
E_{1} & =\text { [later }] \mathrm{GPa}, \\
E_{3} & =\text { [1ater] } \mathrm{GPa}, \\
\mathrm{G}_{1} & =\text { [1 ater] } \mathrm{GPa}, \\
\nu_{12} & =\nu_{13}=0.15 .
\end{aligned}
$$

The elastic modulus given above is the tangent elastic modulus at the origin of the stress-strain curve.

The following modulus/temperature relationship applies to all $\mathrm{E}_{1}$, $E_{3}$, and $G_{1}$, but not $\nu_{12}$ and $\nu_{13}$ (Ref. 3.4-20):

$$
\begin{aligned}
C(T)= & C_{R T}-9.94 \times 10^{-4}(T-21) \\
& +3.09 \times 10^{-6}(T-21)^{2},
\end{aligned}
$$


where $C_{R T}=E_{1}, E_{3}$, or $G_{1}$ at room temperature (GPa),

$\mathrm{T}=$ temperature $\left({ }^{\circ} \mathrm{C}\right)$,

$C(T)=E_{1}, E_{3}$, or $G_{1}$ at temperature $T\left(G P_{a}\right)$.

The relationship is valid up to $1100^{\circ} \mathrm{C}$.

The moduli increase with fast neutron irradiation. The percent increase $(P)$ is given in Table 3.4-5, as well as plotted in Fig. 3.4-3, as a function of neutron fluence and irradiation temperature (Ref. 3.4-21). To calculate modulus $\left(E_{f}\right)$ at any point during neutron irradiation, the following equation applies:

$$
E_{1}=E_{0}(1+P / 100),
$$

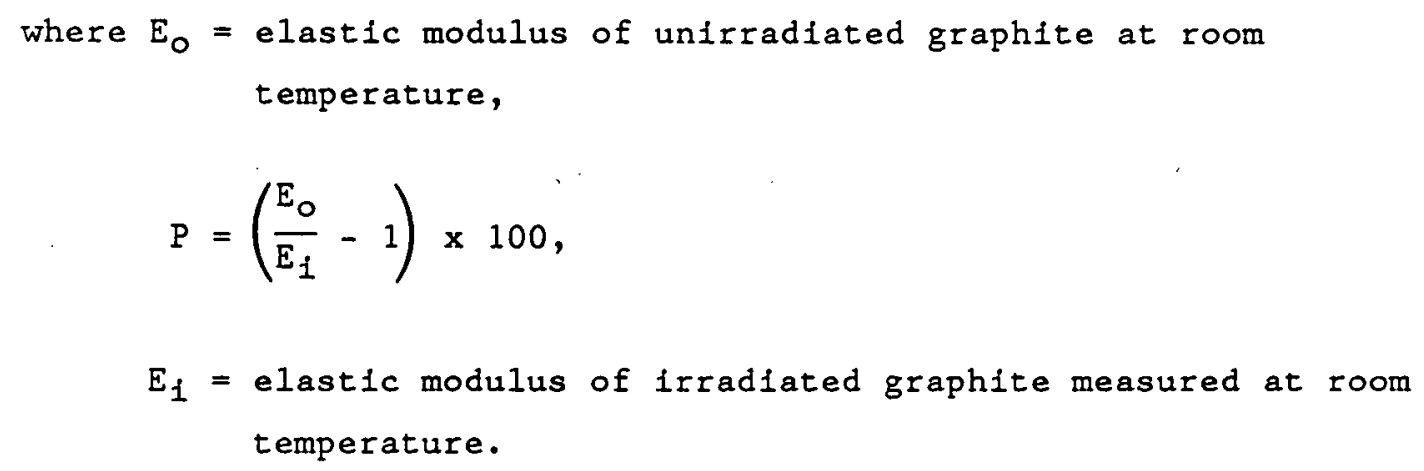

For $P$ at irradiation temperature and fast neutron fluence other than that given in Table 3.4-5, the following relationship shall be used:

1. Logarithm of $P$ is a quadratic function of logarithm of $\phi$.

2. Logarithm of $P$ is a quadratic function of temperature $\left({ }^{\circ} \mathrm{C}\right)$.

3.4.4.2. Stress-Strain Curve. Typical room temperature (RT) tensile and compressive stress-strain curves for 2020 graphite are shown in Figs. 3.4-4 and 3.4-5, respectively (Ref. 3.4-22). The curves are applicable to a nonlinear design analysis when nonlinear analysis. 
$909597 / 0$

\section{(Later)}

Fig. 3.4-3. Design curves for change in elastic modulus of 2020 graphite as a function of irradiation conditions 
TABLE $3.4-5$

PERCENT INCREASE (P) IN ELASTIC MODULUS AS

A FUNCTION OF FLUENCE AND TEMPERATURE

\begin{tabular}{cccr}
\hline & \multicolumn{3}{c}{ Irradiation Temperature } \\
Fast Neutron Fluence & \multicolumn{3}{c}{$(\mathrm{K})$} \\
\cline { 2 - 4 }$\left(10^{22} \mathrm{n} / \mathrm{m}^{2}\right)$ & 673 & 873 & 1173 \\
\hline 1 & 4.3 & 3.1 & 2.3 \\
4 & 13.3 & 9.8 & 7.4 \\
10 & 24.0 & 18.3 & 13.9 \\
\hline
\end{tabular}




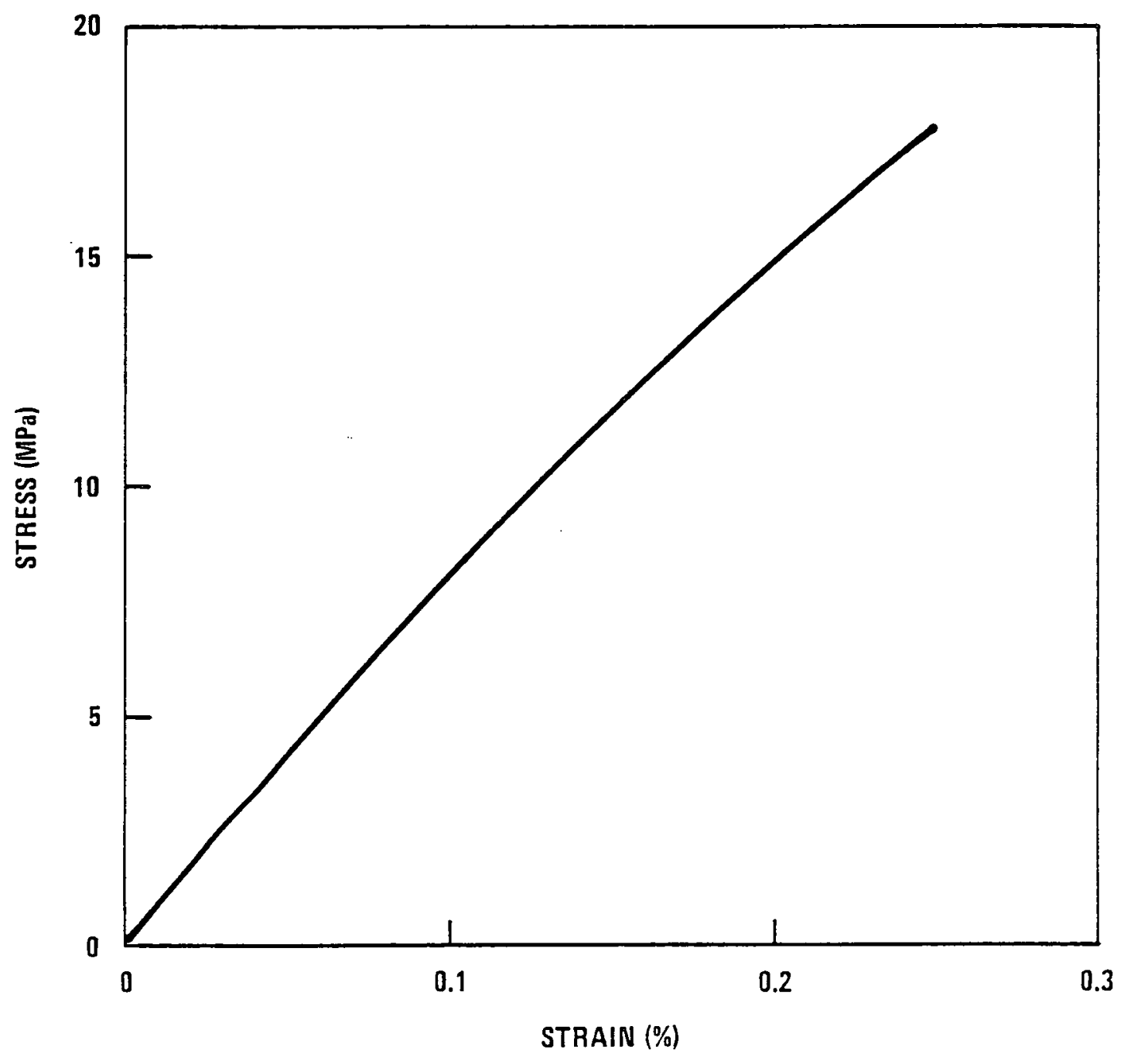

Fig. 3.4-4. Tensile stress-strain curve for 2020 graphite 


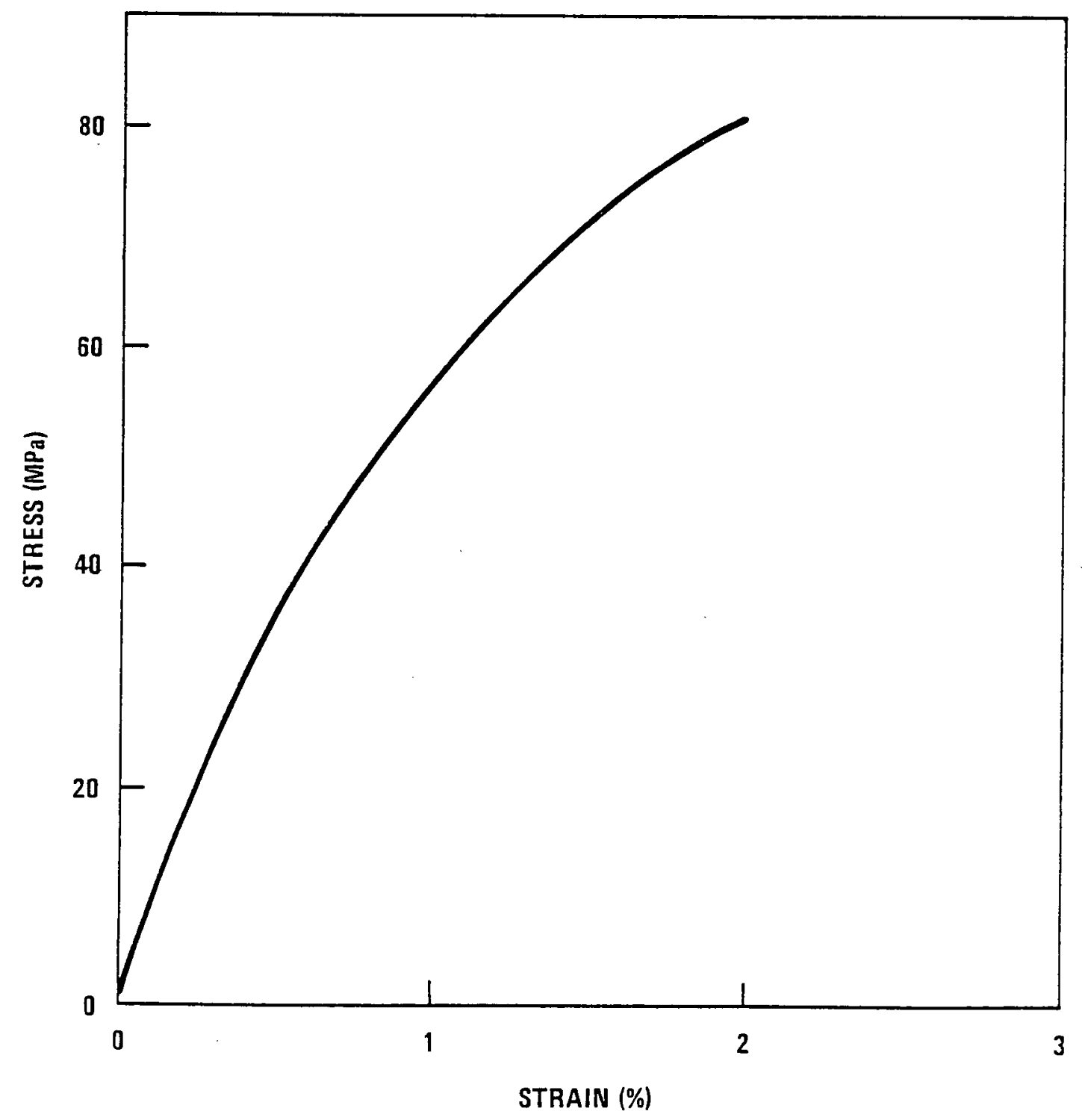

Fig. 3.4-5. Comprehensive stress-strain curve for 2020 graphite 
Typical RT tensile and compressive stress strain curves when compared in the stress range below the specified minimum ultimate tensile strength ( $S_{\text {ut }}$ in Section 3.4.4.3) are slightly deviated from each other by less than one "within-log" standard deviation. For practical purpose in the design analysis, the typical RT compressive stress strain curve can be considered as the same as the tensile curve when the maximum stress is expected to be lower than $\mathrm{S}_{\mathrm{ut}}$. The above assumption is not valid for test evaluation on component failure.

\subsubsection{Strength.}

Specified Minimum Ultimate Strength $\left(S_{u}\right)$. Specified minimum ultimate strength is the uniaxial strength along a principal stress direction which is used in design analysis to measure the structural integrity of a given core support graphite component against the design and accident condition stresses. Per ASME Code Subsection CE (Ref. 3.4-1), specified minimum strength is established from statistical treatment of graphite strength data such that the survival probability is $99 \%$ with a confidence level of $95 \%$.

Since the specified minimum compressive strength $\left(S_{\text {uc }}\right)$ of 2020 graphite is about three to four times its specified minimum tensile strength $\left(S_{u t}\right)$, only $S_{u t}$ is needed in the uniaxial stress analysis.

For unirradiated 2020 graphite at room temperature along the material axes, the specified minimum tensile strength $\left(S_{u t}\right)$ is (Refs. [LATER]) :

$$
\begin{aligned}
& \mathrm{S}_{\mathrm{ut}}(z)=\text { [LATER] MPa in the axial direction, } \\
& \mathrm{S}_{\mathrm{ut}}(r)=\text { [LATER] MPa in the radial direction }
\end{aligned}
$$


The specified minimum compressive strength $\left(S_{u c}\right)$ is

$$
\begin{aligned}
& \mathrm{S}_{\mathrm{uc}}(z)=\text { [LATER] } \mathrm{MPa} \text { in the axial direction, } \\
& \mathrm{S}_{\mathrm{uc}}(r)=\text { [LATER] } \mathrm{MPa} \text { in the radial direction }
\end{aligned}
$$

In the off-axis case, the following Hankinson's formula is recommended for use:

$$
\mathrm{S}_{\mathrm{ut}}(\theta)=\frac{\mathrm{S}_{\mathrm{ut}}(z) \mathrm{S}_{\mathrm{ut}}(\mathrm{r})}{\mathrm{S}_{\mathrm{ut}}(z) \times \sin ^{2} \theta+\mathrm{S}_{\mathrm{ut}}(\mathrm{r}) \times \cos ^{2} \theta} \mathrm{MPa}, \quad, \quad(3.4-11)
$$

where $\theta$ is the angle between the direction of the principal stress and the axlal (material) axis.

Both $S_{\text {ut }}$ and $S_{u c}$ may be assumed to increase with temperature and neutron fluence Identical to that for UTS (until such time as the experimental data are available). The relationship is (Refs. 3.4-20 and $3.4-21$ )

$$
S_{u}(T)=\left[\left(S_{u}\right)_{R T}+0.00392(T-294)\right]\left(E_{1} / E_{O}\right)^{1 / 2}, \quad(3.4-12)
$$

where $\left(S_{\mathrm{u}}\right)_{\mathrm{RT}}=$ room temperature unirradiated $\mathrm{S}_{\mathrm{u}}(\mathrm{MPa})$,

$$
T \text { = temperature }(K) \text {, }
$$

$E_{i}=$ modulus of 1rradlated graphite at room temperature (GPa),

$E_{0}=$ modulus of unfrradiated graphite at room temperature $(\mathrm{GPa})$,

$\mathrm{S}_{\mathrm{u}}(\mathrm{T})=\mathrm{S}_{\mathrm{u}}$ of unirradiated 2020 at temperature $\mathrm{T}$ (MPa).

Specified Minimum Biaxial Strength. In the biaxial stress state, the Coulomb-Mohr theory, modified to include a maximum tensile strength 
cutoff, is the failure theory currently recommended for graphite (Ref. 3.4-23). This theory defines that the maximum principal stress governs fallure in the first and third stress quadrants. In the second and fourth quadrants, the maximum principal stress or the Coulomb-Mohr theory, whichever is more restrictive, is applied.

The specified minimum biaxial strength surface is established similar to that of the above failure surface. The surface is given in Fig. 3.4-6. Caution is required when using the biaxial strength in the third quadrant. Early failure may occur in other modes prior to biaxial compressive fallure. Minimum values are determined by the ASME rules of Ref. 3.4-1.

Fatigue Strength. The normalized fatigue strength (normalized with respect to mean strength) is defined in Table 3.4-6 (Ref. 3.4-24) as a function of stress ratio ( $R$ ) and number of cycles. Mean strength of graphite, as well as fatigue strength, increases with fast fluence and temperature in the range of interest. However, it is assumed that normalized fatigue strength remains constant for the design use.

The design fatigue diagram can be used to interpolate the fatigue strength at other $R$ ratios (Fig. 3.4-7).

\subsubsection{Fracture Toughness and the Critical Defect Size. Fracture} toughness of unirradiated 2020 graphite at room temperature is $(\operatorname{Ref} .3 .4-25)$ :

$$
\mathrm{K}_{\mathrm{IC}}=1.25 \mathrm{MPa} \sqrt{\mathrm{m}} .
$$

The calculated critical defect size is $0.6 \mathrm{~mm}$.

The reduction of $\mathrm{K}_{I C}$ with oxidation follows the relationship

$$
K_{I C} /\left(K_{I C}\right)_{0}=\exp (-7 x)
$$


(Later)

Fig. 3.4-6. Specified minimum biaxial strength surface for 2020 graphite 
TABLE $3.4-6$

UNIAXIAL FATIGUE STRENGTH LIMITS FOR 2020 GRAPHITE

\begin{tabular}{|c|c|c|c|c|}
\hline \multirow[b]{2}{*}{ Orientation } & \multicolumn{4}{|c|}{ Fatigue Strength Limits, Peak Stress/Mean Strength } \\
\hline & $\begin{array}{c}\mathrm{R} \\
\left(\sigma_{\min } / \sigma_{\max }\right)\end{array}$ & $\begin{array}{l}\text { Number of } \\
\text { Cycles }\end{array}$ & $50 \%$ Survival & $\begin{array}{l}99 / 95 \text { Lower } \\
\text { Tolerance Iimit }\end{array}$ \\
\hline \multirow[t]{12}{*}{ Axial } & 0 & 100 & 0.87 & 0.69 \\
\hline & & 1,000 & 0.83 & 0.66 \\
\hline & & 10,000 & 0.80 & 0.63 \\
\hline & & 100,000 & 0.76 & 0.60 \\
\hline & -1 & 100 & 0.84 & 0.66 \\
\hline & & 1,000 & 0.79 & 0.62 \\
\hline & & 10,000 & 0.74 & 0.58 \\
\hline & & 100,000 & 0.70 & 0.54 \\
\hline & -2 & 100 & 0.85 & 0.66 \\
\hline & & 1,000 & 0.80 & 0.62 \\
\hline & & 10,000 & 0.75 & 0.58 \\
\hline & & 100,000 & 0.71 & 0.55 \\
\hline \multirow[t]{12}{*}{ Radial } & 0 & 100 & 0.86 & 0.71 \\
\hline & & 1,000 & 0.81 & 0.67 \\
\hline & & 10,000 & 0.77 & 0.64 \\
\hline & & 100,000 & 0.73 & 0.60 \\
\hline & -1 & 100 & 0.79 & 0.61 \\
\hline & & 1,000 & 0.73 & 0.56 \\
\hline & & 10,000 & 0.68 & 0.52 \\
\hline & & 100,000 & 0.63 & 0.48 \\
\hline & -2 & 100 & 0.81 & 0.66 \\
\hline & & 1,000 & 0.76 & 0.61 \\
\hline & & 10,000 & 0.71 & 0.57 \\
\hline & & 100,000 & 0.66 & 0.53 \\
\hline
\end{tabular}




\section{(Later)}

Fig. 3.4-7. Design fatigue diagram of nuclear grade 2020 graphite at 99\% survival probability with $95 \%$ confidence level 
where $x$ = fractional weight loss due to oxidation and the subscript o represent the unoxidized state. The calculated critical defect size remains unchanged with oxidation.

3.4.4.5. Effect of Oxidation on Mechanical Properties. The reduction in tensile strength ( $S$ ) and elastic modulus (E) is assumed to be the same for the commercial and the nuclear 2020 grades which may be represented by the following relationship (Refs. 3.4-26 and 3.4-27):

$$
\frac{S}{S_{0}}=\frac{E}{E_{0}}=\exp (-10 x),
$$

where $\mathbf{x}=$ fractional weight loss due to oxidation, and the subscript "o" represents the unoxidized state.

For the preliminary calculation on the component subjected to external loads, it may be conservatively assumed that any portion of graphite that oxidized to $\geq 0.1 \%$ and beyond loses its entire strength.

\subsubsection{Material Internal Damping Factor. The internal damping factor} 5 , defined as the ratio of actual damping to crltical damping, is dependent on the stress amplitude. At a stress amplitude of $7.35 \mathrm{MPa}, 5$ is equal to $0.596 \%$ (Ref. 3.4-28). This is for $0.5 \mathrm{~S}_{\text {ut }}$, approximately the $99 / 95$ endurance 1 imit). When the stress amplitude is reduced to half, 5 decreases only by $12 \%$.

\subsubsection{References}

3.4-1. "Proposed Section III, Division 2, ASME Boiler and Pressure Vessel Code, Subsection CE, Design Requirements for Graphite Core Supports," Apr11 1984.

3.4-2. Engle, G. B., "Propertles of Unirradiated HTGR Core Support and Permanent Side Reflector Graphites: PGX, HLM, 2020, and H-440N," ERDA Report GA-A14328, May 1977. 
3.4-3. Engle, G. B., and L. A. Beavan, "Properties of Unirradiated Graphites PGX, HLM, and 2020 for Support and Permanent Side Reflector LHTGR Components," DOE Report GA-A14646, June 1978.

3.4-4. Burnette, R. D., and G. R. Hightower, "Oxidation Kinetics of SC 2020 Nuclear Grade, Lot 1," GA Document 908038/0, May 31, 1985.

3.4-5. Peroomian, M. B., A. W. Barse11, and J. C. Seager, "OXIDE-3: A Computer Code for Analysis of HTGR Steam or Air Ingress Accidents," GA Report GA-A12493 (GA-LTR-7), January 15, 1974.

3.4-6. Burnette, R. D., et al., "Studies of the Rate of Oxidation of ATJ Graphite by Steam," in Proceedings of 13th Biennial Conference on Carbon at Irvine, California, July 13-22, 1977.

3.4-7. "HTGR Fuels and Core Development Program, Quarterly Progress Report for the Period Ending August 31, 1977," ERDA Report GA-A14479, September 1977, p. 11-16.

3.4-8. Jensen, D., M. Tagami, and C. Velasquez, "Air/H-327 Graphite Reaction Rate as a Function of Temperature and Irradiation," GA Report Gulf-GA-A12647, September 24, 1973.

3.4-9. Butland, A. T. D., and R. J. Maddison, "The Specific Heat of Graphite: An Evaluation of Measurements," Journal of Nuclear Material, 49, 45 (1973-1974).

3.4-10. "Graphite Data Manual," DOE-HTGR [LATER], to be issued.

3.4-11. Price, R. J., "Review of the Thermal Conductivity of Nuclear Graphite under HTGR Conditions," GA Report Gulf-GA-A12615, September 1973.

3.4-12. Engle, G. B., and K. Koyama, "Dimensional and Property Changes of Graphites Irradiated at High Temperatures," Carbon, $\underline{6}$, p. 455, 1968.

3.4-13. Kelly, B. T., et al., "The annealing of Irradiation Damage in Graphite," Journal Nuclear Materials, 20, p. 195, 1966.

3.4-14. Grenis, A. F., and A. P. Levilt, "The Spectral Emissivity and Total Normal Emissivity of Commercial Graphites at Elevated Temperatures," Proceedings of Fifth Conference on Carbon, p. 639,1961 . 
3.4-15. Plunkett, J. D., and W. D. Kingery, "The Spectral and Integrated Emissivity of Carbon and Graphite," Proceedings of Fourth Carbon Conference, p. 457, 1960.

3.4-16. Autio, G. W., and E. Scula, "The Normal Spectral Emissivity of Isotropic and Anisotropic Materials," Carbon, 4, pp. 13-28, 1966.

3.4-17. [LATER]

3.4-18. [LATER]

3.4-19. [LATER]

3.4-20. Ho, F. H., and E. Chin, "Test Evaluation Report of the Thermal Stress (T/S) Test for Core Support Graphite," GA Document $904445 / \mathrm{B}$, August 12, 1980.

3.4-21. Price, R. J., "Mechanical Properties of Graphite of HighTemperature Gas-Cooled Reactors: A Review," ERDA Report GA-A13524, September 22, 1975.

3.4-22. [LATER]

3.4-23. Ho, F. H., et al., "Biaxial Fallure Surfaces of 2020 and PGX Graphites," Paper No. L4/6, P. 127, Transactions of the 7th International Conference on Structural Mechanics in Reactor Technology, Chicago, II, August 22, 1983.

3.4-24. Price, R. J., "Test Report: Fatigue Tests on 2020 Graphite," GA Document $906202 / 1$, September 1981 .

3.4-25. Eatherly, W. P., and C. R. Kennedy ORNL 1982 HTGR Program Review, ORNL Progress Report, ORNL GCR/B-87/11, December 1987.

3.4-26. Beavan, L. A., "Test Report: Strength of Oxidized Fine Grain Graphite," GA Document 906249, Issue 1, September 1981.

3.4-27. "Core Support Post and Seat Graphites: Grades 2020 and ATJ," in "HTGR Generic Technology Program: Fuels and Core Development, Quarterly Progress Report for the Period Ending August 31, 1978," DOE Report GA-A15093 (Section 3.6.3.1), September 1978, p. 3-36.

3.4-28. Ho, F. H., and R. Salavatcioglu, "Internal Damping Factor for HTGR Core Support Post Materials," GA Document 904365/1, November 1979.

3.4-29. "Fuel Design Data Manual," GA Document 901866/F, Apr11 1987. 


\section{GRADE H-451 GRAPHITE}

\subsection{DESCRIPTION OF GRADE}

Grade H-451 graphite is a near-1sotopic, petroleum-coke-based, artificial graphite developed specifically for HTGR fuel element and reflector application by Great Lakes Carbon Company. The graphite is extruded into right-circular or oblong cylinders. The logs used for HTGR application are $0.863 \mathrm{~m}$ (34 in.) long by $0.457 \mathrm{~m}$ (18 in.) in diameter.

The design data presented herein have been derived from characterization tests of $\mathrm{H}-451$ preproduction $10 \mathrm{t} 426$ and from strength testing of production lot No. 440, 472, 478, and 482. Several hundred preproduction logs of H-451 graphite were produced for qualification tests. Three production grade lots, totaling over 300 logs, have been produced for use in FSV reload segments.

\subsection{APPLICATION}

Grade H-451 graphite is the reference material for both the fuel elements and the replaceable hexagonal reflectors. The latter consists of the upper and lower reflectors, central reflectors, and hexagonal side reflectors. These components are to be designed to meet the structural criteria for core graphite (Ref. 4-1). Unless otherwise noted, the material properties given below are mean values. 
4.3. PHYSICAL AND CHEMICAL PROPERTIES

\subsubsection{Density}

The density of $\mathrm{H}-451 \mathrm{graphite}$ is $1.74 \mathrm{Mg} / \mathrm{m}^{3}$ averaged over the $1 \mathrm{og}$ (Ref. 4-2).

\subsubsection{Transport and Reaction Rates}

4.3.2.1. Steam-Graphite Oxidation Rates. The Langmuir-Hinshelwood equation, Eq. 4-1, is used to predict chemical kinetically limited steam-graphite oxidation rates for H-451 graphite (Refs. 4-3 and 4-4):

$$
\text { Rate }=\frac{\mathrm{K}_{1} \mathrm{P}_{\mathrm{H}_{2} \mathrm{O}} \mathrm{F}_{\mathrm{b}} \mathrm{F}_{\mathrm{c}}}{1+\mathrm{K}_{2}\left(\mathrm{P}_{\mathrm{H}_{2}}\right)^{\mathrm{n}}+\mathrm{K}_{3} \mathrm{P}_{\mathrm{H}_{2} \mathrm{O}}} \text {, }
$$

where

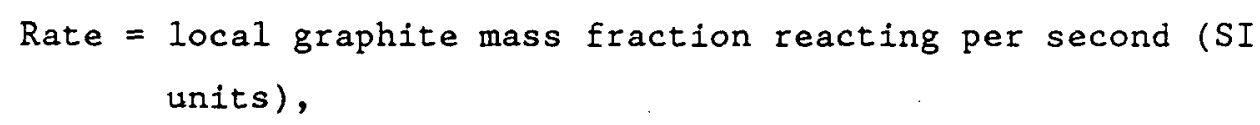
units),

Rate = local graphite mass percent reacting per hour (former units),

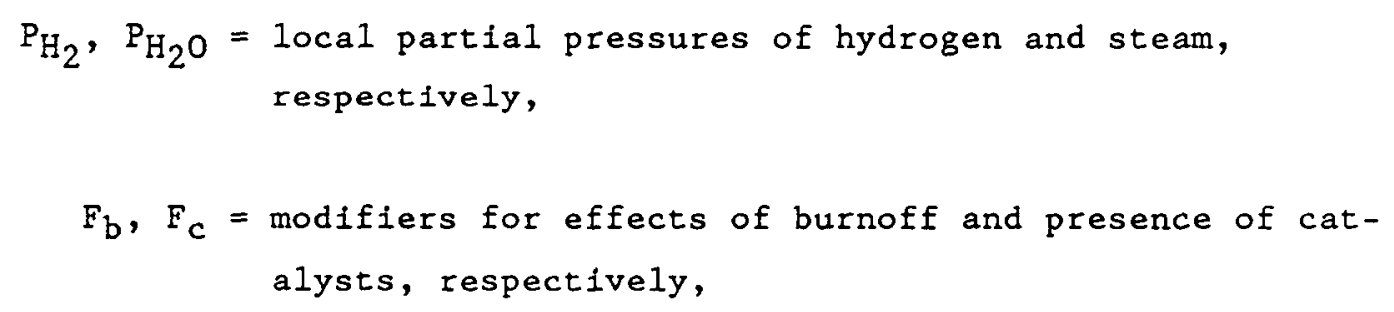




$$
\begin{gathered}
E_{j}=\text { activation energy, } \\
R=8.314 \mathrm{j} / \mathrm{mole} \cdot \mathrm{K} . \\
\text { Constants are given in Table } 4.3-1 \\
F_{b}=0.447+0.8094 \mathrm{~b}-0.3221 \mathrm{~b}^{2}+0.0681 \mathrm{~b}^{3} \\
-0.00613 \mathrm{~b}^{4}+12.32 \times 10^{-6} \mathrm{~b}^{5}+2.89 \times 10^{-5} \mathrm{~b}^{6} \\
-1.15 \times 10^{-6} \mathrm{~b}^{7},
\end{gathered}
$$

where $b$ is the percent graphite burnoff and $F_{b}$ is normalized to $1 \%$ burnoff; i.e., at $1 \%$ burnoff $F_{b}=1.0$. The above equation is restricted to $0 \leq b \leq 13$; for higher burnoffs, the value of $F_{b}$ at $13 \%$ burnoff should be used.

$$
F_{C}=1+\left(C_{B a}+0.2 C_{S r}\right) \exp \left(12.153-4.264 \times 10^{-3} \mathrm{~T}\right)
$$

where $\mathrm{C}_{\mathrm{Ba}}, \mathrm{C}_{\mathrm{Sr}}=$ concentration of barium and strontium catalyst (mg/g graphite),

$$
T=\text { temperature }(K) \text {. }
$$

4.3.2.2. Air-Graphite Reaction Rates. The rate of oxidation of graphite by air is given by Eq. 4-4 (Ref. 4-8):

$$
\text { Rate }=\mathrm{K} \exp (-\mathrm{E} / \mathrm{RT}) \mathrm{P}_{\mathrm{O}_{2}},
$$

where Rate = local graphite mass fraction reacting per second (SI) or local graphite mass fraction reacting per hour (units normally used in OXIDE code calculations),

$$
\mathrm{P}_{2}=\text { local partial pressure of oxygen. }
$$

Table 4.3-2 gives the system of units derived from $\mathrm{H}-327$ experimental data. It is assumed that the air-graphite reaction rate of $\mathrm{H}-451$ is identical to that of $\mathrm{H}-327$. 
TABLE 4.3-1

CONSTANTS FOR H-451 GRAPHITE OXIDATION RATE EQUATION

\begin{tabular}{|c|c|c|c|c|c|c|c|}
\hline Units & $\mathrm{k}_{1}$ & $\mathrm{k}_{2}$ & $k_{3}$ & $E_{1}$ & $E_{2}$ & $\mathrm{E}_{3}$ & $\mathbf{R}$ \\
\hline SI & $\begin{array}{l}900 \\
(\mathrm{~s} \cdot \mathrm{Pa})^{-1}\end{array}$ & $\begin{array}{l}110 \\
\mathrm{~Pa}^{-0.75}\end{array}$ & $\begin{array}{l}30 \\
\mathrm{~Pa}^{-1}\end{array}$ & $\begin{array}{l}-274,000 \\
\mathrm{~J} / \mathrm{mol}\end{array}$ & $\begin{array}{l}-74,660 \\
\mathrm{~J} / \mathrm{mol}\end{array}$ & $\begin{array}{l}-95,850 \\
\mathrm{~J} / \mathrm{mol}\end{array}$ & $\begin{array}{l}8.314 \\
\mathrm{~J} / \mathrm{mol} \cdot \mathrm{K}\end{array}$ \\
\hline OXIDE Code & $\begin{array}{l}3.28 \times 10^{13} \\
(6 \mathrm{~h} \cdot \mathrm{atm})^{-1}\end{array}$ & $\begin{array}{l}6.25 \times 10^{5} \\
\text { atm }-0.75\end{array}$ & $\begin{array}{l}3.04 \times 10^{6} \\
\text { atm }^{-1}\end{array}$ & $\begin{array}{l}-65,460 \\
\mathrm{cal} / \mathrm{mol}\end{array}$ & $\begin{array}{l}-17,840 \\
\mathrm{ca} 1 / \mathrm{mol}\end{array}$ & $\begin{array}{l}-22,900 \\
\mathrm{cal} / \mathrm{mol}\end{array}$ & $\begin{array}{l}1.986 \\
\mathrm{cal} / \mathrm{mol} \cdot \mathrm{K}\end{array}$ \\
\hline
\end{tabular}


TABLE 4.3-2

AIR-GRAPHITE REACTION RATE COEFFICIENTS

\begin{tabular}{lllll}
\hline Systems of Units & \multicolumn{1}{c}{$\mathrm{K}$} & \multicolumn{1}{c}{$\mathrm{E}$} & $\mathrm{T}$ & \multicolumn{1}{c}{$\mathrm{R}$} \\
\hline SI & $\begin{array}{l}0.79 \\
(\mathrm{~s} \cdot \mathrm{Pa})-1\end{array}$ & $\begin{array}{l}1.7 \times 10^{5} \\
\mathrm{~J} / \mathrm{mol} \cdot \mathrm{K}\end{array}$ & $\mathrm{K}$ & $\begin{array}{l}8.314 \\
\mathrm{~J} / \mathrm{mol} \cdot \mathrm{K}\end{array}$ \\
OXIDE code & $\begin{array}{l}2.88 \times 10^{10} \\
(\% \mathrm{~h} \cdot \mathrm{atm})-1\end{array}$ & $\begin{array}{l}4.06 \times 10^{4} \\
\mathrm{cal} / \mathrm{mol}\end{array}$ & $\mathrm{K}$ & $\begin{array}{l}1.986 \\
\mathrm{cal} / \mathrm{mol} \cdot \mathrm{K}\end{array}$ \\
\hline
\end{tabular}


4.3.2.3. Radiolytic Effect on Oxidation Rate. Irradiation was shown to have no discernible effect on reaction rate of $\mathrm{H}-327$ graphite in the temperature range of $385^{\circ}$ to $566^{\circ} \mathrm{C}$ (Ref. 4-9). Eto, et al. (Ref. 4-10) showed that the contribution of radiolytic effect on the reaction rate was small enough to neglect above $1050 \mathrm{~K}$, and neutron irradiation did not affect the reaction rate unless the graphite was at the initial stage of irradiation. For design analysis, the radiolytic effect on oxidation rate shall be disregarded.

4.3.2.4. Transport of Steam in Helium by Diffusion. The effective diffusion coefficient of steam in graphite is given by Eq. 4-5 (Refs. 4-5 through 4-7):

$$
\mathrm{D}_{\mathrm{H}_{2} \mathrm{O}}=\frac{1.0 \times 10^{-10} \times \mathrm{T}^{1.58} \times \mathrm{P}}{\mathrm{P}_{\text {total }}}\left(\mathrm{m}^{2} / \mathrm{s}\right)
$$

where $D_{\mathrm{H}_{2} \mathrm{O}}=$ effective diffusion coefficient through graphite,

$\mathrm{T}=$ temperature $(\mathrm{K})$,

$P=$ pressure at $\operatorname{STP}^{*}(\mathrm{~Pa})$,

$P_{\text {total }}=$ total pressure $(\mathrm{Pa})$.

A parameter such as diffusion through graphite is recognized to vary by as much as a factor of three from sample to sample or from position to position in the graphite block. Equation 4-5 describes the present best estimate for $\mathrm{H}_{2} \mathrm{O}$ diffusion in graphite having $1 \%$ average oxidation burnoff.

Equation 4-5 was obtained by pooling all available experimental data on steam diffusion through graphite in helium. No corrections were made for the differences in porosity and pore structure. Equation 4-5 is assumed to be applicable to all reference HTGR graphites.

\footnotetext{
${ }^{\star}$ STP - standard temperature and pressure.
} 
The effective diffusion coefficients recommended for carbon monoxide, oxygen, and hydrogen are as follows:

$$
\begin{aligned}
& \mathrm{D}_{\mathrm{CO}}=\mathrm{D}_{\mathrm{H}_{2} \mathrm{O}}, \\
& \mathrm{D}_{\mathrm{O}_{2}}=\mathrm{D}_{\mathrm{H}_{2} \mathrm{O}}, \\
& \mathrm{D}_{\mathrm{H}_{2}}=2 \mathrm{D}_{\mathrm{H}_{2} \mathrm{O}},
\end{aligned}
$$

4.3.2.5. Transport of Steam in Helium by Convection. The transport of steam by convection involves the permeation of graphite. The permeability coefficients of graphite (Ref. 4.4-42) are:

$$
\begin{aligned}
& \mathrm{K}_{\mathrm{I}}=1.55 \mathrm{E}-13 \mathrm{~m}^{2} \\
& \mathrm{~K}_{\mathrm{P}}=9.20 \mathrm{E}-14 \mathrm{~m}^{2},
\end{aligned}
$$

where the subscripts represent the following regions of the hexagonal graphite blocks:

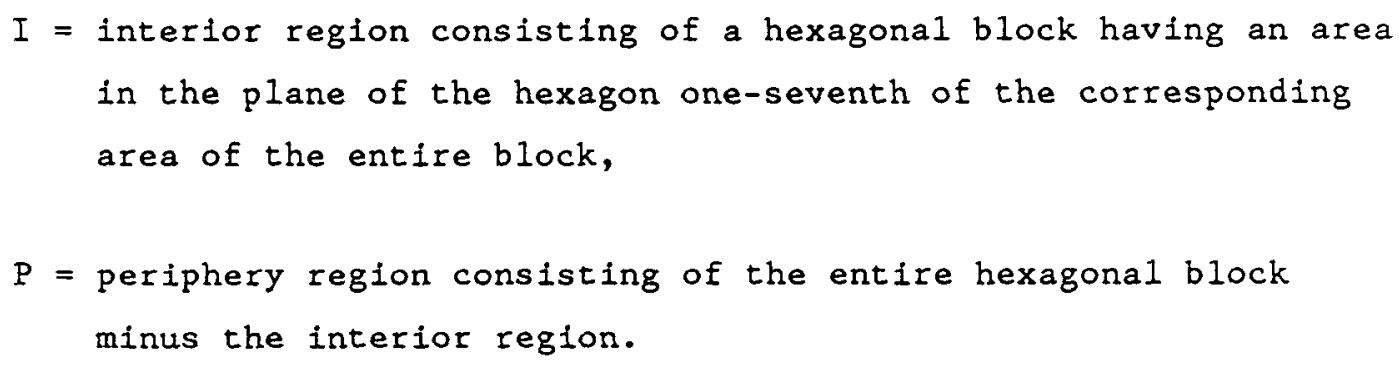
in the plane of the hexagon one-seventh of the corresponding area of the entire block,

The values of $K_{I}$ and $K_{P}$ are derived from data on $H-327$ graphite; they are assumed to apply to $\mathrm{H}-451$ graphite. 
4.4. THERMAL PROPERTIES

\subsubsection{Specific Heat}

The specific heat of $\mathrm{H}-451$ graphite for temperatures from 250 to $3000 \mathrm{~K}$ is given below (Ref. 4-11):

$$
\begin{aligned}
C_{p}= & \left(0.54212-2.42667 \times 10^{-6} \mathrm{~T}-9.02725 \times 10^{1} \mathrm{~T}^{-1}\right. \\
& -4.34493 \times 10^{4} \mathrm{~T}^{-2}+1.59309 \times 10^{7} \mathrm{~T}^{-3} \\
& \left.-1.43688 \times 10^{9} \mathrm{~T}^{-4}\right) \times 4184,
\end{aligned}
$$

where $C_{p}=$ specific heat at constant pressure $(\mathrm{J} / \mathrm{kg}-\mathrm{K})$,

$\mathrm{T}=$ temperature $(\mathrm{K})$.

Equation 4-7 is also presented graphically in Fig. 4.4-1.

\subsubsection{Thermal Expansivity}

Mean Coefficient of Thermal Expansion. The mean CTE for unirradiated $\mathrm{H}-451 \mathrm{graphite}$ between room temperature and $500^{\circ} \mathrm{C}$ is $4.09 \times 10^{-6} /{ }^{\circ} \mathrm{C}$ and $4.65 \times 10^{-6} /{ }^{\circ} \mathrm{C}$ in the axial and radial directions, respectively (Refs. 4-12 through 4-14). Its dependence on temperature can be calculated from the thermal strain given in Table 4.4-1 and Fig. 4.4-2.

The thermal expansivity of H-451 graphite changes during neutron irradiation. The fractional change in thermal expansivity, $\left(\alpha_{i}-\alpha_{0}\right) /$ $\alpha_{0}$, is given in the following equation and Figs. 4.4-3 and 4.4-4 (Ref. 4-9):

$$
\begin{aligned}
\left(\alpha_{i}-\alpha_{0}\right) / \alpha_{0}= & \left(0.27830-4.2734 \times 10^{-4} \mathrm{~T}\right. \\
& \left.+1.7815 \times 10^{-7} \mathrm{~T}^{2}\right) \Phi-2.0664 \times 10^{-2} \Phi^{2} \\
& +1.3601 \times 10^{-3} \Phi^{3},
\end{aligned}
$$




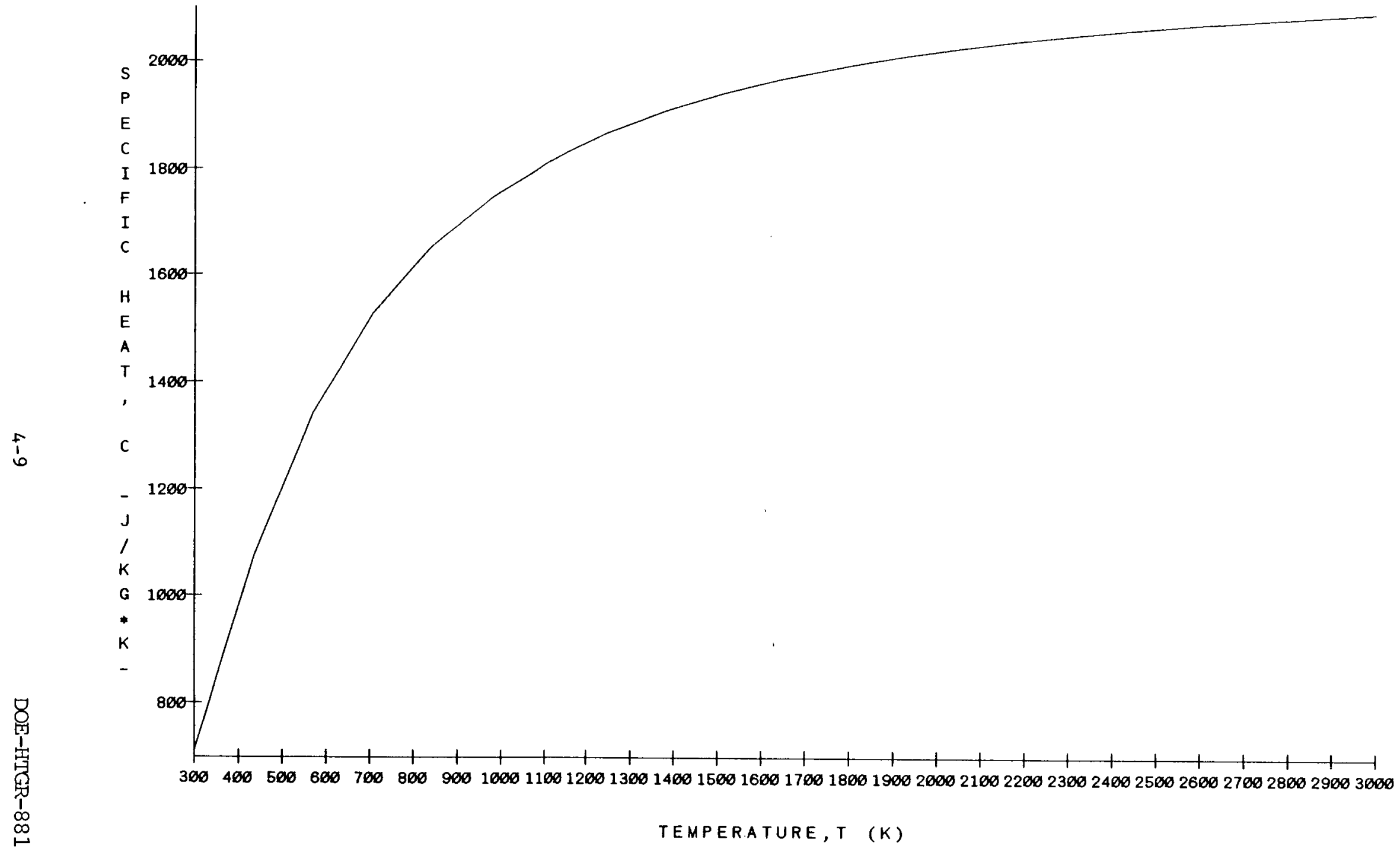

Fig. 4.4-1 Specific Heat of Graphite as a Function of Temperature 
TABLE $\quad 4.4-1$

THERMAL EXPANSION OF H-451 GRAPHITE

\begin{tabular}{|c|c|c|}
\hline \multirow{2}{*}{$\begin{array}{c}\text { Temperature } \\
\left({ }^{\circ} \mathrm{C}\right)\end{array}$} & \multicolumn{2}{|c|}{ Thermal Strain $\left(10^{-3}\right)$} \\
\hline & Axial & Radial \\
\hline 25 & 0 & 0 \\
\hline 100 & 0.26 & 0.32 \\
\hline 150 & 0.42 & 0.52 \\
\hline 200 & 0.60 & 0.74 \\
\hline 250 & 0.80 & 0.95 \\
\hline 300 & 1.00 & 1.20 \\
\hline 350 & 1.20 & 1.43 \\
\hline 400 & 1.42 & 1.68 \\
\hline 450 & 1.65 & 1.93 \\
\hline 500 & 1.88 & 2.19 \\
\hline 550 & 2.12 & 2.46 \\
\hline 600 & 2.35 & 2.75 \\
\hline 650 & 2.60 & 3.03 \\
\hline 700 & 2.83 & 3.32 \\
\hline 750 & 3.10 & 3.58 \\
\hline 800 & 3.35 & 3.88 \\
\hline 850 & 3.58 & 4.16 \\
\hline 900 & 3.84 & 4.41 \\
\hline 950 & 4.10 & 4.73 \\
\hline 1000 & 4.33 & 5.06 \\
\hline 1050 & 4.60 & 5.32 \\
\hline 1100 & 4.88 & 5.62 \\
\hline 1150 & 5.14 & 5.91 \\
\hline 1200 & 5.42 & 6.23 \\
\hline 1250 & 5.70 & 6.53 \\
\hline 1300 & 6.00 & 6.85 \\
\hline 1350 & 6.30 & 7.16 \\
\hline 1400 & 6.60 & 7.50 \\
\hline 1450 & 6.90 & 7.85 \\
\hline 1500 & 7.24 & 8.20 \\
\hline 1550 & 7.55 & 8.52 \\
\hline 1600 & 7.90 & 8.90 \\
\hline
\end{tabular}


TEMPERATURE $\left({ }^{\circ} \mathrm{C}\right)$

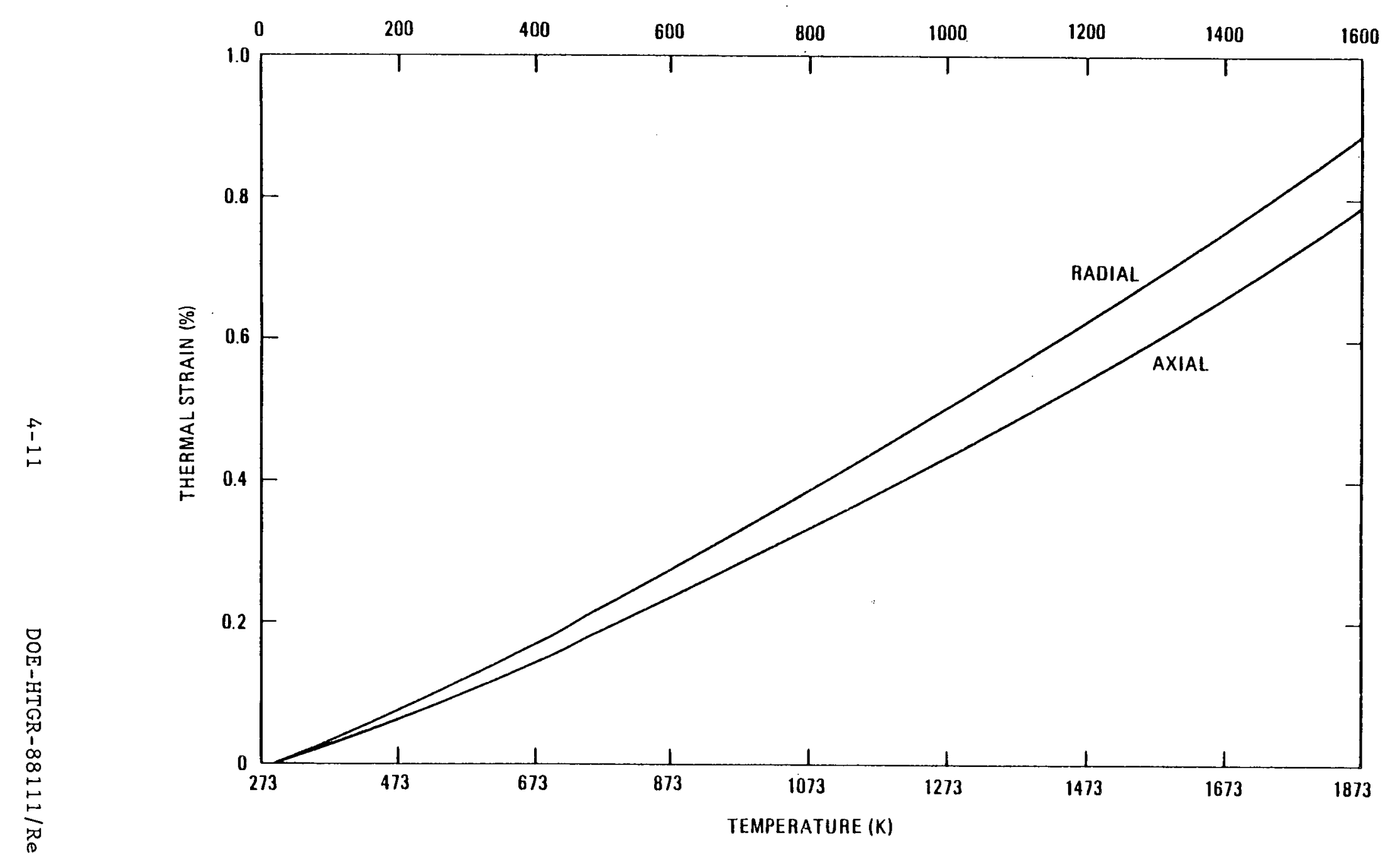

Fig. 4.4-2. Thermal expansion of $1-451$ graphite 


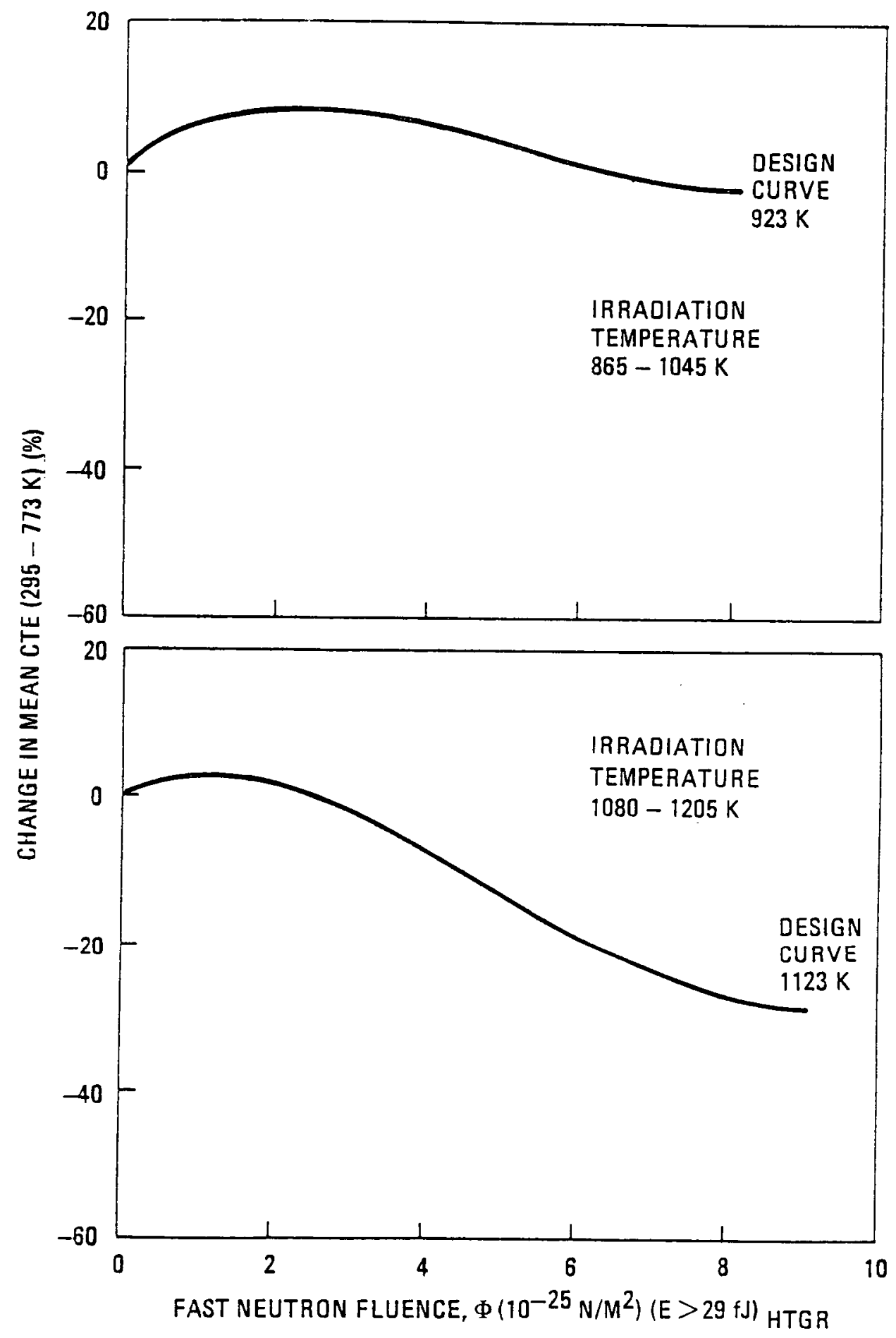

Fig. 4.4-3. Change in mean cte of $\mathrm{H}-451$ graphite as a function of irradiation conditions $(865-1205 \mathrm{~K})$, axial and radial directions 


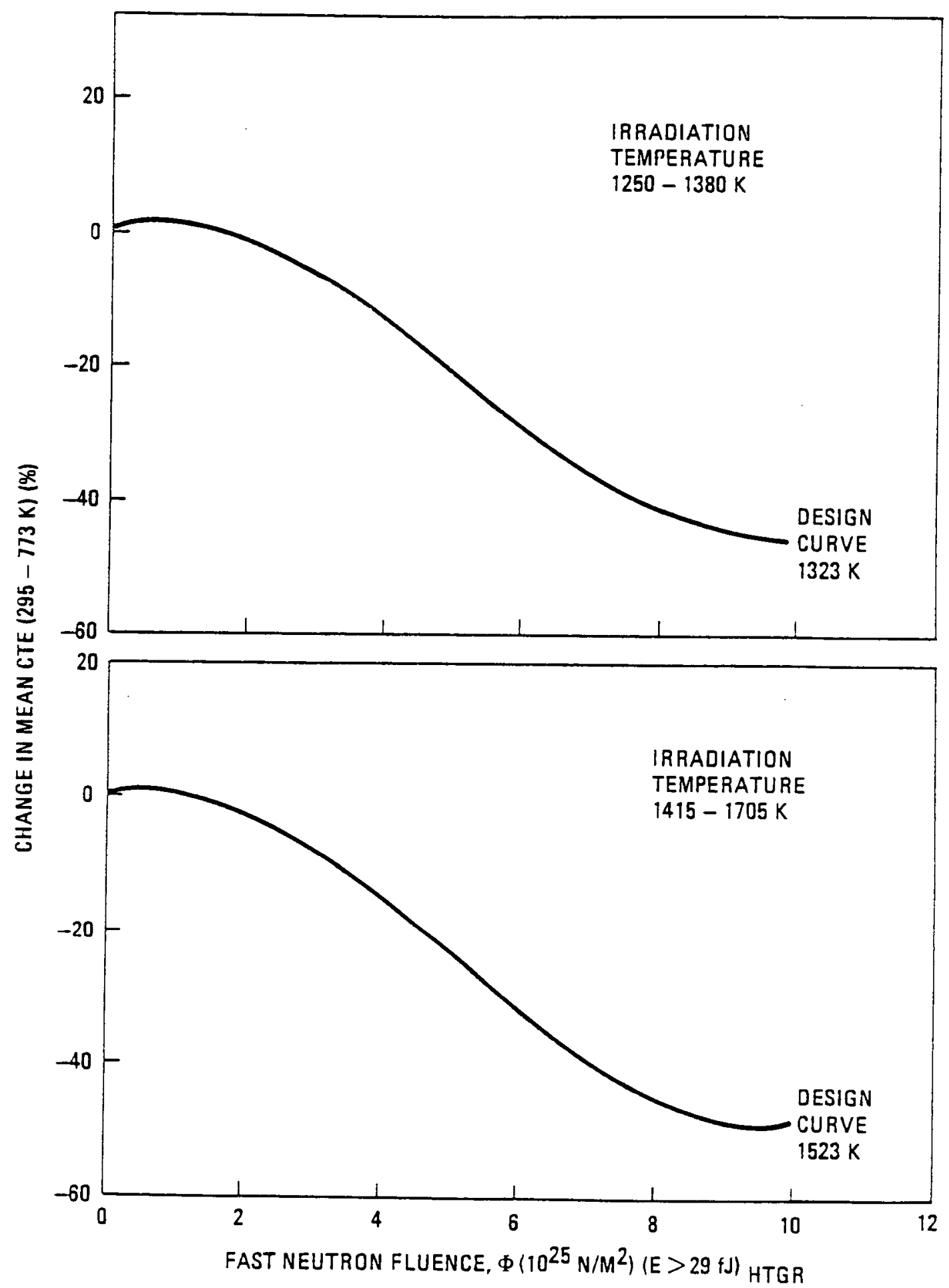

Fig. 4.4-4. Change in mean cte of H-451 graphite as a function of irradiation conditions (1250-1705 K), axial and radial directions 


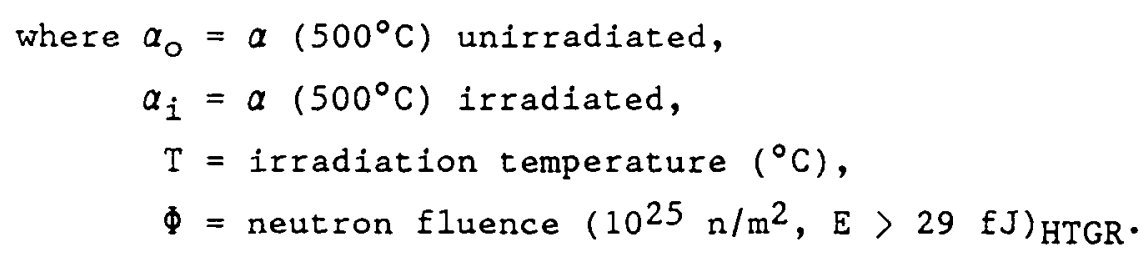

The shifting rule for the mean CTE under nonisothermal irradiation shall be performed at equal neutron damage as determined from the dimensional change curve given in Section 4.6.1 (Rule 3 in Ref. 4-16).

\subsubsection{Thermal Conductivity}

The thermal conductivity of near-isotropic graphite is given by the current models reviewed in Ref. 4-17. This model considers the dependence of thermal conductivity $(K)$ on the current measurement temperature $\left(T_{C}\right)$ and on the past history of irradiation temperature ( $T_{I}$ ) and fast neutron fluence $(\Phi)$. The model is extended here to the case of a nonisothermal irradiation.

The thermal conductivity as a function of current measurement temperature can be considered as a superposition of three temperaturedependent resistance mechanisms through Eq. 4-6 (Ref. 4-17):

$$
K\left(T_{c}\right)=\frac{1}{a\left(\frac{1}{K_{U}\left(T_{c}\right)}+\frac{b}{K_{b}\left(T_{c}\right)}+\frac{d}{K_{d}\left(T_{c}\right)}\right)},
$$

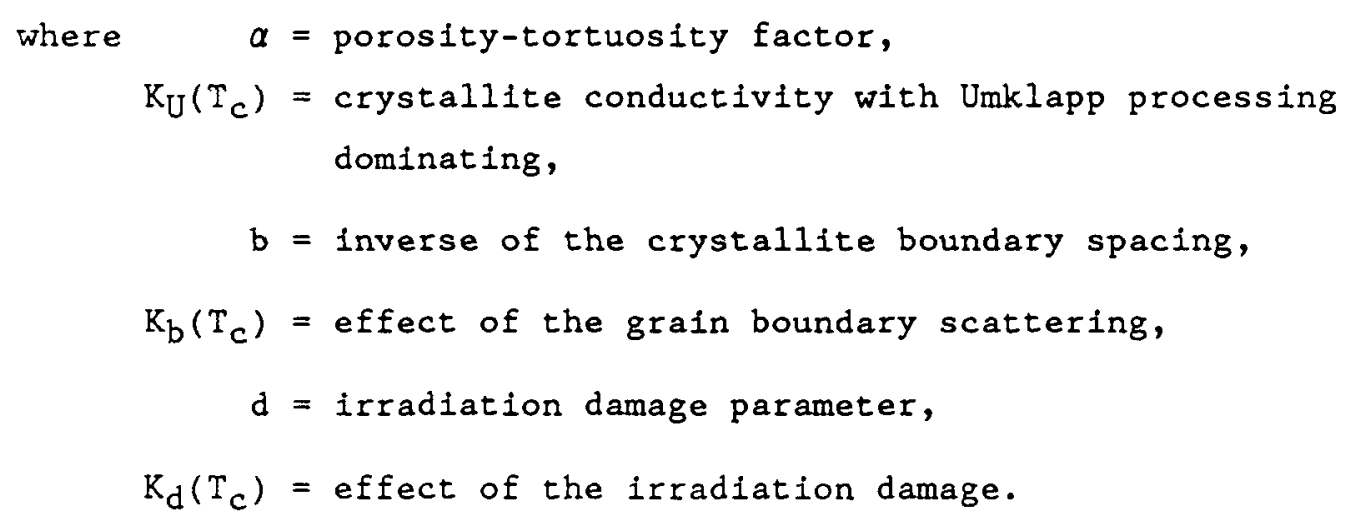


All of the above quantities are given as known input data in Tables 4.4-2 and 4.4-3 except for the irradiation damage parameter, d. As shown below, parameter d can be obtained by comparing conductivities before and after irradiation.

4.4.3.1. Therma1 Conductivity, Unirradiated. For unirradiated material, the damage parameter $d$ in Eq. 4-6 is zero. Equation 4-6 reduces to

$$
\mathrm{K}_{\mathrm{o}}\left(\mathrm{T}_{\mathrm{c}}\right)=\frac{1}{\alpha\left(\frac{1}{\mathrm{~K}_{U}\left(\mathrm{~T}_{\mathrm{c}}\right)}+\frac{\mathrm{b}}{\mathrm{K}_{\mathrm{b}}\left(\mathrm{T}_{\mathrm{c}}\right)}\right)} .
$$

4.4.3.2. Thermal Conductivity, Isothermal Irradiation. The damage parameter $d$ in Eq. 4-6 can be found by comparing the unirradiated and irradiated conductivities at one particular measurement temperature. Room temperature ( $R T$ ) is conveniently taken to be the reference temperature. Thus, Eqs. 4-6 and 4-7 combine to give the following:

$$
\mathrm{d}=\frac{\mathrm{K}_{\mathrm{d}}(\mathrm{RT})}{a}\left(\frac{1}{\mathrm{~K}_{\mathrm{i}}(\mathrm{RT})}-\frac{1}{\mathrm{~K}_{\mathrm{o}}(\mathrm{RT})}\right),
$$

where $K_{O}(R T)$ = unirradiated room temperature conductivity, found by evaluating Eq. 4-7 at $\mathrm{T}_{\mathrm{c}}=\mathrm{RT}$,

$K_{i}(R T)=$ irradiated room temperature conductivity found by the procedure outlined below.

4.4.3.3. Thermal Conductivity, Nonisothermal Irradiation. The procedure to be used for calculating room temperature conductivity during a nonisothermal irradiation is as follows:

1. Divide the irradiation period into $n$ isothermal intervals. The irradiation temperature during interval $i$ is $T_{i}$. The 
TABLE 4.4-2

TEMPERATURE-DEPENDENT CONDUCTIVITY COMPONENTS OF H-451 GRAPHITE(a)

\begin{tabular}{|c|c|c|c|}
\hline $\begin{array}{l}\text { Temperature } \\
\text { (K) }\end{array}$ & $\begin{array}{c}\text { Umklapp } \\
\mathrm{K}_{\mathrm{U}}\left(\mathrm{T}_{\mathrm{c}}\right) \\
\left(10^{3} \mathrm{~W} / \mathrm{m} \cdot \mathrm{K}\right)\end{array}$ & $\begin{array}{c}\text { Grain Boundary } \\
\mathrm{K}_{\mathrm{b}}\left(\mathrm{T}_{\mathrm{c}}\right) \\
\left(10^{9} \mathrm{~W} / \mathrm{m} \cdot \mathrm{K}\right)\end{array}$ & $\begin{array}{c}\text { Irradiation Damage } \\
\mathrm{K}_{\mathrm{d}}\left(\mathrm{T}_{\mathrm{c}}\right) \\
\left(10^{3} \mathrm{~W} / \mathrm{m} \cdot \mathrm{K}\right)\end{array}$ \\
\hline 100 & 39.12 & 1.20 & 1.87 \\
\hline 150 & 20.42 & 2.49 & 1.60 \\
\hline 200 & 5.36 & 4.02 & 1.34 \\
\hline 250 & 2.67 & 5.54 & 1.30 \\
\hline 300 & 2.00 & 6.97 & 1.26 \\
\hline 350 & 1.49 & 8.19 & 1.31 \\
\hline 400 & 1.21 & 9.41 & 1.36 \\
\hline 450 & 1.07 & 10.36 & 1.41 \\
\hline 500 & 0.929 & 11.30 & 1.47 \\
\hline 550 & 0.864 & 11.99 & 1.50 \\
\hline 600 & 0.799 & 12.68 & 1.53 \\
\hline 650 & 0.743 & 13.18 & 1.56 \\
\hline 700 & 0.686 & 13.68 & 1.58 \\
\hline 750 & 0.653 & 14.10 & 1.60 \\
\hline 800 & 0.619 & 14.52 & 1.62 \\
\hline 850 & 0.590 & 14.69 & 1.63 \\
\hline 900 & 0.561 & 14.85 & 1.64 \\
\hline 950 & 0.538 & 14.96 & 1.64 \\
\hline 1000 & 0.515 & 15.06 & 1.65 \\
\hline 1050 & 0.487 & 15.06 & 1.65 \\
\hline 1100 & 0.460 & 15.06 & 1.65 \\
\hline 1150 & 0.441 & 15.06 & 1.65 \\
\hline 1200 & 0.423 & 15.06 & 1.65 \\
\hline 1250 & 0.408 & 15.06 & 1.65 \\
\hline 1300 & 0.393 & 15.06 & 1.65 \\
\hline 1350 & 0.381 & 15.06 & 1.65 \\
\hline 1400 & 0.368 & 15.06 & 1.65 \\
\hline 1450 & 0.360 & 15.06 & 1.65 \\
\hline 1500 & 0.352 & 15.06 & 1.65 \\
\hline 1550 & 0.343 & 15.06 & 1.65 \\
\hline 1600 & 0.335 & 15.06 & 1.65 \\
\hline 1650 & 0.328 & 15.06 & 1.65 \\
\hline 1700 & 0.320 & 15.06 & 1.65 \\
\hline 1750 & 0.315 & 15.06 & 1.65 \\
\hline 1800 & 0.310 & 15.06 & 1.65 \\
\hline
\end{tabular}

(a) Refer to Eq. 4-6.

(b) The temperature points are equally spaced in order to facilitate the linear interpolation. 
TABLE $4.4-3$

MATERIAL CONSTANTS FOR H-451 GRAPHITE THERMAL CONDUCTIVITY

\begin{tabular}{|c|c|c|c|c|c|c|}
\hline \multirow[b]{2}{*}{ Symbol } & \multirow{2}{*}{$\begin{array}{l}\text { Reference } \\
\text { Equation }\end{array}$} & \multirow{2}{*}{\multicolumn{2}{|c|}{$\begin{array}{c}\text { Temperature } \\
\text { Range } \\
\text { (K) }\end{array}$}} & \multicolumn{2}{|c|}{ Value } & \multirow[b]{2}{*}{ Units (a) } \\
\hline & & & & Axial & Radial & \\
\hline A & $\begin{array}{l}4-10 \\
4-10\end{array}$ & $\begin{array}{l}573 \\
873\end{array}$ & $\begin{array}{l}\text { to } 873 \\
\text { to } 1673\end{array}$ & $\begin{array}{l}0.2687 \\
-0.5676\end{array}$ & $\begin{array}{l}0.2687 \\
-0.5676\end{array}$ & $\begin{array}{l}10^{25} \mathrm{n} / \mathrm{m}^{2} \\
10^{25} \mathrm{n} / \mathrm{m}^{2}\end{array}$ \\
\hline$B$ & $\begin{array}{l}4-10 \\
4-10\end{array}$ & $\begin{array}{l}573 \\
873\end{array}$ & $\begin{array}{ll}\text { to } & 873 \\
\text { to } & 1673\end{array}$ & $\begin{array}{l}0 \\
9.58 \times 10^{-4}\end{array}$ & $\begin{array}{l}0 \\
9.58 \times 10^{-4}\end{array}$ & $10^{25^{--} \mathrm{n} / \mathrm{m}^{2} \cdot \mathrm{K}}$ \\
\hline $\mathrm{C}$ & $4-11$ & 573 & to 1673 & 2.3897 & 2.2726 & $\ln (\mathrm{W} / \mathrm{m} \cdot \mathrm{K})$ \\
\hline $\mathrm{D}$ & $4-11$ & 573 & to 1673 & $1.207 \times 10^{-3}$ & $1.222 \times 10^{-3}$ & $\mathrm{~K}^{-1}$ \\
\hline$a$ & $4-6$ & 573 & to 1673 & 5.334 & 5.707 & -- \\
\hline$b$ & $4-6$ & 573 & to 1673 & $5.192 \times 10^{6}$ & $6.165 \times 10^{6}$ & $m^{-1}$ \\
\hline
\end{tabular}

(a) Neutron fluence units $\left(10^{25} \mathrm{n} / \mathrm{m}^{2}\right)$ are in terms of HTGR fast fluence, (E > $29 \mathrm{fJ})_{\mathrm{HTGR}}$. 
fluence at the start of the interval is $(\Phi)_{i-1}$, and the fluence at the end of the interval is $(\Phi)_{i}$.

2. At the start of the first interval, the room temperature conductivity is initialized to $\mathrm{K}_{\mathrm{O}}(\mathrm{RT})$ through Eq. 4-7.

3. At the end of interval $i$, the room temperature irradiated conductivity is given by the recursive formula, Eq. 4-9:

$$
\begin{aligned}
K_{i}(R T)= & K_{\text {sat }}^{R T}\left(T_{i}\right) \\
& +\left(K_{i-1}(R T)-k_{s a t}^{R T}\left(T_{i}\right)\right) \exp -\frac{\left[(\Phi)_{i}-(\Phi)_{i-1}\right]}{\tau\left(T_{i}\right)},
\end{aligned}
$$

where

$$
\tau\left(T_{1}\right)=A+B T_{1}
$$

and

$$
\begin{aligned}
& \mathrm{K}_{\text {sat }}^{\mathrm{RT}}\left(\mathrm{T}_{i}\right)=\exp \left(\mathrm{C}+\mathrm{DT}_{i}\right) \\
& \text { where } \\
& \Phi=\text { fast neutron fluence }\left(10^{25} \mathrm{n} / \mathrm{m}^{2}\right) \\
& \text { (E > } 29 \mathrm{fJ})_{\mathrm{HTGR}} \text {, } \\
& \tau=\text { relaxation time in units of fluence, } \\
& \mathrm{K}_{\mathrm{sat}}^{\mathrm{RT}}=\text { saturation value of the room conductivity, } \\
& A, B, C, D=\text { constants given in Table 4.4-3. } \\
& T_{i}=\text { irradiation temperature during interval }
\end{aligned}
$$


4. Calculate the conductivity at the assumed current temperature $T_{C}$ by applying Eqs. 4-6 and 4-8.

\begin{abstract}
4.4.3.4. Thermal Conductivity Input Data for Near-Isotropic Graphite. The input data required to calculate the thermal conductivity of nearisotropic graphite in $\mathrm{W} / \mathrm{m} \cdot \mathrm{K}$ in the axial and radial directions are given in Tables 4.4-2 and 4.4-3. The calculated curves are shown in Fig. 4.4-5.
\end{abstract}

4.4.3.5. Effect of Thermal Annealing. Thermal annealing on thermal conductivity appears to begin at $1273 \mathrm{~K}$ and is completed by $1573 \mathrm{~K}$ (Refs. 4-18 and 4-19). The fractional change decreases almost linearly with increasing temperature. The irradiation damage parameter, $d$ in Eq. 4-6, is assumed to decrease linearly to zero over the above temperature range.

\title{
4.4.4 Emissivity
}

No emissivity data for H-451 graphite have been reported. However, emissivity does not vary much between graphite grades, and emissivity of 0.85 for a machined graphite surface shall be used (Refs. 4-20 through 4-22).

\subsection{MECHANICAL PROPERTIES}

\subsubsection{Transversely Isotropic Linear Elastic Constants}

The five independent linear elastic constants in the transversely isotropic material are two elastic moduli, $E_{1}$ and $E_{3}$; shear modulus, $G_{1}$; and two Poisson's ratios, $\nu_{12}$ and $\nu_{13}$. The axes in the isotropic plane are designated 1 -axis and 2-axis. The axis normal to the isotropic plane is labeled as the 3 -axis. 


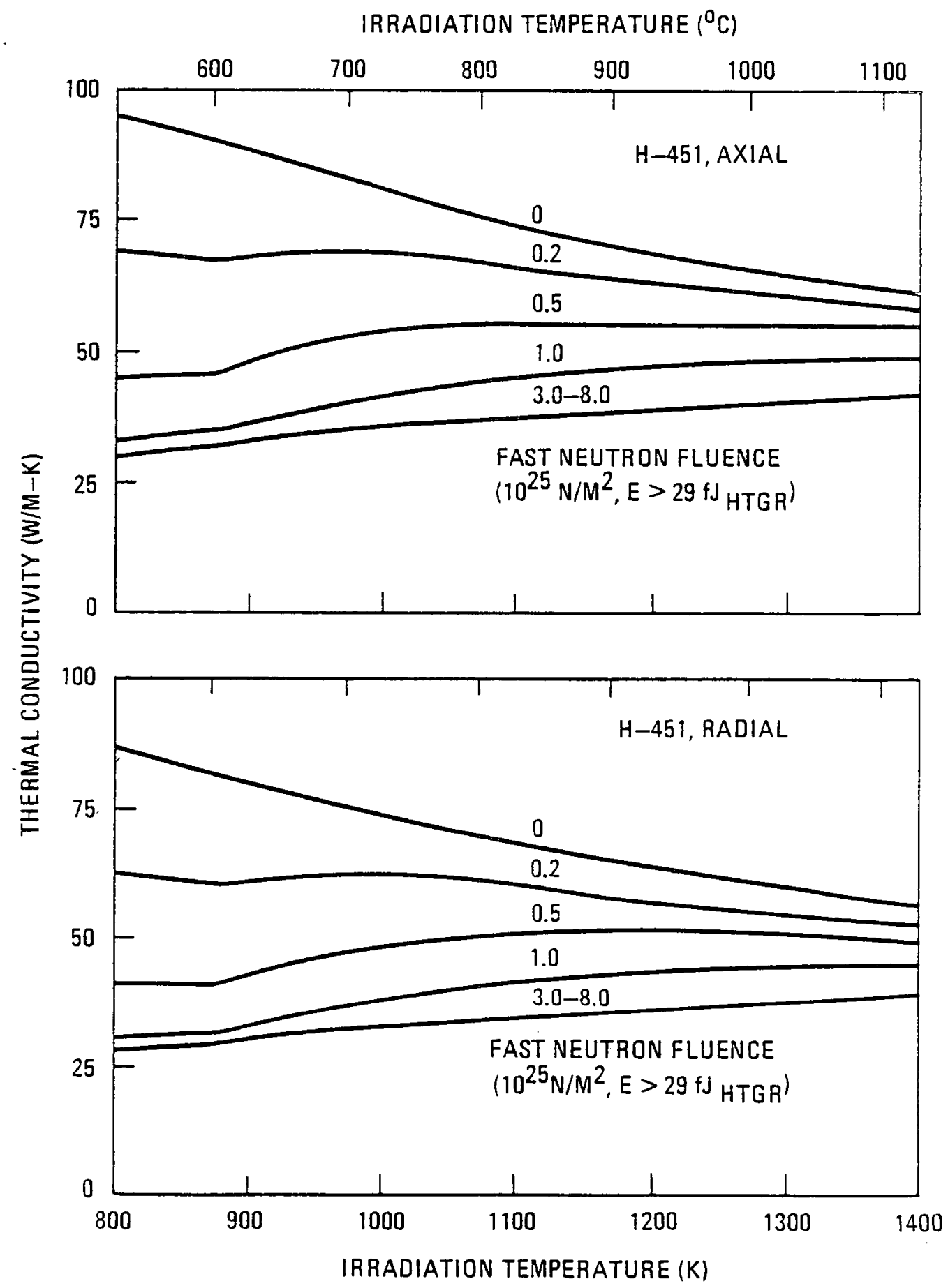

Fig. 4.4-5. Thermal conductivity of $\mathrm{H}-451$ graphite as a function of neutron irradiation 
The mean values of these elastic constants at room temperature, including the effect of spatial distribution, are (Ref. 4-23):

$$
\begin{aligned}
E_{1}= & 7.35+1.11 \times 10^{-2} \cdot \mathrm{r}^{2}+2.95 \times 10^{-3} \cdot \mathrm{z}^{2} \\
& -3.8 \times 10^{-5} \mathrm{r}^{2} \mathrm{z}^{2}, \\
\mathrm{E}_{3}= & 8.31+1.76 \times 10^{-2} \cdot \mathrm{r}^{2}+1.53 \times 10^{-3} \cdot \mathrm{z}^{2} \\
& -2.7 \times 10^{-5} \mathrm{r}^{2} \mathrm{z}^{2}, \\
\mathrm{G}_{1}= & \mathrm{E}_{1} / 2(1+\nu), \\
\text { all } \nu= & 0.12,
\end{aligned}
$$

where $E_{1}, E_{3}$, and $G_{1}$ are in $G P a$,

$r=$ radial distance from the axis of the billet, $\leq 8.5 \mathrm{in.}$ (in.),

$z$ = axial distance from midlength of the billet, $\leq 16$ in. (1n.).

The elastic moduli given above are the secant moduli of the second loading curve between 0 and $6.9 \mathrm{MPa}$.

The following modulus/temperature relationship applies to all $E$ and G's, except $\nu(\operatorname{Ref}, 4-24)$ :

$$
C(T)=C_{R T}\left(1+1.5 \times 10^{-4} \mathrm{~T}\right),
$$

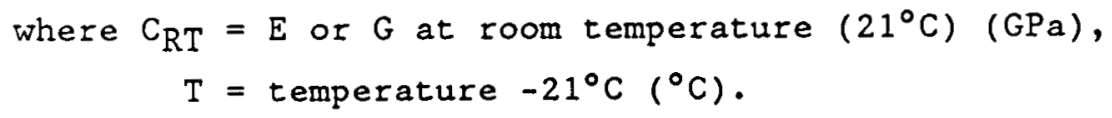

The fractional change in elastic modulus of $\mathrm{H}-451$ graphite due to isothermal neutron irradiation is given in Table 4.5-1, which is also presented graphically in Fig. 4.5-1 (Ref. 4-25). The elastic modulus due to nonisothermal neutron irradiation shall be evaluated using the shifting rule identical to that for the dimensional change (Section 4.6.2). 
TABLE $4.5-1$

PERCENTAGE CHANGE IN ELASTIC MODULUS OF H-451 GRAPHITE DURING NEUTRON IRRADIATION

\begin{tabular}{|c|c|c|c|c|c|}
\hline \multirow{2}{*}{ Fast } & \multirow{2}{*}{$\begin{array}{l}\text { Neutron Fluence, } \Phi \\
\quad\left(10^{25} \mathrm{n} / \mathrm{m}^{2}\right) \\
(E) 29 \mathrm{fJ})_{\text {HTGR }}\end{array}$} & \multicolumn{4}{|c|}{$\begin{array}{c}\text { Change in Elastic Modulus at } \\
\text { Irradiation Temperature } \\
(\%)\end{array}$} \\
\hline & & $673 \mathrm{~K}$ & $873 \mathrm{~K}$ & $1173 \mathrm{~K}$ & $1473 \mathrm{~K}$ \\
\hline & 0 & 0 & 0 & 0 & 0 \\
\hline & 0.25 & 83.0 & 68.0 & 54.0 & 52.0 \\
\hline & 0.50 & 90.5 & 76.8 & 63.8 & 62.0 \\
\hline & 0.75 & 95.0 & 81.6 & 68.6 & 66.6 \\
\hline & 1.00 & 98.1 & 85.3 & 71.4 & 68.5 \\
\hline & 1.25 & 100.8 & 88.0 & 73.2 & 69.0 \\
\hline & 1.50 & 102.8 & 90.4 & 75.0 & 69.0 \\
\hline & 1.75 & 104.8 & 92.0 & 75.7 & 69.0 \\
\hline & 2.00 & 106.5 & 93.5 & 76.7 & 69.0 \\
\hline & 2.25 & 108.0 & 94.8 & 77.0 & 69.0 \\
\hline & 2.50 & 109.8 & 95.5 & 77.3 & 69.0 \\
\hline & 2.75 & 111.3 & 96.5 & 78.0 & 69.0 \\
\hline & 3.00 & 113.0 & 97.5 & 78.7 & 69.0 \\
\hline & 3.25 & 114.5 & 98.4 & 79.3 & 69.2 \\
\hline & 3.50 & 116.3 & 99.0 & 80.8 & 70.0 \\
\hline & 3.75 & 117.4 & 100.0 & 82.3 & 70.5 \\
\hline & 4.00 & 119.3 & 100.8 & 85.2 & 71.0 \\
\hline & 4.25 & 121.0 & 101.2 & 90.6 & 71.5 \\
\hline & 4.50 & 122.8 & 102.0 & 95.9 & 72.7 \\
\hline & 4.75 & 124.3 & 102.8 & 101.0 & 73.2 \\
\hline & 5.00 & 126.0 & 103.4 & 106.0 & 74.3 \\
\hline & 5.25 & 127.4 & 104.0 & 111.3 & 75.2 \\
\hline & 5.50 & 129.0 & 104.7 & 116.8 & 76.7 \\
\hline & 5.75 & 130.6 & 105.3 & 122.0 & 78.1 \\
\hline & 6.00 & 132.2 & 105.9 & 127.2 & 79.8 \\
\hline & 6.25 & 133.8 & 106.5 & 132.4 & 81.5 \\
\hline & 6.50 & 135.4 & 107.1 & 137.6 & 83.4 \\
\hline & 6.75 & 137.0 & 107.8 & 142.8 & 85.9 \\
\hline & 7.00 & 138.6 & 108.4 & 148.0 & 88.5 \\
\hline & 7.25 & 140.2 & 109.0 & 153.2 & 91.2 \\
\hline & 7.50 & 141.8 & 109.6 & 158.4 & 94.8 \\
\hline & 7.75 & 143.4 & 110.2 & 163.6 & 98.4 \\
\hline & 8.00 & 145.2 & 110.6 & 169.0 & 103.0 \\
\hline
\end{tabular}




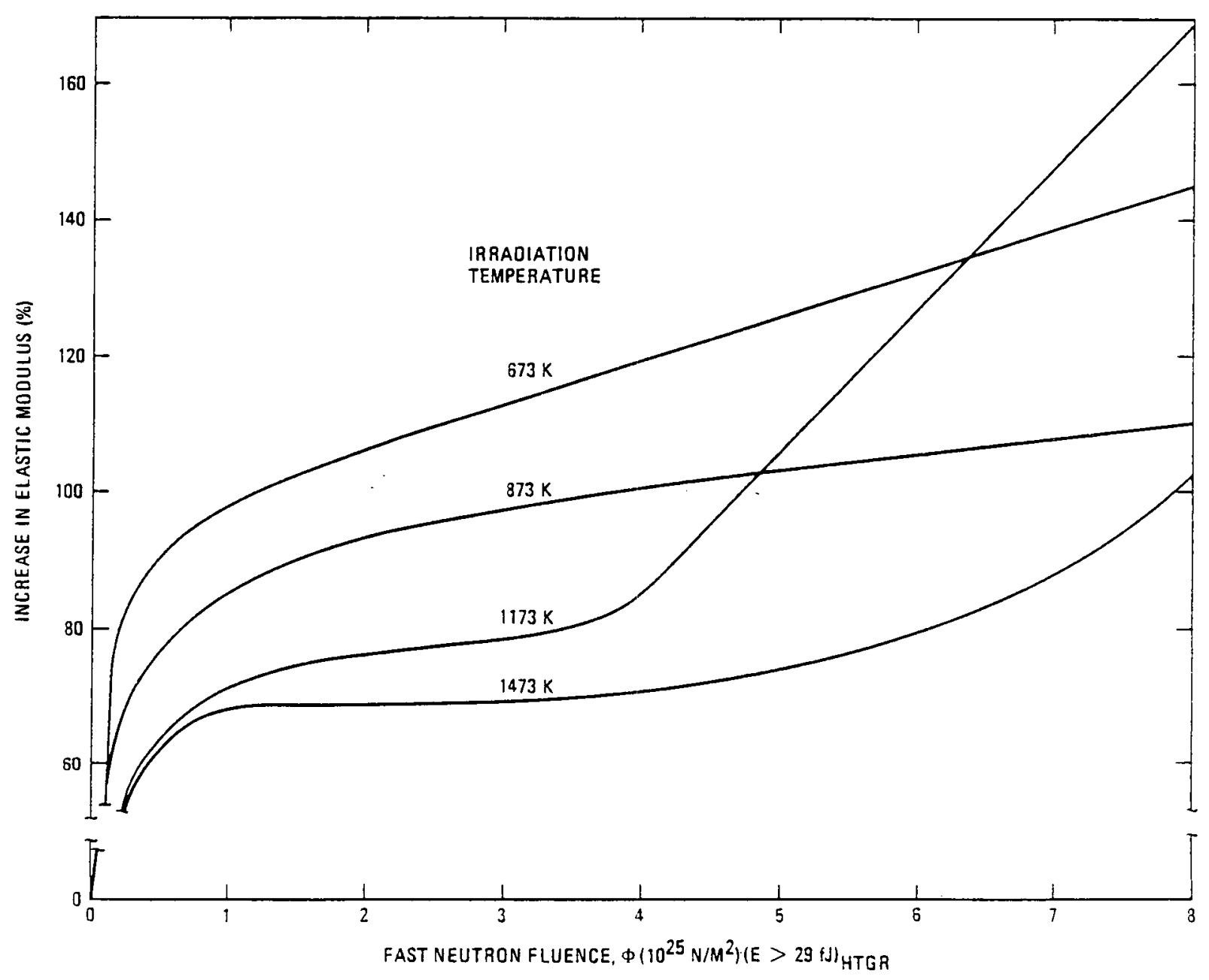

F1g. 4.5-1. Fractional change in elastic modulus of H-451 graphite as a function of irradiatioan conditions 
The Poisson's ratios, $\nu_{12}$ and $\nu_{13}$, are assumed to remain constant with respect to temperature and neutron irradiation.

\subsubsection{Stress-Strain Curve}

A typical room temperature tensile and compressive stress-strain curve found for the axial direction of unirradiated $\mathrm{H}-451$ graphite are presented in Figs. 4.5-2 and 4.5-3, respectively (Ref. 4-26). A typical tensile stress-strain curve in the radial direction can be constructed by increasing the axial strain at a given stress by $15 \%$. This factor was obtained form the mean ratio of axial elastic modulus to radial elastic modulus. The mean failure point has a fracture strain of $8 \%$ higher in the axial direction than in the radial direction.

The irradiated tensile stress strain curve [LATER] Fig. 4.5-4 (Ref. 4-27).

\subsubsection{Strength}

4.5.3.1. Ultimate Tensile and Compressive Strength (UTS and UCS). Per Core Graphite Structural Design Criteria (Ref. 4-1), mean ultimate strength is used in stress analyses to evaluate the structural integrity of a given core graphite component against the design and accident condition stresses. Spatial distribution of ultimate strength in both the axial and radial directions in a log may be considered.

Since UCS of H-451 is almost four times its UTS, only UTS is needed in the stress analysis.

The spatial distribution of room temperature mean UTS in the unirradiated reference $H-451 \log$ is presented by (Ref. 4-17):

$$
\text { UTS }=a+b r^{2}+C z^{2}+d r^{2} z^{2},
$$




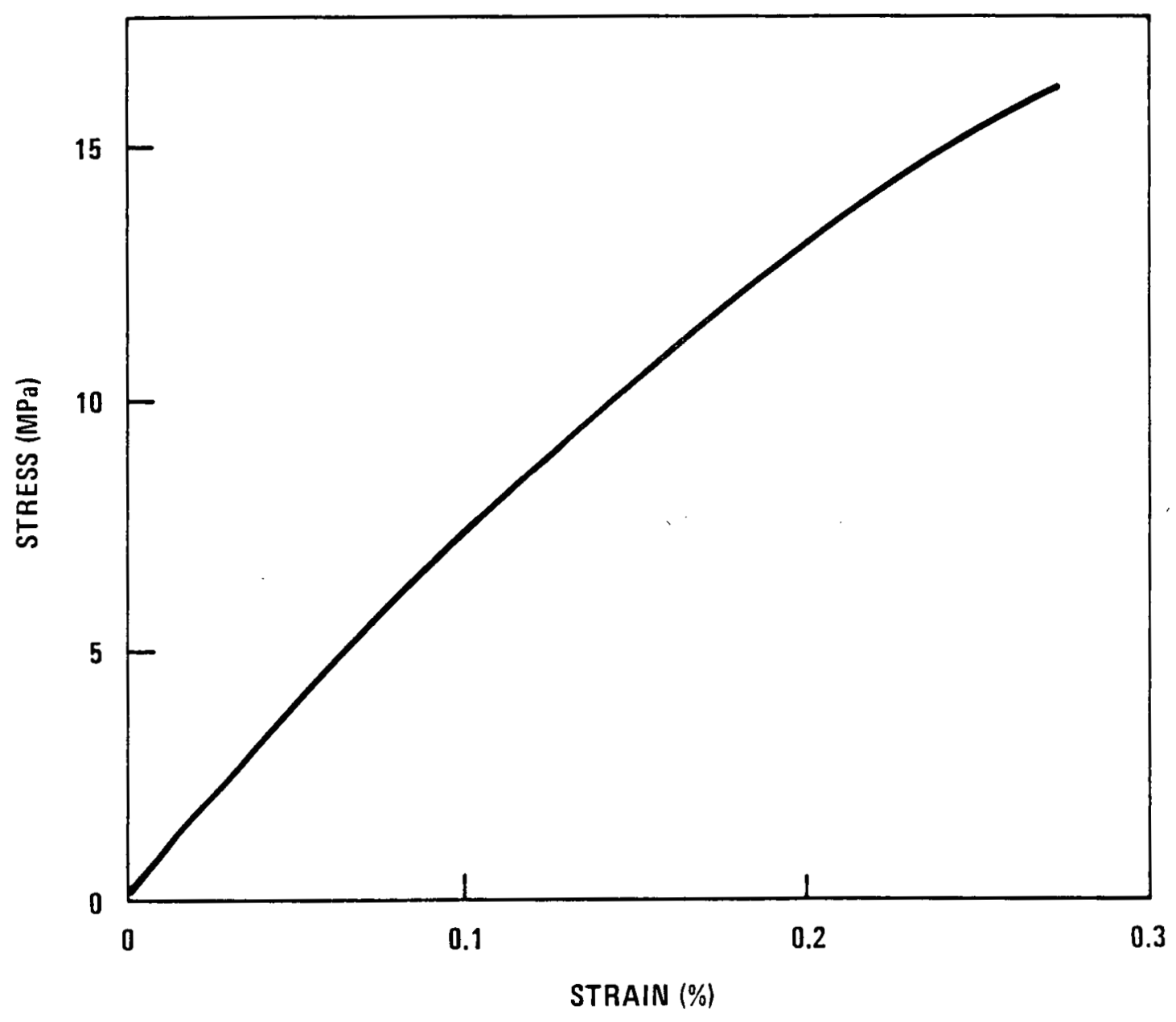

Fig. 4.5-2(a) Tensile stress-strain curve for H-45I graphite, axial orientation 


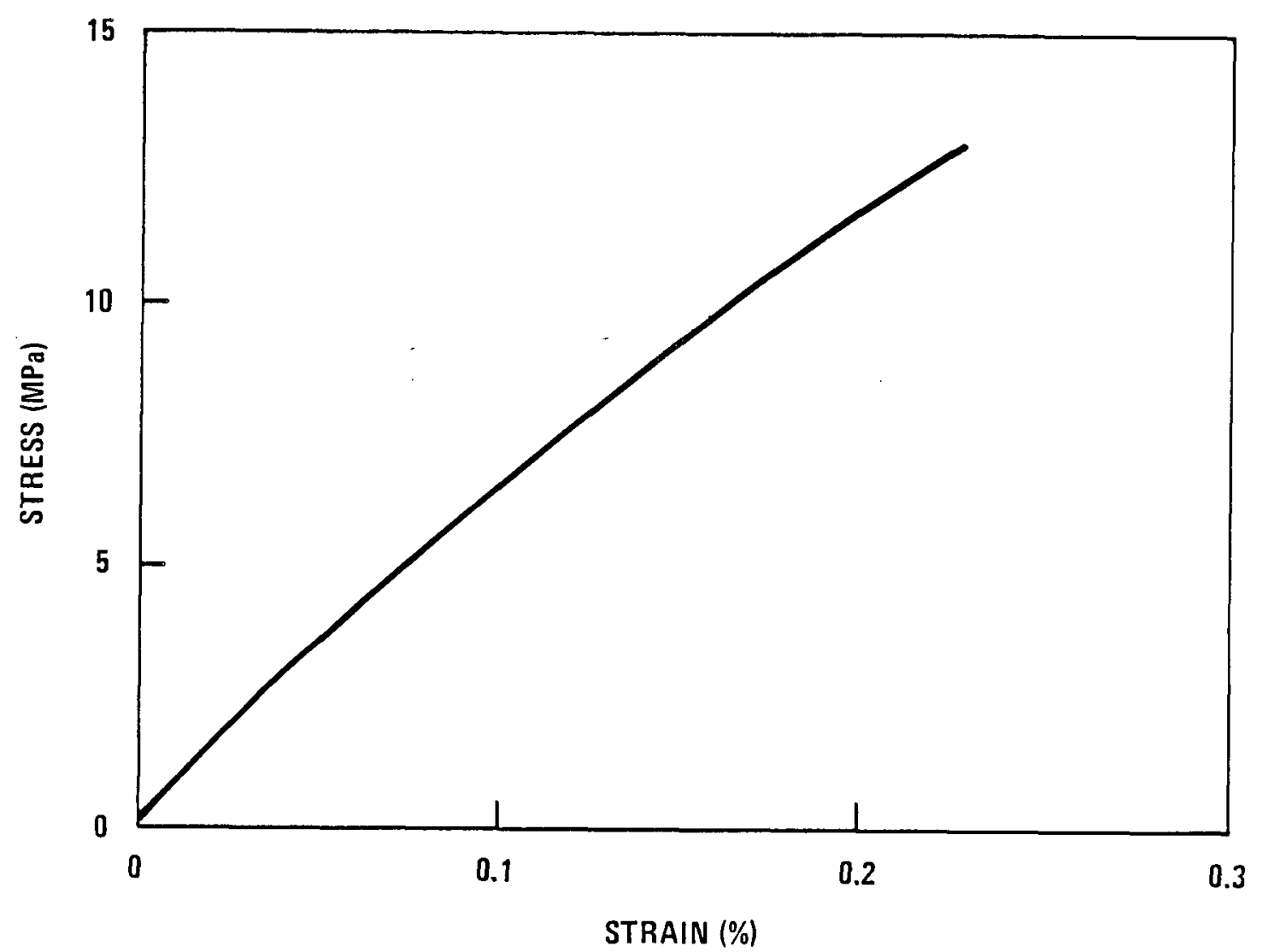

Fig. 4.5-2(b) Tensile stress-strain curve for H-45I graphite, radial orientation 


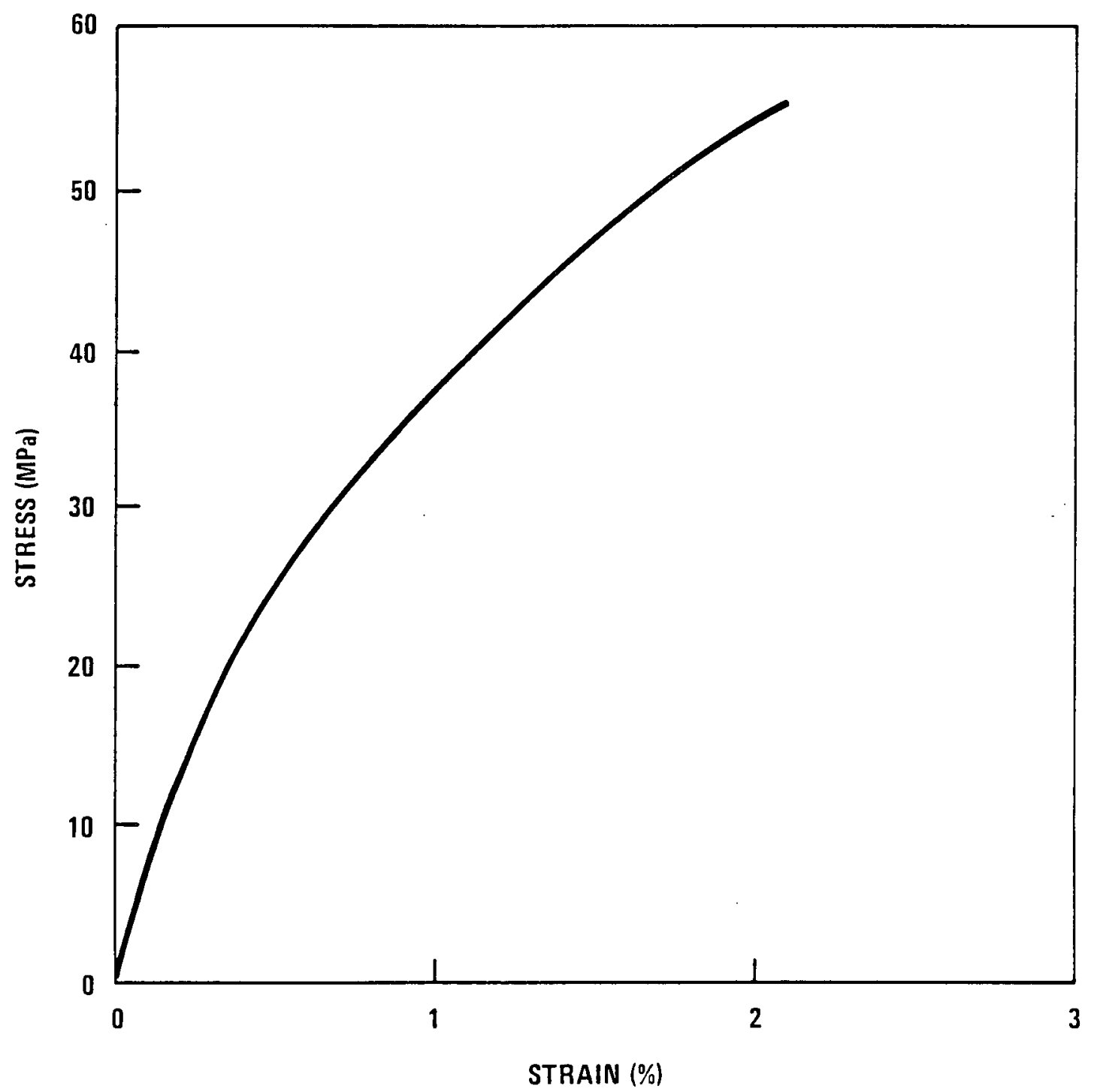

Fig. 4.5-3(a) Compressive stres-strain curve for $\mathrm{H}-451$ graphite, axial orientation 


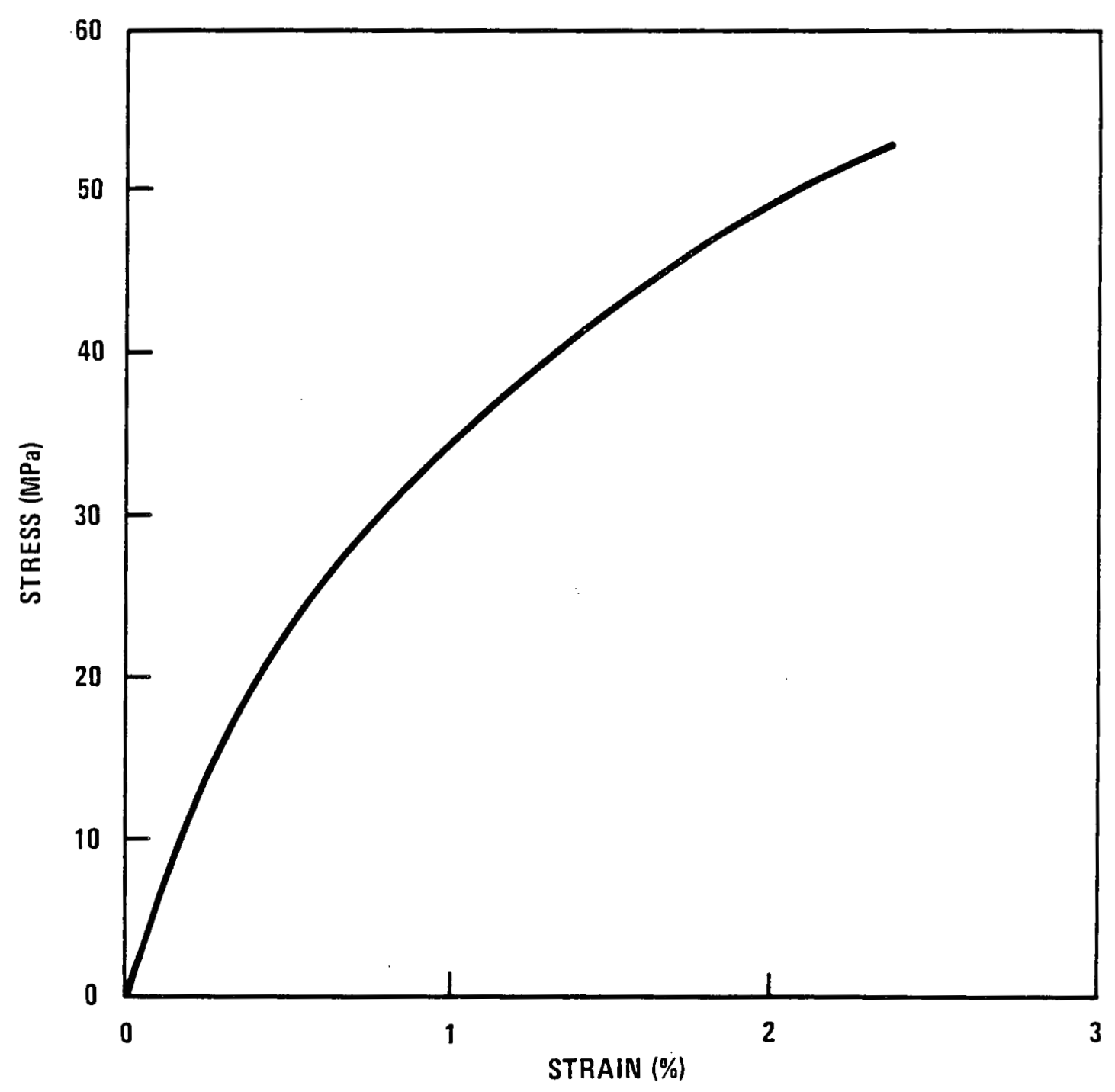

Fig. 4.5-3(b) Compressive stress-strain curve for H-451 graphite, radial orientation 


\section{(Later)}

Fig. 4.5-4a. Tensile stress-strain curve for irradiated H-451 graphite 
Fig. 4.5-4b. Compressive stress-strain curve for 1rradiated H-45I graphite 


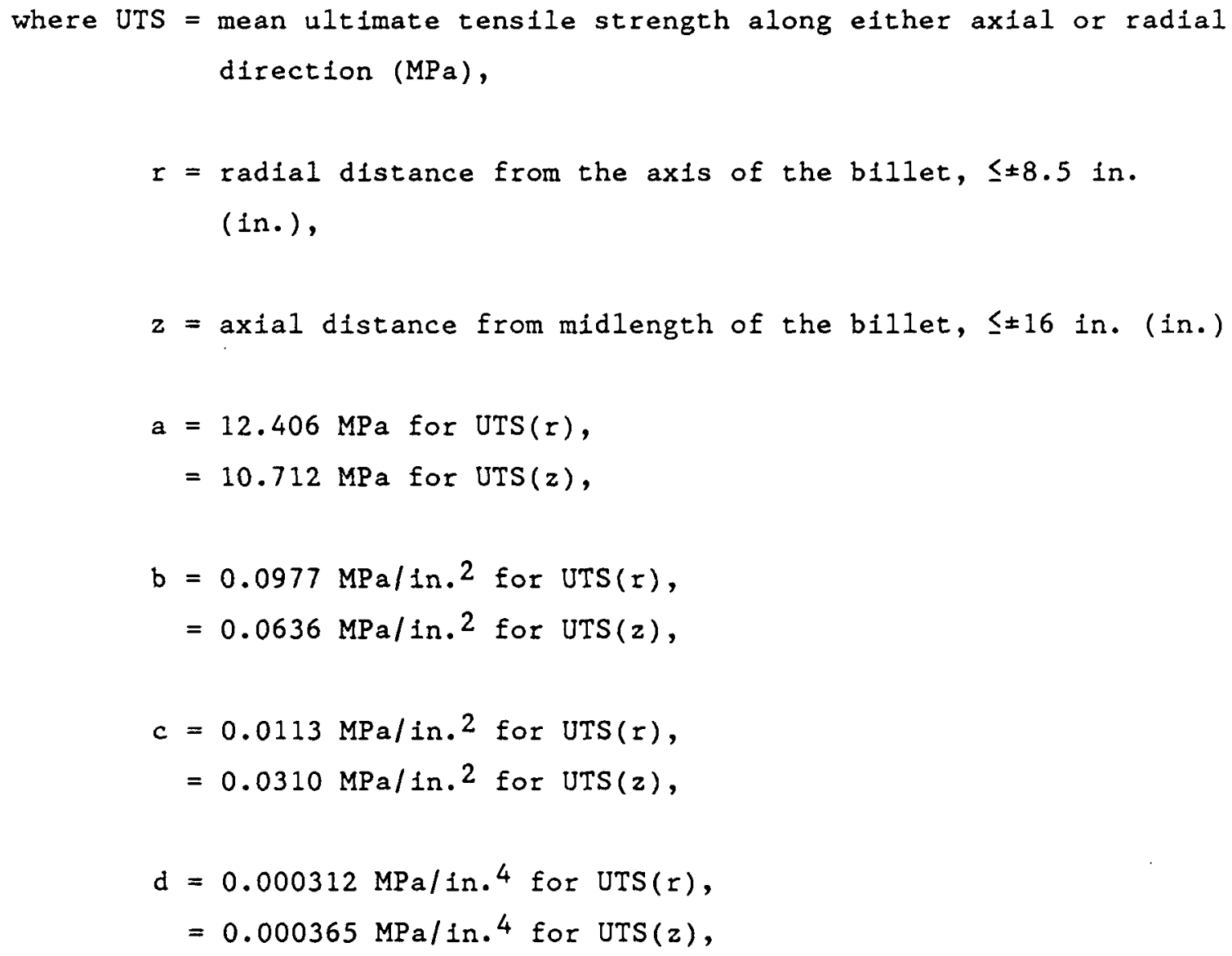

and the origin $(r=0$ and $z=0)$ is at the center of the log.

In the off-axis case the following Hankinson's formula is recommended for use:

$$
\operatorname{UTS}(\theta)=\frac{\operatorname{UTS}(z) \times \operatorname{UTS}(r)}{\operatorname{UTS}(z) \sin ^{2} \theta+\operatorname{UTS}(r) \cos ^{2} \theta},
$$

where $\theta$ is the angle between the direction of the principal stress and the axial axis. UTS $(z)$ and UTS $(r)$ are the UTS in the axial and radial directions, respectively.

The UTS increases with temperature. At the present, the percentage incrase is assumed to be similar to that of 2020 graphite (the first factor on the right hand size of Eq. 3.3-11 in Section 3.3.4.3). 
The change in UTS due to neutron irradiation is related to the irradiation-induced change in modulus by (Ref. 4-15):

$$
\frac{S_{i}}{S_{o}}=\left(\frac{E_{i}}{E_{o}}\right)^{0.64},
$$

where $\mathrm{S}_{\mathrm{O}}=$ UTS of unirradiated $\mathrm{H}-451$,

$S_{i}=$ UTS of 1rradiated $\mathrm{H}-451$,

$E_{O}=$ elastic modulus of unirradiated $\mathrm{H}-451$,

$E_{i}=$ elastic modulus of irradiated $\mathrm{H}-451$.

The fractional changes in modulus during irradiation are given in Table 4.5-1.

4.5.3.2. Biaxial Strength. In the biaxial stress state, the Coulomb-Mohr theory, modifled to include a maximum tensile strength cutoff, is the fallure theory currently recommended for graphite (Ref. 4-21).8 To construct a fallure surface, the UTS at any generic point of interest including the environmental effects governs the failure in the first tension/tension quadrant. In the third compression/compression quadrant, a constant ultimate compressive strength (UCS) of $51 \mathrm{MPa}$ (7400 psi) is used for both the axial (A) and radial ( $R$ ) directions. In the remaining two quadrants, the modified Coulomb-Mohr theory as defined by

$$
\begin{aligned}
& \sigma_{\mathrm{A}}=-51.0+2 \times \sigma_{\mathrm{R}} \mathrm{MPa} \text { in the Fourth quadrant, } \\
& \sigma_{\mathrm{R}}=-51.00+2 \times \sigma_{\mathrm{A}} \mathrm{MPa} \text { in the Second quadrant, },(4-17)
\end{aligned}
$$

and the maximum princlpal stress theory, whichever is more restrictive, applies.

The effects of environment, such as temperature and neutron irradiation, are assumed to be identical to that of UTS (Section 4.5.3.1). 


\subsubsection{Fracture Toughness and the Critical Defect Size}

Room temperature fracture toughness of unirradiated H-451 graphite is (Ref. 4-28):

$$
\begin{aligned}
\mathrm{K}_{\mathrm{IC}}= & 1.54 \mathrm{MPa} \sqrt{\mathrm{m}}(1400 \mathrm{psi} \sqrt{\mathrm{in} .}) & & \mathrm{AR} \text { orientation } \\
& 1.40 \mathrm{MPa} \sqrt{\mathrm{m}}(1270 \mathrm{psi} \sqrt{\mathrm{in} .}) & & R R \text { orientation }
\end{aligned}
$$

The first letter in the orientation indicates the direction normal to the crack and the second letter the direction of propagation. $A$ and $R$ stand for the axial and radial directions, respectively.

The calculated critical defect size is $1.5 \mathrm{~mm}(0.06 \mathrm{in.})$.

The reduction of $\mathrm{K}_{\mathrm{IC}}$ with oxidation follows the relationship (Ref. 4-22)

$$
\mathrm{K}_{\mathrm{IC}} /\left(\mathrm{K}_{\mathrm{IC}}\right)_{0}=\exp (-4.66 \mathrm{x})
$$

where $x$ = fractional weight loss due to oxidation. The calculated critical defect size increases with oxidation.

$\mathrm{K}_{\mathrm{IC}}$ increases slightly with neutron irradiation (Ref. 4-29). For design use, $K_{I C}$ is assumed to remain constant.

\subsubsection{Effect of Oxidation on Mechanical Properties}

The reduction in tensile strength ( $S$ ) and elastic modulus (E) of uniformly oxidized $\mathrm{H}-451$ graphite is represented by the following relationship (Ref, 4-30):

$$
\begin{aligned}
& S / S_{0}=\exp (-5 x), \\
& E / E_{0}=\exp (-6 x),
\end{aligned}
$$


where $x=$ fractional weight loss due to oxidation, subscript "o" = the unoxidized state.

The relationship is valid for uniformly oxidized H-451 graphite with burnoff up to $20 \%$.

\subsection{NEUTRON IRRADIATION EFFECTS ON DIMENSIONS}

4.6.1. Irradiation-Induced Dimensional Change (Refs. 4-15 4-25, 4-31, 4-32, and 4-33)

The permanent dimensional change $\left(\epsilon^{I}\right)$ due to fast neutron damage has been expressed in terms of average irradiation temperature $\left(T_{\phi}\right)$ and fast neutron fluence ( $\Phi$ ) for H-451 graphite. The irradiation-induced dimensional change $\left(\epsilon^{I}\right)$ is expressed by the polynomial in Eq. 4-20, which is valid for irradiation between 623 and $1573 \mathrm{~K}$ and to fast neutron fluences of $10 \times 10^{25} \mathrm{n} / \mathrm{m}^{2}$ (E > $29 \mathrm{fJ}$ ) HTGR:

$$
\begin{aligned}
& \epsilon^{I}=\left(C_{1}+C_{2} T_{\phi}+C_{3} T_{\phi}^{2}+c_{4} T_{\phi}^{3}+C_{5} T_{\phi}^{4}\right) \Phi
\end{aligned}
$$

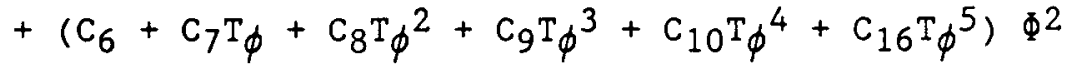

$$
\begin{aligned}
& +\left(c_{11}+c_{12} \mathrm{~T}_{\phi}+\mathrm{C}_{13} \mathrm{~T}_{\phi}{ }^{2}+\mathrm{c}_{14} \mathrm{~T}_{\phi}{ }^{3}+\mathrm{C}_{15} \mathrm{~T}_{\phi}{ }^{4}\right. \\
& \left.+\mathrm{c}_{17} \mathrm{~T}^{5}+\mathrm{c}_{18} \mathrm{~T}^{6}\right) \Phi^{3} \text {, }
\end{aligned}
$$

where $\epsilon^{I}=$ Irradiation-induced dimensional change, $\Delta l / \ell(\%)$,

$$
\begin{aligned}
\Phi= & \text { fast neutron fluence }(E>29 \mathrm{fJ})_{\mathrm{HTGR}}\left(10^{\left.25 \mathrm{n} / \mathrm{m}^{2}\right),}\right. \\
\mathrm{T}_{\phi}= & \text { average irradiation temperature }-273(\mathrm{~K}), \\
\mathrm{C}_{i}= & \text { coefficients determined for each orientation of } \mathrm{H}-451 \mathrm{graph}- \\
& \text { ite (coefficients are listed in Table } 4.6-1) .
\end{aligned}
$$

The design curves described by the polynomial (Eq. 4-20) are presented graphically in Figs. 4.6-1 and 4.6-2. 
TABLE $4.6-1$

POLYNOMIAL COEFFICIENTS FOR DIMENSIONAL CHANGE DESIGN EQUATIONS: H-451 GRAPHITE

\begin{tabular}{lll}
\hline Coefficient & \multicolumn{1}{c}{ Axial } & \multicolumn{1}{c}{ Radial } \\
\hline$c_{1}$ & 1.11617 & 1.15132 \\
$c_{2}$ & $-0.92197 \times 10^{-2}$ & $-0.82968 \times 10^{-2}$ \\
$c_{3}$ & $+0.20463 \times 10^{-4}$ & $+0.17060 \times 10^{-4}$ \\
$c_{4}$ & $-0.16458 \times 10^{-7}$ & $-0.12645 \times 10^{-7}$ \\
$c_{5}$ & $+0.40809 \times 10^{-11}$ & $+0.27657 \times 10^{-11}$ \\
$c_{6}$ & $+0.64947 \times 10^{-1}$ & +0.39177 \\
$c_{7}$ & $-0.56929 \times 10^{-2}$ & $-0.36540 \times 10^{-2}$ \\
$c_{8}$ & $+0.18972 \times 10^{-4}$ & $+0.12750 \times 10^{-4}$ \\
$c_{9}$ & $-0.29277 \times 10^{-7}$ & $-0.20230 \times 10^{-7}$ \\
$c_{10}$ & $+0.20435 \times 10^{-10}$ & $+0.14233 \times 10^{-10}$ \\
$c_{11}$ & $-0.59274 \times 10^{-2}$ & $+0.13110 \times 10^{-1}$ \\
$c_{12}$ & $-0.65404 \times 10^{-5}$ & $-0.18768 \times 10^{-3}$ \\
$c_{13}$ & $+0.32751 \times 10^{-6}$ & $+0.10199 \times 10^{-5}$ \\
$c_{14}$ & $-0.13449 \times 10^{-8}$ & $-0.27004 \times 10^{-8}$ \\
$c_{15}$ & $+0.22245 \times 10^{-11}$ & $+0.36498 \times 10^{-11}$ \\
$c_{16}$ & $-0.51973 \times 10^{-14}$ & $-0.35768 \times 10^{-14}$ \\
$c_{17}$ & $-0.16038 \times 10^{-14}$ & $-0.23579 \times 10^{-14}$ \\
$c_{18}$ & $+0.41756 \times 10^{-18}$ & $+0.57329 \times 10^{-18}$ \\
\hline & &
\end{tabular}




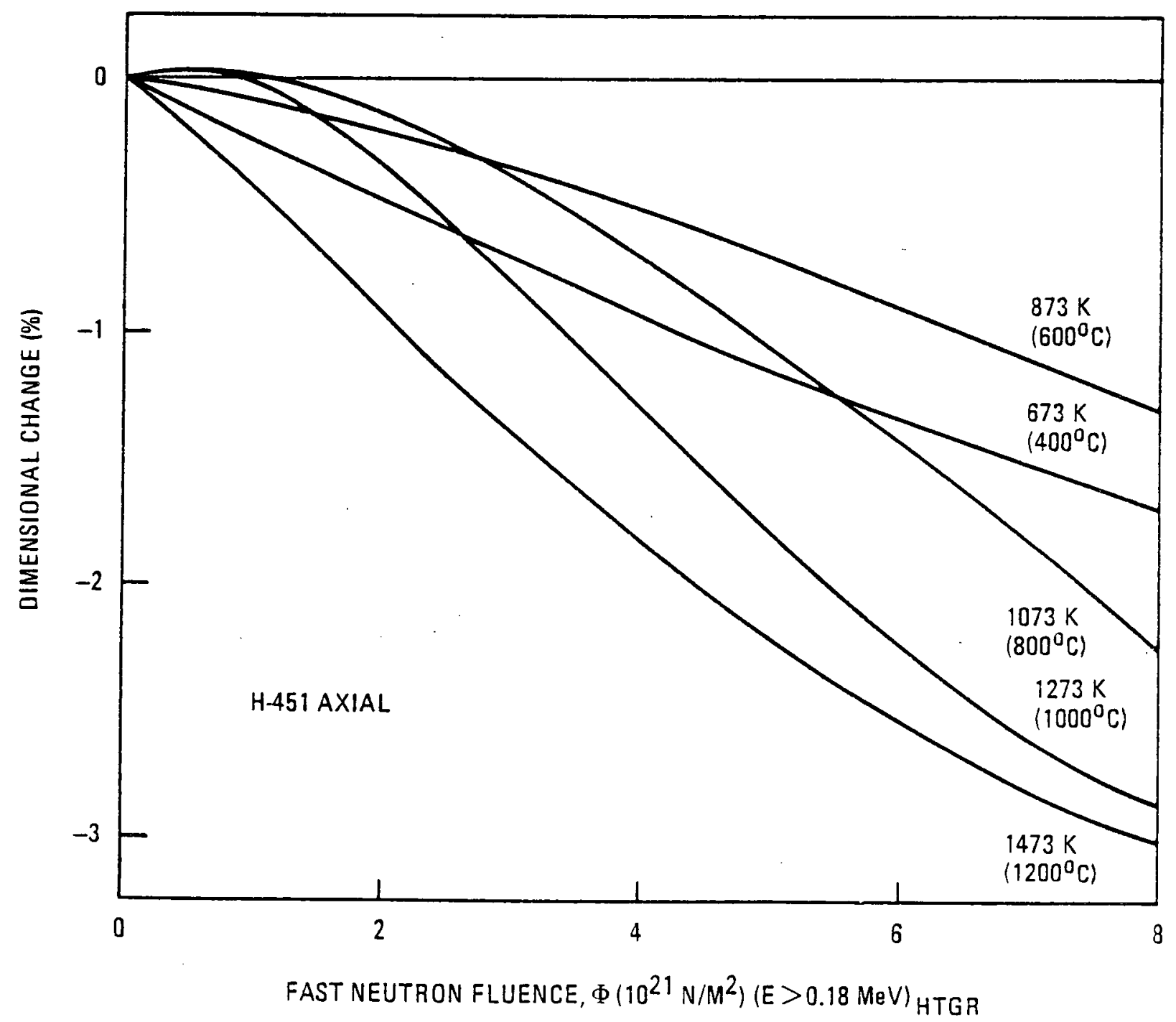

Fig. 4.6-1. Design curves for dimensional change of H-451 graphite, axial orientation, as a function of irradiation conditions 


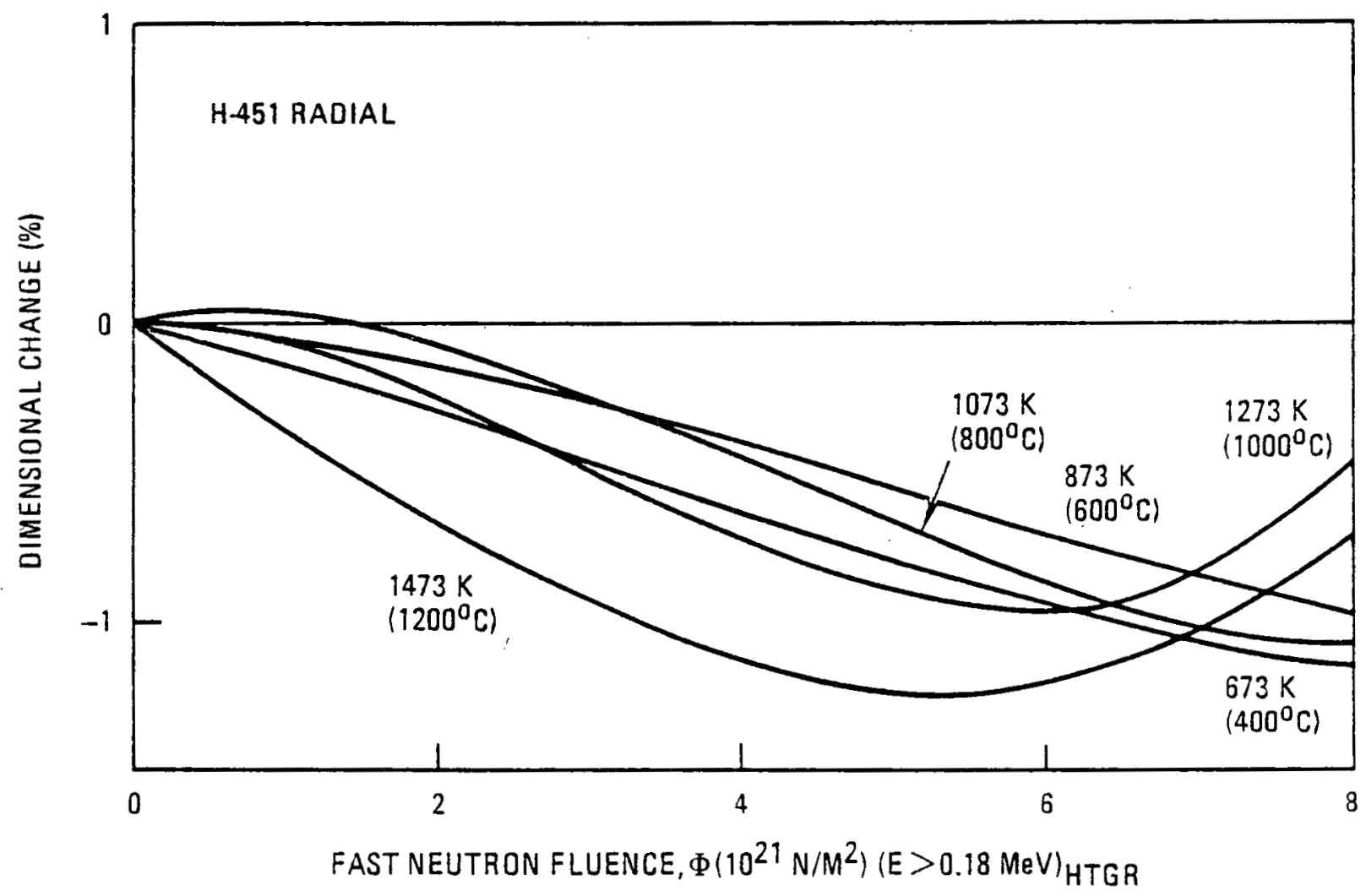

Fig. 4.6-2. Design curves for dimensional change of H-451 graphite, radial orientation, as a function of irradiation conditions 
The maximum densification point and crossover point [LATER] are shown in Fig. 4.6-3 (Ref. 4-34).

The following horizontal shifting rule for the dimensional change shall be used for the nonisothermal operating condition:

1. Usable lifetime is conservatively defined as the fluence when the graphite under irradiation returns to its original volume. This fluence is represented by $L\left(T_{i}\right)$ at temperature $T_{i}$.

2. The fraction of lifetime used by a fluence increment of $\Delta \gamma\left(T_{i}\right)$ is $\Delta \mathrm{U}_{1}=\Delta \gamma\left(\mathrm{T}_{1}\right) / \mathrm{L}\left(\mathrm{T}_{1}\right)$.

3. The cumulative usage fraction is $\sum \Delta U_{1}=U_{1}$.

4. A shift from the $\epsilon^{I}\left(T_{1}\right)$ curve to $\epsilon^{I}\left(T_{1+1}\right)$ curve under the nonisothermal condition is performed at equal $U_{1}$. The $\epsilon^{I}\left(T_{i+1}\right)$ curve at $U_{i}$ and beyond is horizontally shifted to the vertical line (constant fluence) with the same $U_{i}$ on the $\epsilon^{I}\left(T_{1}\right)$ curve.

5. The vertical gap in $\epsilon^{I}$ [between the $\epsilon^{I}\left(T_{1}\right)$ and the shifted $\epsilon^{I}\left(T_{i+1}\right)$ at $U_{1}$ ] is assumed to be closed by the transient expression:

$\epsilon^{I}\left(T_{i+1}\right)=\epsilon_{s h}^{I}\left(T_{i+1}\right)+\Delta \epsilon_{s h}^{I}\left(T_{1+1}\right) \exp -\frac{\Delta \gamma\left(T_{i+1}\right)}{\tau}$,

where $\epsilon^{I}\left(T_{1+1}\right)=$ the predicted dimensional change at $T_{i+1}$,

$$
\begin{aligned}
& \epsilon_{s h}^{I}\left(T_{1+1}\right)=\epsilon^{I} \text { on the shifted } \epsilon I\left(T_{1+1}\right) \text { curve, } \\
& \Delta \epsilon_{s h}^{I}\left(T_{1+1}\right)=\text { the vertical gap at } \Delta \gamma\left(T_{1+1}\right)=0,
\end{aligned}
$$


$909597 / 0$

\section{(Later)}

Fig. 4.6-3. Maximum densification point and crossover point for irradiated $\mathrm{H}-451$ graphite as a function of irradiation temperature 


$$
\begin{aligned}
& \Delta \gamma\left(t_{i+1}\right)=\text { the fluence measured from the point with } \\
& U_{i} \text { (the temperature change point), } \\
& \tau=a \text { fluence constant, equal to } 0.8 \times
\end{aligned}
$$

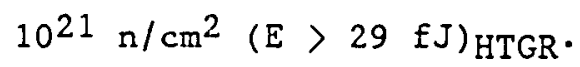

\subsubsection{Irradiation-Induced Creep}

4.6.2.1. Rheological Model. Mechanical behavior of graphite under irradiation has always been modeled for the HTGR as a standard linear solid, as proposed by Head (Ref. 4-35). The one-dimensional standard linear solid consists of a Kelvin element (spring and dashpot in parallel) and a Maxwell element (spring and dashpot in series) in series. The Kelvin element represents the transient response, and the Maxwell element the steady-state response. Beside the above two elements, there are two black box elements to represent the thermal strain and irradiation strain components.

In the standard linear solid model, the total strain at any generic point in an irradiated materfal body can be conveniently partitioned into the following five components:

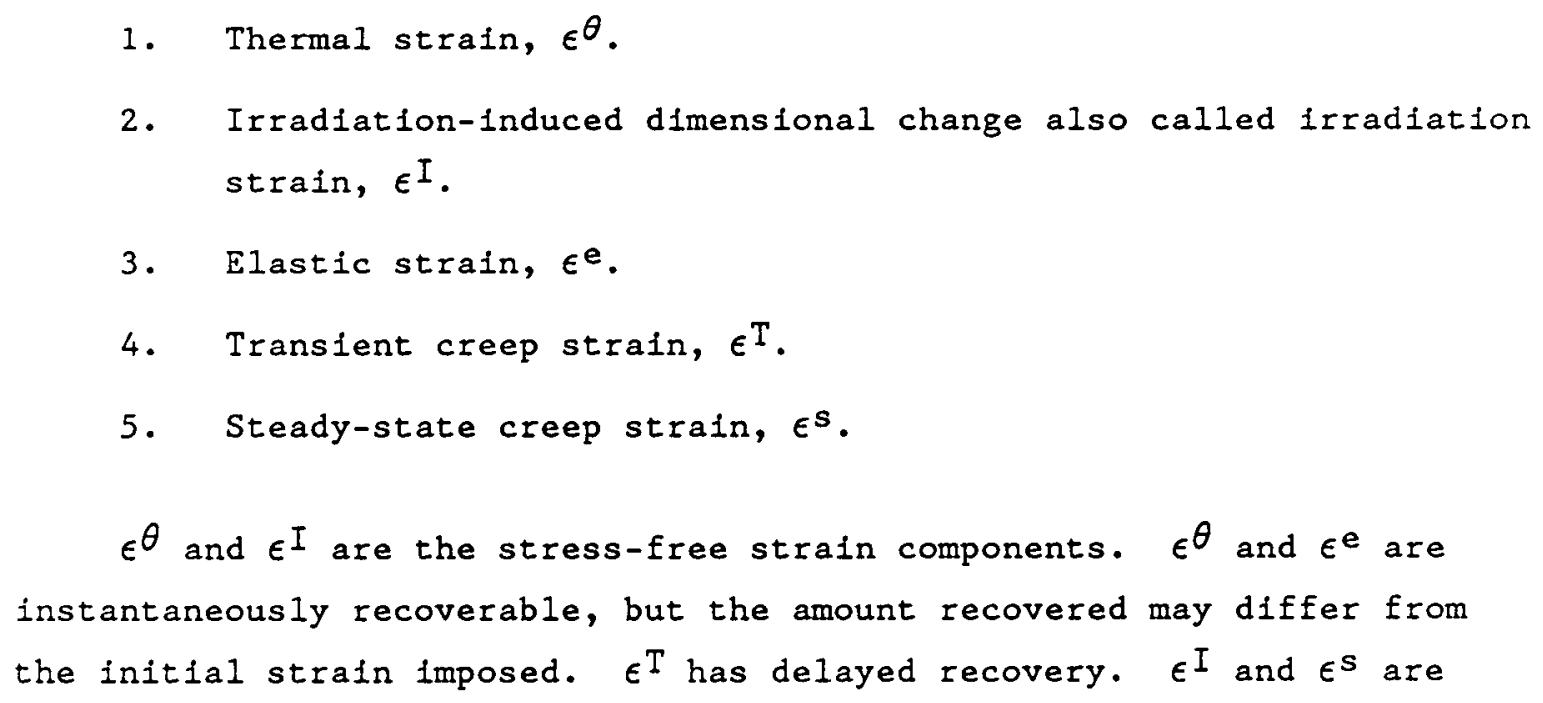


The thermal strain, $\epsilon^{\theta}$, can be calculated for a given temperature distribution and thermal expansivity given in Section 4.4.2. The irradiation-induced dimensional change, $\epsilon^{I}$, can be obtained from Section 4.6.2. The remaining three strain components will be discussed later.

Generalization of the one-dimensional creep model to multiaxial case was reported in Ref. 4-36. The remaining three strain components in the multiaxial case can be represented as a system of matrix differential equations. These are:

\section{Elastic}

$$
q={\underset{\sim}{E}}^{e} \epsilon^{e}
$$

Transient Creep

$$
\dot{\epsilon}^{\mathrm{T}}={\underset{\sim}{\mathrm{M}}}^{\mathrm{T}}\left(\underset{\sim}{\sim}-{\underset{\sim}{\mathrm{E}}}^{\mathrm{T}} \epsilon^{\mathrm{T}}\right)
$$

\section{Steady Creep}

$$
\dot{\epsilon}^{S}={\underset{\sim}{M}}^{S} q,
$$

where the dot represents differentiation with respect to fluence.

Equations 4-22 to 4-24 are coupled by the fact that the total

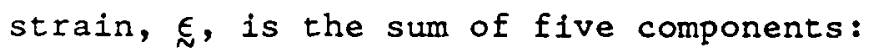

$$
\xi=\xi^{\mathrm{e}}+\epsilon^{\mathrm{T}}+\epsilon^{\mathrm{S}}+\xi^{\theta}+\epsilon^{\mathrm{I}}
$$

In the last four equations, $q$ and all $\epsilon^{\prime}$ 's all (6xi) vectors, while the material properties $\underset{\sim}{E^{e}}, \underset{\sim}{E^{T}}, \underset{\sim}{M}$, and $\underset{\sim}{M}$ are $(6 \times 6)$ matrices. Using the 
assumption of transverse isotropy and referring to a rectangular Cartesian coordinate system, typical vectors and matrices of these quantities can be represented in component form as:

$$
\begin{aligned}
& \underset{\sim}{\sigma}=\left\{\sigma_{\mathrm{x}}, \sigma_{\mathrm{y}}, \sigma_{\mathrm{z}}, \tau_{\mathrm{xy}}, \tau_{\mathrm{yz}}, \tau_{\mathrm{zx}}\right\}, \\
& \underset{\sim}{\epsilon}=\left\{\epsilon_{\mathrm{x}}, \epsilon_{\mathrm{y}}, \epsilon_{\mathrm{z}}, \gamma_{\mathrm{xy}}, \gamma_{\mathrm{yz}}, \gamma_{\mathrm{zx}}\right\},
\end{aligned}
$$

and

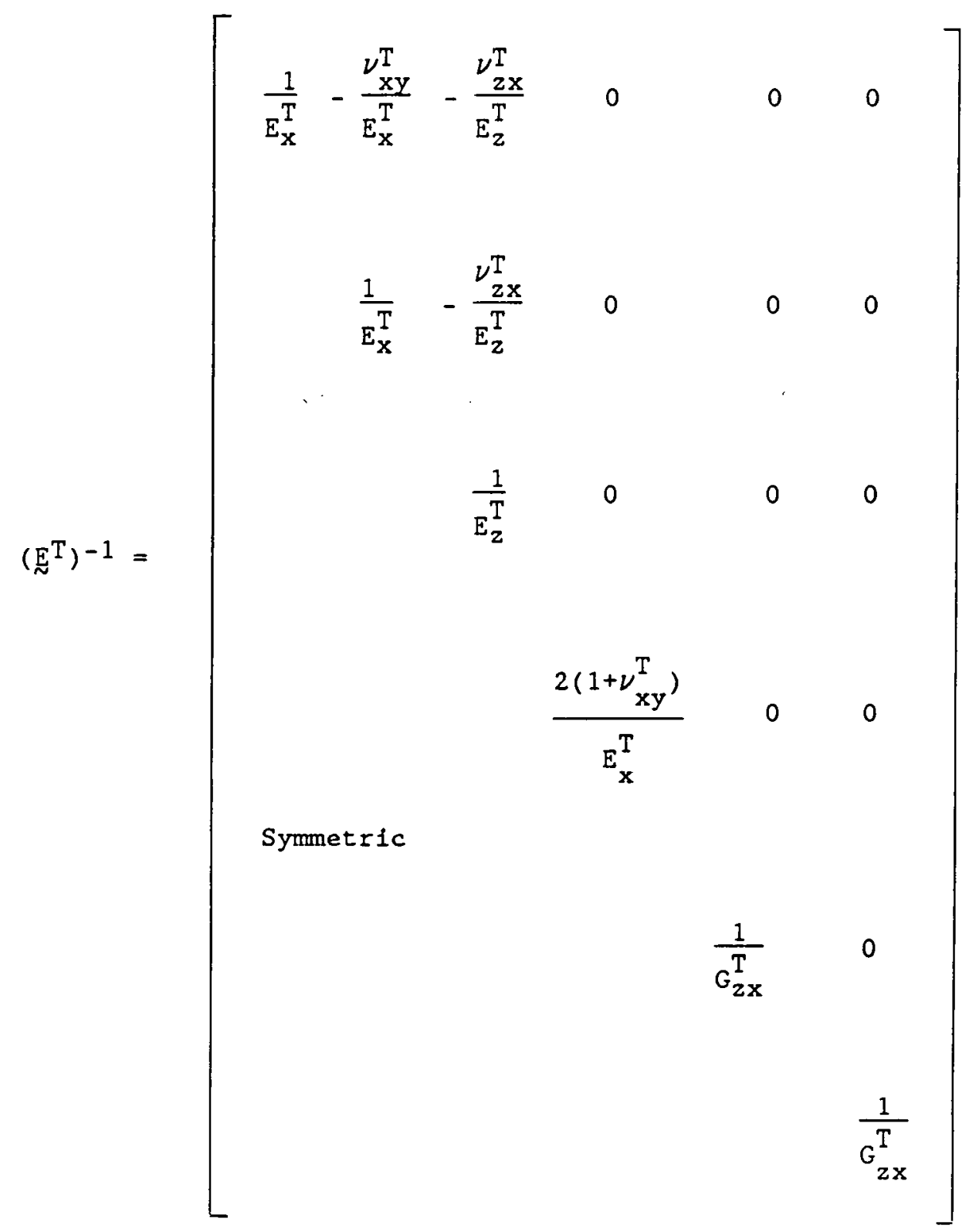




$$
\begin{aligned}
& 909597 / 0
\end{aligned}
$$

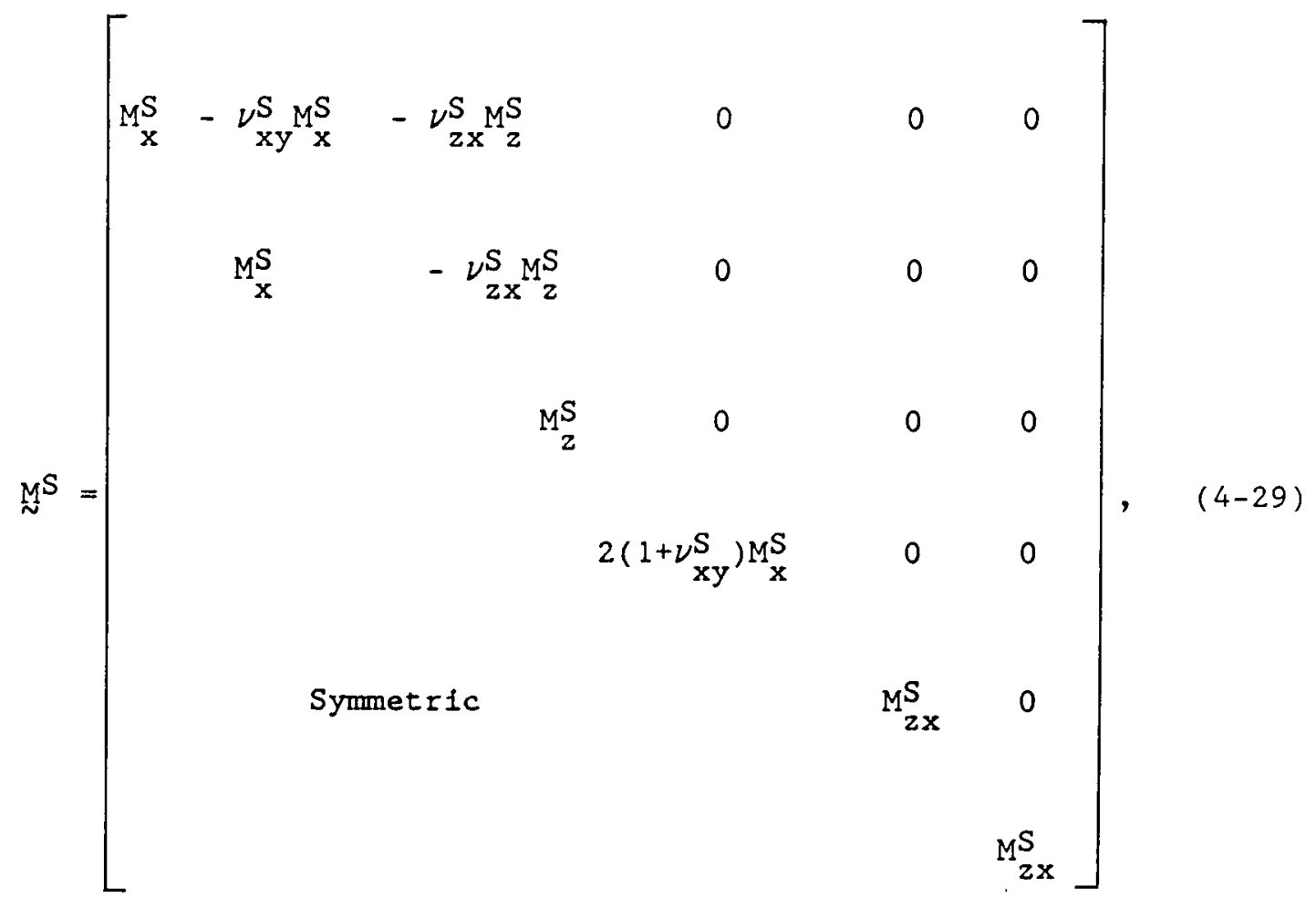

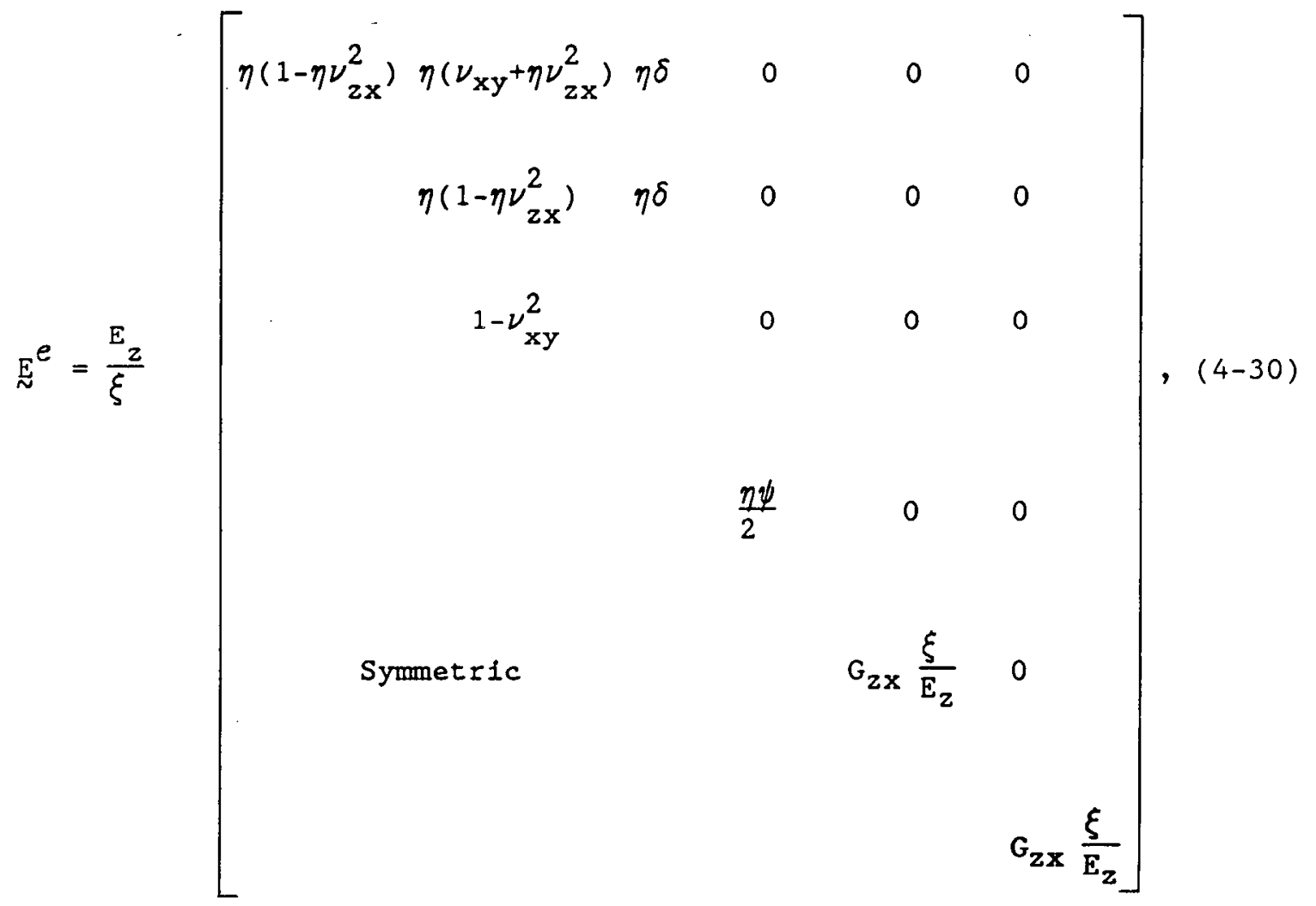


where $\eta=\frac{E_{x}}{E_{z}}$,

$$
\begin{aligned}
& \psi=1-\nu_{x y}-2 \eta \nu_{z x}^{2}, \\
& \xi=\left(1+\nu_{x y}\right)\left(1-\nu_{x y}-2 \eta \nu_{z x}^{2}\right), \\
& \delta=\nu_{z x}\left(1+\nu_{x y}\right)
\end{aligned}
$$

It should be clear that there are five independent material parameters contained in each of the material property matrices as a direct consequence of the transverse isotropy assumption.

A further reduction in the number of primitive material parameters is made by assuming:

$$
\underset{\sim}{M} \underset{\sim}{\mathbb{E}^{T}}=\frac{\underset{\sim}{\sim}}{\Phi_{R}}
$$

where $\underset{\sim}{I}$ is an identity matrix and $\Phi_{R}$ is a scalar called the "relaxation time." With this assumption, the system of matrix Eq. 4-23 becomes:

$$
\dot{\epsilon}^{\mathrm{T}}=\frac{1}{\Phi_{\mathrm{R}}} \quad\left(\left(\mathrm{E}^{\mathrm{T}}\right)^{-1} \underset{\sim}{\sigma}-\epsilon^{\mathrm{T}}\right),
$$

which is decoupled and, therefore, can be integrated easily. The physical implication of the assumption (4-23) is that the relaxation time constant is the same in all directions and that the Poisson's ratios are the same in both the parallel spring and the dashpot mechanisms, $\underset{\sim}{\mathrm{M}}$ and $\underset{\sim}{\mathrm{E}}$.

An intuitive assumption is introduced for $G_{2 x}, M_{2 x}^{S}$, and $G_{2 x}^{T}$ :

$$
G_{z X}=\frac{\frac{1}{2} E_{x}+E_{z}}{2\left(1+\nu_{z X}\right)}
$$




$$
\begin{aligned}
& \frac{1}{M_{z X}^{S}}=\frac{\frac{1}{2} \frac{1}{M_{X}^{S}}+\frac{1}{M_{z}^{S}}}{1+\nu_{z X}^{S}}, \\
& G_{z X}^{T}=\frac{\frac{1}{2} E_{X}^{T}+E_{z}^{T}}{21+\nu_{z X}^{T}} .
\end{aligned}
$$

After the last two assumptions, the independent material parameters for the viscoelastic response of core graphite are:

\section{Elastic}

$$
E_{x}, E_{z}, \nu_{x y}, \nu_{z x}
$$

Steady Creep

$$
\mathrm{M}_{\mathrm{x}}^{\mathrm{S}}, \mathrm{M}_{\mathrm{z}}^{\mathrm{S}}, \nu_{\mathrm{xy}}^{\mathrm{S}}, \nu_{\mathrm{zx}}^{\mathrm{S}}
$$

\section{Transient Creep}

$$
\Phi_{R}, E_{x}^{T}, E_{z}^{T}, \nu T=, \nu_{z x}^{T}
$$

The linear elastic material properties are given in Section 4.5.1. The remaining material properties will be specified in the next section.

\subsubsection{Irradiation Creep Parameter. All the Poisson's ratios in} creep, namely, $\nu_{\mathrm{xy}}^{\mathrm{S}}, \nu_{\mathrm{zX}}^{\mathrm{S}}, \nu_{\mathrm{Xy}}^{\mathrm{T}}$, and $\nu_{\mathrm{zx}}^{\mathrm{T}}$ are assumed to be constant. This is due to two considerations. First, the creep data are not sufficient and derive a set of values as a function of temperature and fluence. Secondly, the more important one is that the stress results are not 
sensitive to the creep Poisson's ratios. Based on the OC creep series, the following value is recommended for use (Ref. 4-37):

$$
\begin{aligned}
& \nu_{x y}^{S}=\nu_{z x}^{s}=0.5, \\
& \nu_{x y}^{T}=\nu_{z x}^{T}=0
\end{aligned}
$$

The "relaxation time," $\Phi_{R}$, is best estimated to be $4 \times 10^{19} \mathrm{n} / \mathrm{cm}^{2}$ (E) $0.18 \mathrm{MeV}$, HTGR) from pooled data of all available graphite experiments (Ref. 4-38). This value is assumed to apply to H-451 graphite. The relaxation time does not have significant effect on the irradiation stress at or beyond a fluence of, say, five times the "relaxation time."

The transient creep elastic moduli, $E_{\mathbf{X}}^{T}$ and $E_{\mathbf{z}}^{T}$, are taken to equal the respective elastic moduli at the "time" loading or unloading occurs (Ref. 4-38).

The remaining last two material properties are the steady creep mobility coefficients in two directions (or called steady-state creep coefficients), $M_{X}^{S}$ and $M_{Z}^{S}$. Due to small number of radial creep specimens, it is reasonable to assume:

$$
M_{\mathbf{x}}^{S}=M_{z}^{S}
$$

Reference 4-39 recommends the following expression for design use:

$$
\begin{aligned}
\epsilon^{C}= & \epsilon^{T}+\epsilon^{S} \\
= & \frac{\sigma}{E}[1-\exp (-25 \Phi)]+\frac{\sigma}{E}(2.87128 \Phi+0.14853 \Phi \mathrm{T} \\
& -2.48083 \Phi^{2}+0.25992 \Phi^{2} \mathrm{~T}+0.44420 \Phi^{3} \\
& \left.-0.05671 \Phi^{2} \mathrm{~T}\right),
\end{aligned}
$$


where $\Phi=$ fast neutron fluence $\left(\mathrm{n} / \mathrm{cm}^{2} \times 10^{-21}, \mathrm{E}>29 \mathrm{fJ}\right)$,

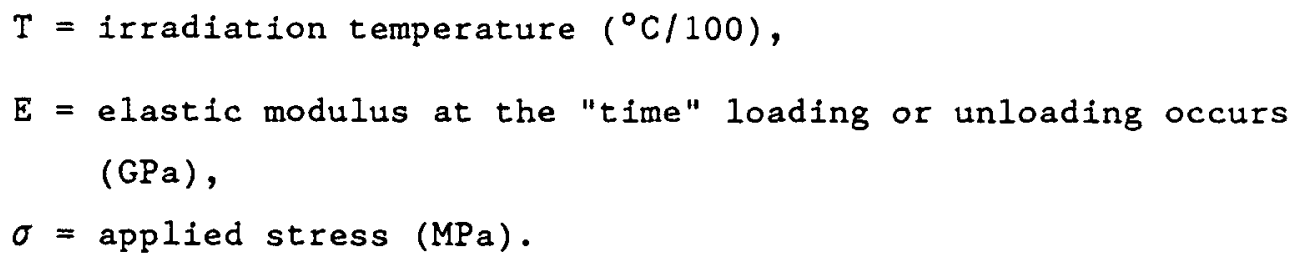

\subsubsection{Effect of Creep Strain on Physical Properties. Creep strain up to $4.5 \%$ does not significantly alter density, elastic modulus, defect size (hence sonic attenuation) and electrical resistivity (Refs. 4-40 and 4-41). Thermal expansivity is the only property known to be notice- ably affected by a creep strain component. The following relationship is obtained at $800^{\circ} \mathrm{C}$ from axial specimens in a compression creep series (Ref. 4-41):

$$
\alpha_{c}=\alpha_{o}-0.504 \epsilon^{\mathrm{c}}
$$

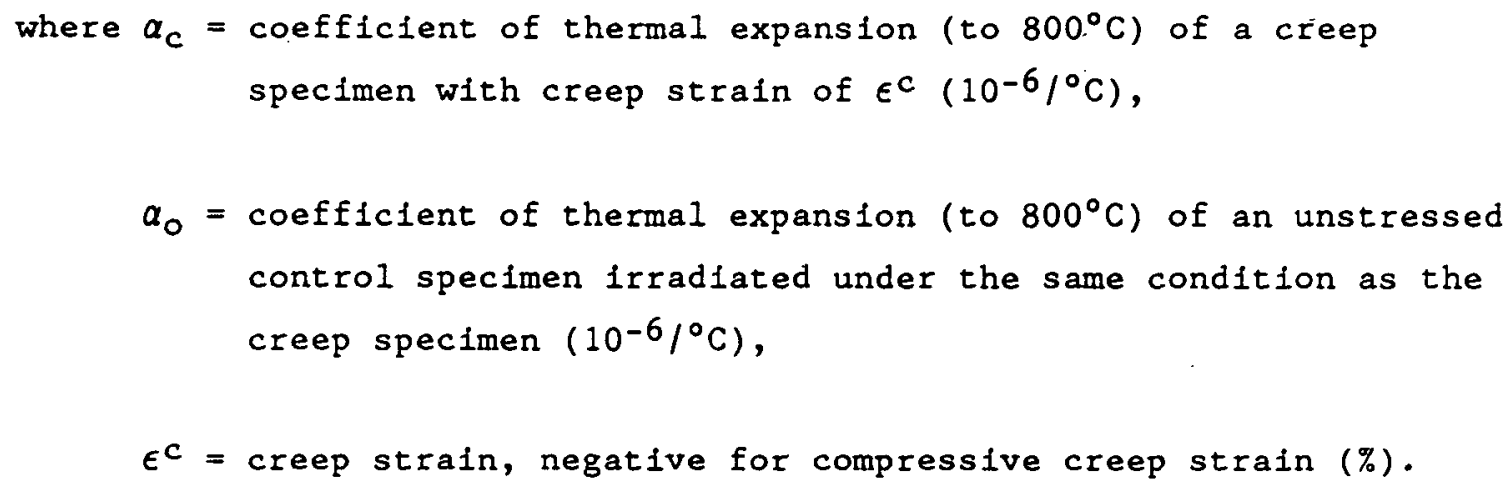

The relationship is assumed to be applicable to tensile creep region as well as to the radial direction.

\subsection{REFERENCES}

4-1. "Core Graphite Conceptual Design Criteria," Document 908950/0, August 29, 1986.

4-2. Engle, G. B., and R. J. Price, "Strength Testing of Production Grade H-451 Graphite; Lots 472, 478, and 482," ERDA Report GA-A14269, March 1977. 
4-3. "Coolant Impurity/Core Material Interaction," in "HTGR Fuels and Core Development Program, Quarterly Progress Report for the Period Ending August 31, 1976," ERDA Report GA-A14046, September 24, p. 4-26 (1976).

4-4. Velasquez, C., G. Hightower, and R. Burnette, "The Oxidation of H-451 Graphite by Steam, Part 1: Reaction Kinetics," DOE Report GA-A14951, August 1978.

4-5. Peroomian, M. B., A. W. Barsel1, and J. C. Seager, "OXIDE-3: A Computer Code for Analysis of HTGR Steam or Air Ingress Accidents," GA Report GA-A12493 (GA-LTR-7), January 15, 1974.

4-6. Burnette, R. D., et al., "Studies of the Rate of Oxidation of ATJ Graphite by Steam," in Proceedings of 13th Biennial Conference on Carbon at Irvine, California, July 13-22, 1977.

4-7. "HTGR Fuels and Core Development Program, Quarterly Progress Report for the Period Ending August 31, 1977," ERDA Report GA-A14479, September 1977, p. 11-16.

4-8. Jensen, D., M. Tagami, and C. Velasquez, "Air/H-327 Graphite Reaction Rate as a Function of Temperature and Irradiation," GA Report Gulf-GA-A12647, September 24, 1973.

4-9. Jensen, D., et al., "Afr/H-327 Graphite Reaction Rate as a Function of Temperature and Irradiation," Gulf-GA-A12647, September 24, 1973.

4-10. Eto, M., et al., "Estimation of the Graphite Materials With Water Vapor," presented at IAEA Specialists Meeting on Graphite Component Design, September 8, 1986, at JAERI, Japan. See also JAERI-M8848 and 9166 (1980).

4-11. Butland, A. T. D., and R. J. Maddison, "The Specific Heat of Graphite: An Evaluation of Measurements," Journal of Nuclear Material, 49, 45 (1973 to 1974).

4-12. Johnson, W. R., and G. B. Engle, "Properties of Unfrradiated Fuel Element Graphites H-451 and TS-1240," ERDA Report GA-A13752, January 31, 1976.

4-13. Engle, G. B., and W. R. Johnson, "Propertles of Unirradiated Fuel Element Graphites H-451 and S0818," ERDA Report GA-A14068, October 1976 . 
4-14. Beavan, L. A., "Properties of Unirradiated Production Grade H-451, Lot 478," DOE Report GA-A15116, January 1979.

4-15. Price, R. J., and L. A. Beavan, "Final Report on Graphite Irrad1ation Test OG-3," ERDA Report GA-A14211, January 1977.

4-16. Price, R. J., and G. Hagg, "Property Changes in Graphite Irradiated at Changing Irradiation Temperature," GA Report GA-A15270, July 1979.

4-17. Price, R. J., "Review of the Thermal Conductivity of Nuclear Graphite Under HTGR Conditions," GA Report Gulf-GA-A12615, September 1973.

4-18. Engle, G. B., and K. Koyama, "Dimensional and Property Changes of Graphites Irradiated at High Temperatures," Carbon 6, p. 455, 1968.

4-19. Kelly, B. T., et al., "The annealing of Irradiation Damage in Graphite," Journal of Nuclear Material, 20, p. 195, 1966.

4-20. Grenis, A. F., and A. P. Levilt, "The Spectral Emissivity and Total Normal Emissivity of Comnercial Graphites at Elevated Temperatures," Proceedings of Fifth Conference on Carbon, p. 639 (1961).

4-21. Plunkett, J. D., and W. D. Kingery, "The Spectral and Integrated Emissivity of Carbon and Graphite," Proceedings of Eourth Carbon Conference, p. 457 (1960).

4-22. Autio, G. W., and E. Scula, "The Normal Spectral Emissivity of Isotropic and Anisotropic Materials," Carbon 4, pp. 13-28 (1966).

4-23. Ho, F. H., to be determined.

4-24. Smith, M. C., "Effects of Temperature and Strain Rate on Transverse Tensile Properties of H4LM Graphite Tested in Helium and in Vacuum," Carbon 1, 147 (1964).

4-25. Price, R. J., "Test Status Report: Graphite Irradiation Capsule OG-5," GA Document 906247, Issue 1, October 20, 1981.

4-26. Price, R. J., "Test Status Report: Uniaxial Stress-Strain Tests on H-451 Graphite," GA Document 906469, Issue 1, Apri1 30, 1982.

4-27. [LATER] 
4-28. Ho, F. H., et al., "Biaxial Fallure Surfaces of 2020 and PGX Graphites," Paper No. L4/6, P. 127, Transactions of the 7th International Conference on Structural Mechanics in Reactor Technology, Chicago, IL, August 22, 1983.

4-28. "High-Temperature Gas-Cooled Reactor Technology Development Program, Annual Progress Report for Period Ending December 31, 1982," ORNL-5960, June 1983.

4-29. "HTGR Technology Development Program Annual Progress Report for Period Ending December 31, 1983," ORNL-6053, June 1984.

4-30. Velasquez, C., et a1., "The Effect of Steam Oxidation on the Strength and Young's Modulus of Graphite H-451," DOE Report GA-A14657, December 1977.

4-31. Price, R. J., and L. A. Beavan, "Final Report on Graphite Irradiation Test OG-1, "USAEC Report Ga-A13089, August 1, 1974.

4-32. Price, R. J., and L. A. Beavan, "Flnal Report on Graphite Irradiation Test OG-2," ERDA Report GA-A13556, December 15, 1975.

4-33. Price, R. J., "Design Polynomial for Irradiation Strain in H-327 and H-451 Graphite, Rev. 10/8/83," GA Document 907173, Issue 1, October 28, 1983.

4-34. [IATER]

4-35. Head, J. L., "The Transient Creep of Graphite in a Reactor Environment," Proceedings 3rd SMIRT Conference, London, United Kingdom, September 1-5, 1975, Paper C1/6.

4-36. Tang, P., "Graphite Creep Subroutines in the TWOD/THREED Codes," GA Document 906120/1, August 10, 1981.

4-37. "Monthly Progress Report for February 1982, HTR Technology Program," ORNL/GCR/B-82/2, March 1982.

4-39. Ho, F. H., "H-451 Irradiation Creep Design Model"; DOE-HTGR$88097 / 0$, GA Document 909679/0, May 27, 1988.

4-40. "High-Temperature Gas-Cooled Reactor Technology Development Program Annual Progress Report for Period Ending December 31, 1983," ORNL-6053, UC-77, June 1984.

4-41. "Graphite Data Manua1," DOE-HTGR [LATER], to be issued.

4-42. "Fuel Design Data Manual," GA Document 901866/F, April 1987. 